\title{
Impact of Pore Size on Gas Condensate Critical Properties Confined in Marcellus Shale
}

\author{
Erfan Mustafa Allawe
}

Follow this and additional works at: https://researchrepository.wvu.edu/etd

\section{Recommended Citation}

Allawe, Erfan Mustafa, "Impact of Pore Size on Gas Condensate Critical Properties Confined in Marcellus Shale" (2015). Graduate Theses, Dissertations, and Problem Reports. 5075.

https://researchrepository.wvu.edu/etd/5075

This Thesis is protected by copyright and/or related rights. It has been brought to you by the The Research Repository @ WVU with permission from the rights-holder(s). You are free to use this Thesis in any way that is permitted by the copyright and related rights legislation that applies to your use. For other uses you must obtain permission from the rights-holder(s) directly, unless additional rights are indicated by a Creative Commons license in the record and/ or on the work itself. This Thesis has been accepted for inclusion in WVU Graduate Theses, Dissertations, and Problem Reports collection by an authorized administrator of The Research Repository @ WVU. For more information, please contact researchrepository@mail.wvu.edu. 


\title{
Impact of Pore Size on Gas Condensate Critical Properties Confined in Marcellus Shale
}

\author{
Erfan Mustafa Allawe \\ Thesis submitted to the \\ Benjamin M. Statler College of Engineering and Mineral Resources \\ at West Virginia University
}

in partial fulfillment of the requirements for the degree of

Master of Science in

Petroleum and Natural Gas Engineering

Aminian, Kashy, PhD, Chair

Ameri, Samuel, Prof

Belyadi, Fatemeh, PhD

Department of Petroleum and Natural Gas Engineering

Morgantown, West Virginia

2015

Keywords: Pore Size, gas-condensate, phase behavior, Critical Properties, Marcellus Shale, etc. 


\title{
Abstract \\ Impact of Pore Size on Gas Condensate Critical Properties Confined in Marcellus Shale
}

\author{
Erfan Mustafa Allawe
}

Gas condensate reservoirs have become an important topic of research for reservoir engineers due to the drop in gas prices in the past few years. Because of this drop, the majority of gas producers have become more interested in condensate and wet gas resources. However, gas condensate reservoirs have a unique phase behavior system and they are considered the most complicated reservoirs to develop due to the continuous composition changes. Therefore, the effects of nanopores on the critical properties of the confined gas condensate in the Marcellus Shale will be investigated in this research in order to achieve the optimum gas and condensate production and to improve reservoir management plans for this kind of reservoir.

In this study, the given fluid data were used to construct a fluid model, which was then history matched with the given experimental measurements. The shift in the critical properties of gas condensate due to the pore confinement within the reservoir was calculated based on different pore sizes of $2 \mathrm{~nm}, 4 \mathrm{~nm}$, and $5 \mathrm{~nm}$. Then, a phase behavior and reservoir fluid program was used to build four fluid models, three models for the confinement case and a fourth model which represents the unconfined case, by the use of Peng-Robinson equation of the state (EOS). Next, four reservoir models were constructed by using a compositional and an unconventional reservoir simulator based on the obtained fluid models, from the phase behavior \& reservoir fluid program, and the geological data of the Marcellus Shale. Finally, after constructing the reservoir models, many simulation runs were carried out in order to study the impact of the pore confinement on the gas phase behavior and gas condensate reservoir's performance.

This research provides an insight and an explanation regarding how to optimize the gas and condensate production and maximize the economic revenue of the unconventional resources. It was concluded that producing more condensate and sustaining high gas production rate for a longer time can be achieved through producing the hydrocarbon from the confined formation with a nanopore size around $2 \mathrm{~nm}$. The pore size of $2 \mathrm{~nm}$ can retard the pressure drop throughout the reservoir and result in sustaining the reservoir pressure higher than the dew point pressure. However, the confinement cases of pore size of $4 \mathrm{~nm}$ and $5 \mathrm{~nm}$ were found to have a negative effect on the gas and condensate production. 


\section{Objective}

The objective of this research is to investigate the impact of pore size within Marcellus Shale on the critical properties and the phase behavior of the gas condensate with emphasis on the dew point pressure. After calculating the shift in the critical properties of the gas condensate the calculated values will be used in a commercial simulator in order to establish the fluid and the reservoir models. Then the built models will be simulated many times for different scenarios in order to investigate the impact of the shale confinement on gas condensate reservoirs performance. 


\section{Dedication}

This research work is dedicated to my family and my friends. A special thank you to my parents who have encouraged me in every possible way to help me achieve my goals. I also dedicate this work to my brothers and sisters for supporting me and for the wonderful encouraging words while I was working on this research. 


\section{Acknowledgements}

I would like to thank my committee members for their help who were more than generous with

their time. A special and deep thanks to Dr. Kashy Aminian, my advisor and my committee chairman for his hours of reviewing, reading, and most of all, patience throughout the entire process.

My gratitude and appreciation also goes to Dr. Samuel Ameri and Dr. Fatemeh Belyadi, who kindly accepted to be part of my advising committee.

Finally, I would like to thank all my professors and my colleagues from the Petroleum and Natural Gas Engineering department, especially my officemates, for their help and support during my work. Lastly, I owe a big thank you to West Virginia University for everything. 


\section{Table of Contents}

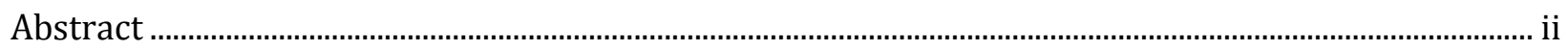

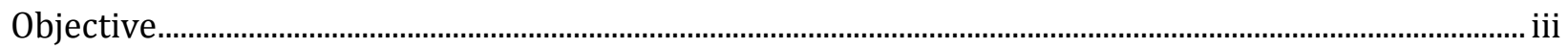

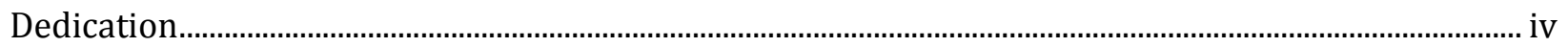

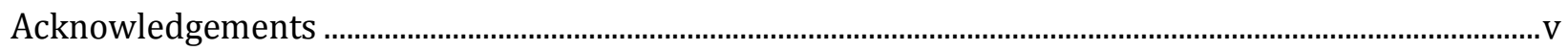

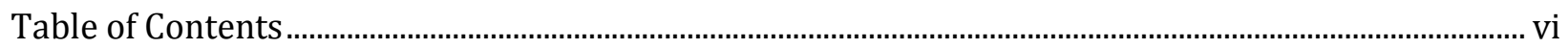

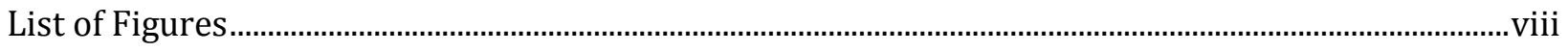

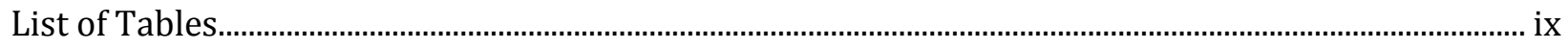

Nomenclature

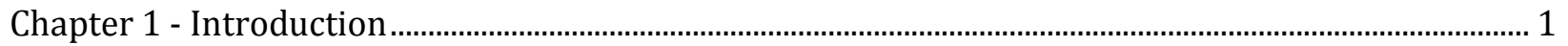

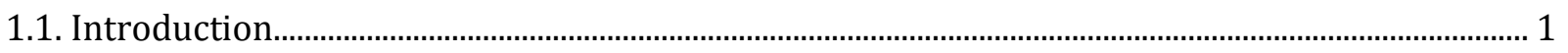

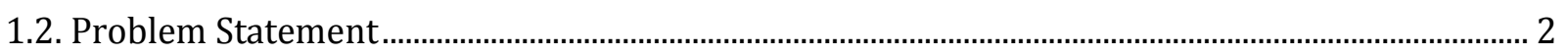

1.3. Unconventional Hydrocarbon Resources ......................................................................................... 3

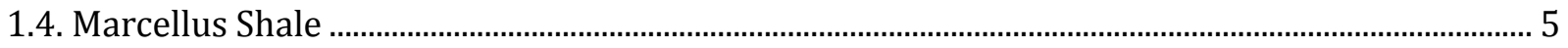

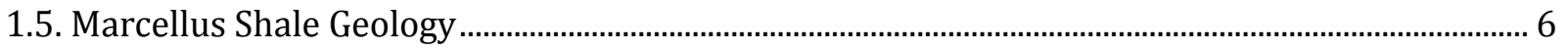

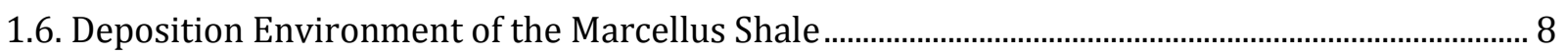

1.7. Marcellus Shale Characteristics................................................................................................. 10

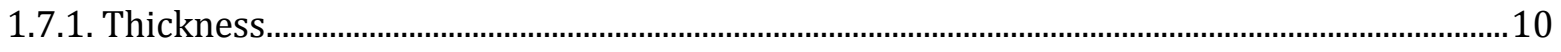

1.7.2. Depth

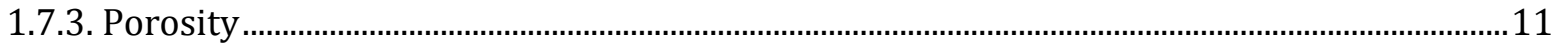

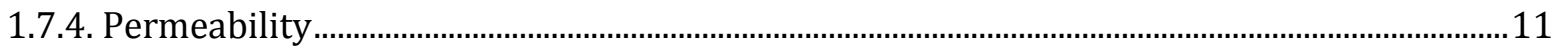

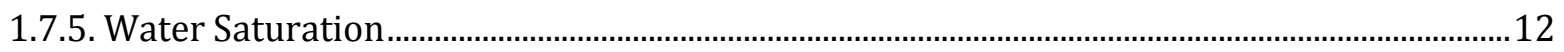

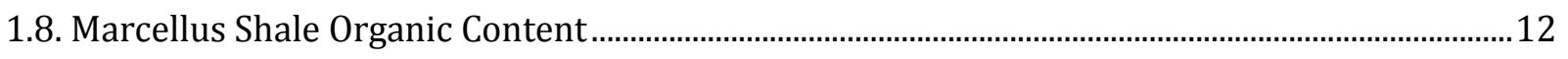

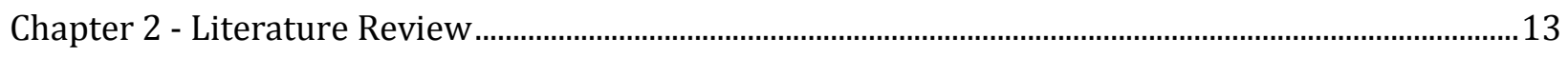

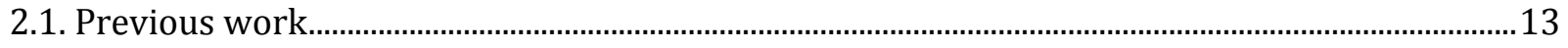

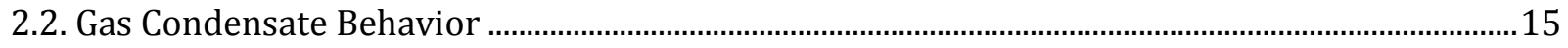

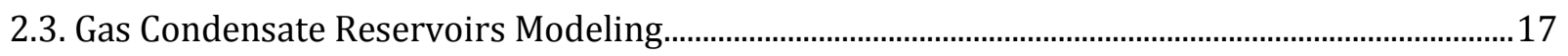

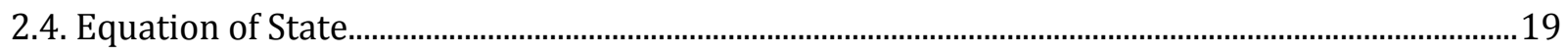

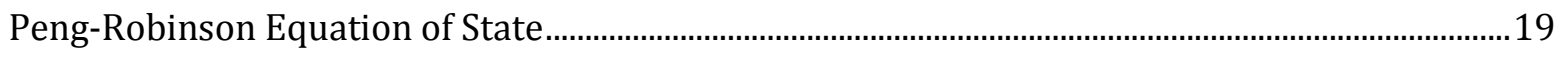

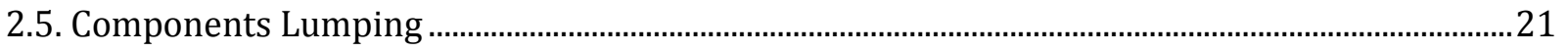

2.6. CMG (Computer Modeling Group) Software .......................................................................................22

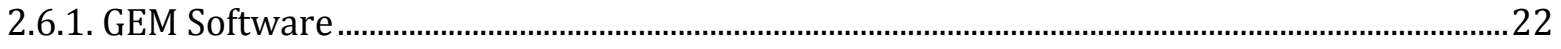

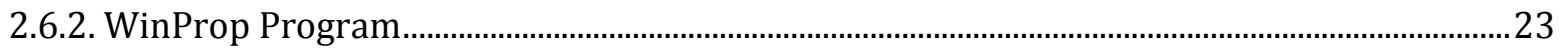




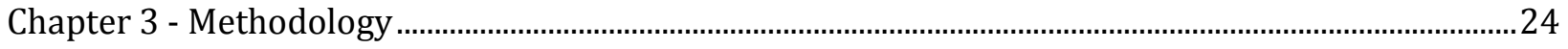

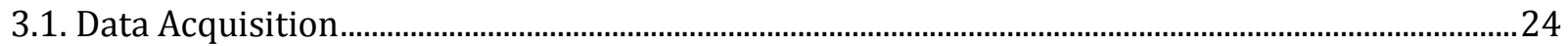

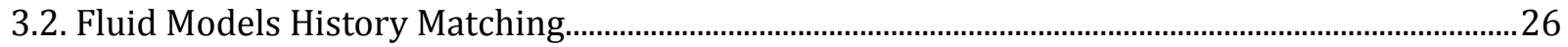

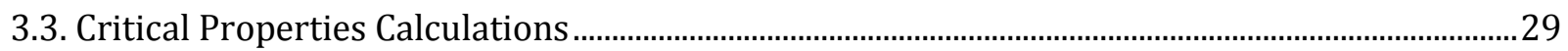

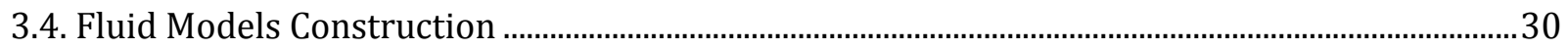

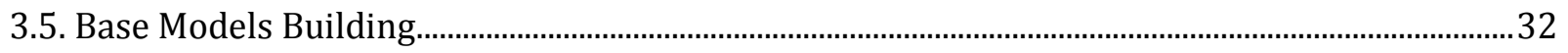

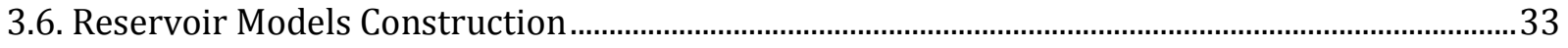

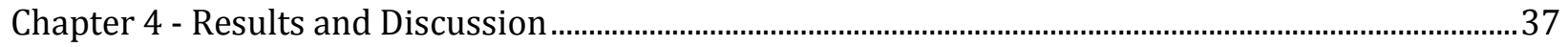

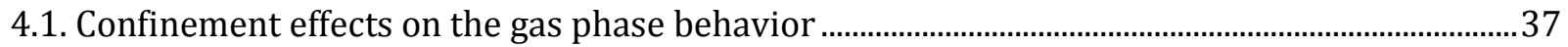

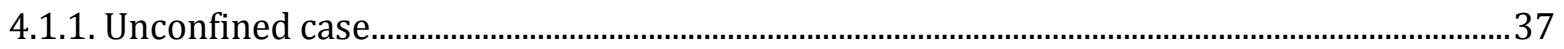

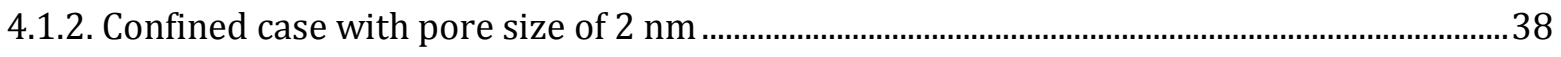

4.1.3. Confined case with pore size of $4 \mathrm{~nm}$............................................................................................ 40

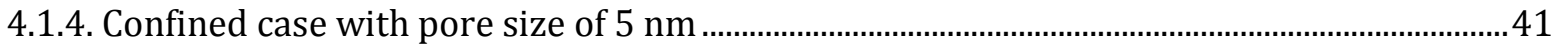

4.2. Confinement Effects on Gas and Condensate Production.................................................................. 43

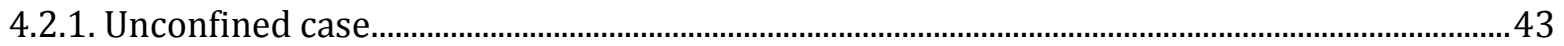

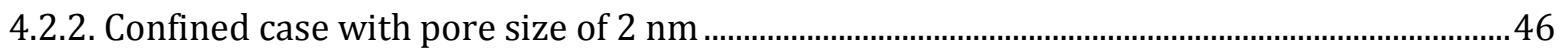

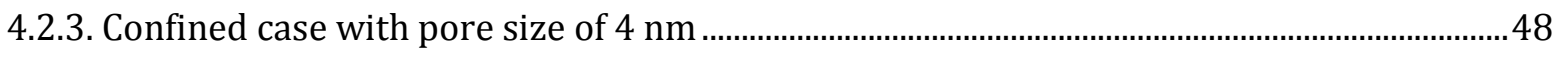

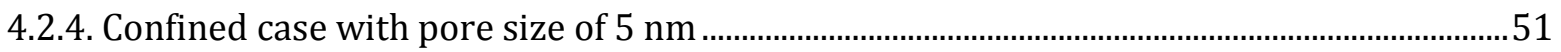

4.3. Gas Recovery Factor of the Unconfined and Confined Cases ..............................................................53

4.4. Permeability Adjustment Due to Confinement Effects .........................................................................54

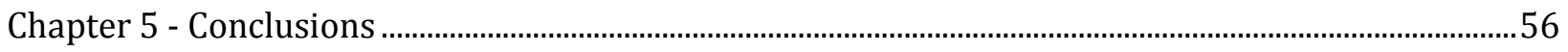

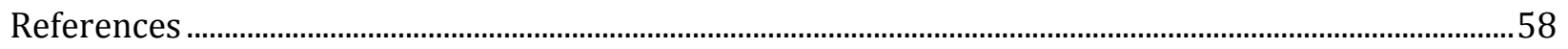

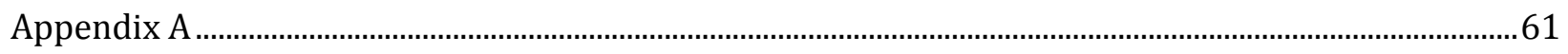

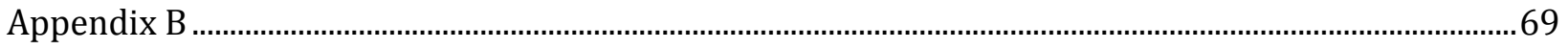




\section{List of Figures}

Fig. 1 worldwide hydrocarbon resources (Unconventional Resources, n.d.) ………….............................. 3

Fig. 2 unconventional Gas Production Methods (Burwen \& Flegal, 2013)..................................................... 4

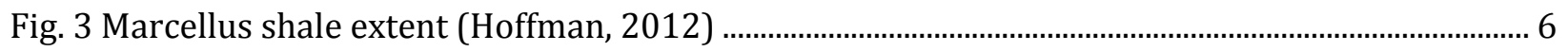

Fig. 4 the sequence of the formations above and below the Marcellus shale (Curtis, 2011).................. 7

Fig. 5 Marcellus shale geography during the Devonian era (Curtis, 2011) ................................................. 9

Fig. 6 the resulted natural fracture due to the chemical reaction in the Marcellus shale (Engelder \&

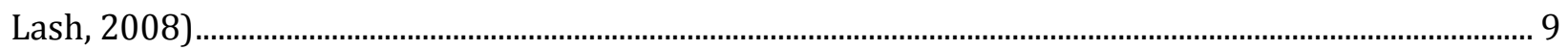

Fig. 7 Marcellus shale thickness map (King, n.d.) .......................................................................................... 10

Fig. 8 Marcellus shale base depth in feet (Sumi, 2008) ...........................................................................11

Fig. 9 gas condensate distribution in the reservoir, (Fevang \& Whitson, 1996)......................................16

Fig. 10 relative permeability and condensate saturation relationship (Fan, et al., 2005/2006) .........17

Fig. 11 pressure and volume relations (Coleman, 2014) .......................................................................25

Fig. 12 retrograte liquid volume (Coleman, 2014) .......................................................................................26

Fig. 13 pressure and volume relation based on constant composition expansion ..................................28

Fig. 14 retrograde liquid calculation based on constant composition expansion ...................................29

Fig. 15 PVT curves of the four fluid models based on different pore sizes....................................................32

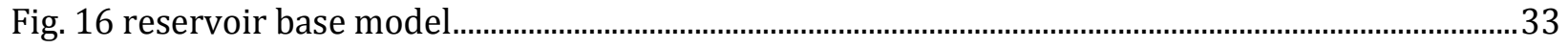

Fig. 17 relative permeability curves (Hooks, 2013).................................................................................... 34

Fig. 18 the 14 fracture stages in the reservoir model..................................................................................36

Fig. 19 the volume of the produced liquid and gas for the unconfined case based on CVD ..................38

Fig. 20 the volume of the produced liquid and gas for the $2 \mathrm{~nm}$ pore size based on CVD......................39

Fig. 21 the volume of the produced liquid and gas for the $4 \mathrm{~nm}$ pore size based on CVD.......................41

Fig. 22 the volume of the produced liquid and gas for the $5 \mathrm{~nm}$ pore size based on CVD...................... 42

Fig. 23 cumulative gas and oil prouction for the unconfine case for 30 years...........................................4

Fig. 24 gas and oil daily production of the unconfined case for 30 years ...................................................45

Fig. 25 gas and oil daily production of the unconfined case for the first two years ................................45

Fig. 26 cumulative gas and oil production for the confine case with $2 \mathrm{~nm}$ pore size for 30 years......47

Fig. 27 gas and oil daily production of the confined case with pore size of $2 \mathrm{~nm}$ for 30 years ............ 47

Fig. 28 gas and oil daily production of the confined case with pore size of $2 \mathrm{~nm}$ for the first two

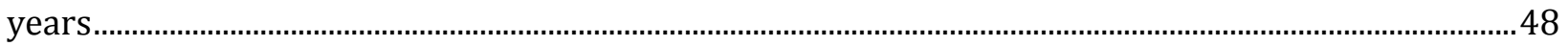

Fig. 29 cumulative gas and oil production for the confine case with $4 \mathrm{~nm}$ pore size for 30 years......49

Fig. 30 gas and oil daily production of the confined case with pore size of $4 \mathrm{~nm}$ for 30 years.............50

Fig. 31 gas and oil daily production of the confined case with pore size of $4 \mathrm{~nm}$ for the first two

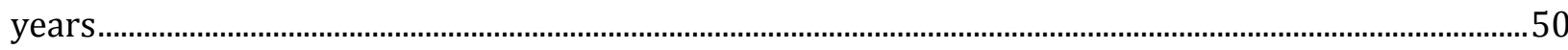

Fig. 32 cumulative gas and oil production for the confine case with $5 \mathrm{~nm}$ pore size for 30 years......51

Fig. 33 gas and oil daily production of the confined case with pore size of $5 \mathrm{~nm}$ for 30 years.............52

Fig. 34 gas and oil daily production of the confined case with pore size of $5 \mathrm{~nm}$ for the first two

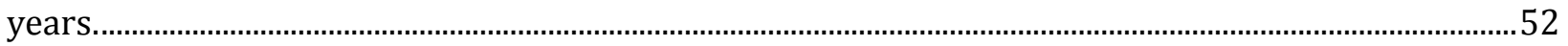

Fig. 35 gas and oil cumulative production of the $2 \mathrm{~nm}$ pore with permeability adjustment................55 


\section{List of Tables}

Table 1 Constant Composition Expansion at 130 F (Coleman, 2014) ............................................................24

Table 2 EOS input parameters (Coleman, 2014) ..........................................................................................25

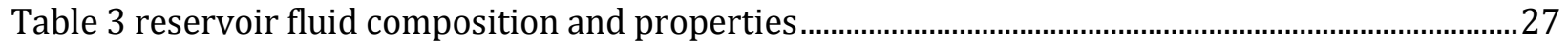

Table 4 constant composition expansion results of the tuned fluid model.................................................28

Table 5 the shift in the Critical pressure and temperature values of the given fluid data at different

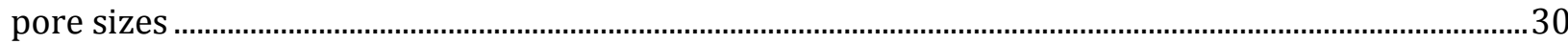

Table 6 the modified critical pressure and temperature values due to confinement effects ................31

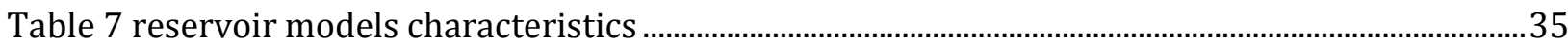

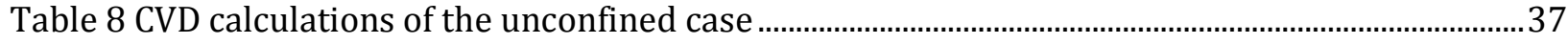

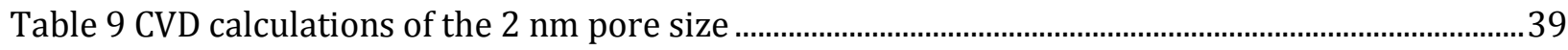

Table 10 CVD calculations of the $4 \mathrm{~nm}$ pore size....................................................................................

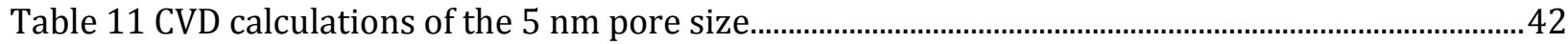

Table 12 oil and gas production of the unconfined case...........................................................................43

Table 13 oil and gas production under confinement effects with $2 \mathrm{~nm}$ pore size. ..................................46

Table 14 oil and gas production under confinement effects with $4 \mathrm{~nm}$ pore size. ..................................49

Table 15 oil and gas production under confinement effects with $5 \mathrm{~nm}$ pore size..................................51

Table 16 initial gas in place for the unconfined and confined cases. ........................................................53

Table 17 gas recover factor values for the unconfined and the confined cases. ......................................53

Table 18 oil and gas production under confinement effects with $2 \mathrm{~nm}$ pore size with the

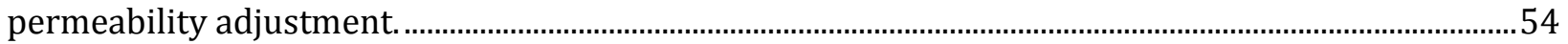

Table 19 gas recovery factor of the $2 \mathrm{~nm}$ pore size reservoir model with the permeability adjustment. 


\section{Nomenclature}

$\mathrm{h}$ : The Thickness of the Producing Zone, $\mathrm{ft}$.

$\mathrm{k}_{\mathrm{h}:}$ Horizontal Permeability, md

$\mathrm{k}_{\mathrm{v}}$ : Vertical Permeability, md

MW: Molecular Weight, g/mol.

$\mathrm{P}_{\mathrm{cb}}$ : Bulk Critical Pressure, atm.

$\mathrm{P}_{\mathrm{cp}}$ : Critical Pressure, atm.

$\mathrm{r}_{\mathrm{w}}$ : Wellbore Radius, $\mathrm{ft}$.

$S_{\text {wi: }}$ Initial Water Saturation

$\mathrm{T}_{\mathrm{cb}}$ : Bulk Critical Temperature, $\mathrm{K}$

$\mathrm{T}_{\mathrm{cp}}$ : Critical Temperature, $\mathrm{K}$

$\mathrm{V}_{\mathrm{m}}$ : Molar Volume

$\Delta \mathrm{P}_{\mathrm{c}}$ : Relative Shift in Critical Pressure, atm.

$\Delta \mathrm{T}_{\mathrm{c}}$ : Relative Shift in Critical Temperature, $\mathrm{K}$ 


\section{Chapter 1 - Introduction}

\subsection{Introduction}

Gas condensate reservoirs have been considered an interesting topic of research for reservoir engineers due to their unique phase behavior (Marir \& Tiab, 2006). The discovery of the large volume of dry gas resources resulted in gas price decrease. Consequently, most of the producers have focused on developing gas condensate and wet gas due to economic advantages. Effective reservoir management plans are essential for developing gas condensate reservoirs. Moreover, good understanding of flow characteristics is quite important for precise prediction of well deliverability and liquid production in gas condensate reservoirs. Gas condensate reservoir flow is an imbibition process, whereas, oil reservoir flow is a decreasing saturation process, therefore the knowledge of conventional reservoirs is not applicable in the gas condensate reservoirs (Nagarajan, Honarpour, Sampath, \& McMichael, 2004). Gas condensate reservoirs are more complex because of the composition and phase changes. One of the important features of the gas condensate reservoir is retrograde condensation which occurs when there is a severe drop in the reservoir pressure (Dehane, Tiab, \& Osisanya, 2000). The main issue with the production of gas condensate reservoirs begins as the reservoir pressure or the near wellbore pressure falls below the dew point pressure. When the pressure around the wellbore falls below the dew point pressure, the subsequent condensation in this area will cause many production problems. The critical properties of the gas condensate have a direct impact on the condensation process and the accumulation of liquids near the wellbore. Also, it was found that gas condensate flow behavior changes from Darcian to nonDarcian flow in shale formations due to the change in the fluid properties; density, phase behavior, viscosity, and surface tension, as a result of the confinement of gas in the nanopores especially at high reservoir pressure and temperature (Civan \& Michel, 2013). The objective of this thesis is to study the impact of nanopores on the critical properties of gas condensate in the Marcellus shale. 


\subsection{Problem Statement}

Liquid (condensate) accumulation in gas condensate reservoirs, particularly near the wellbore, is considered to be the main production problem. The accumulated condensate around the wellbore region or through the reservoir causes numerous problems which impact economics of gas production. As the formation pressure falls below the dew point pressure, condensate starts to accumulate in the reservoirs. The formation of the condensate through the reservoir significantly diminishes the gas deliverability and in severe cases can completely prevent gas production. The reduction in gas deliverability is mainly attributed to the multi-phase flow effects (relative permeability) and blockage of gas flow pathways (Ahmed, Evans, Kwan, \& Vivian, 1998). Furthermore, condensate accumulation through the reservoir causes a reduction in condensate production on the surface which has major economic implications as opposed to the wet gas production. When condensation occurs in the reservoir, the produced gas will be leaner as most of the heavy hydrocarbons will be concentrated in liquid trapped by the reservoir rock (Fan, et al., 2005/2006).

In order to avoid the above outlined problems, it is necessary to maintain the reservoir pressure above the dew point pressure in order to extend the single phase production period as long as possible. This can be achieved by efficient reservoir management and to understand the factors that have direct impact on dew point pressure. Pore size, particularly the nanopores in shale formations, is one of the factors that influence the critical properties of gas condensate which in turn impact the dew point pressure (Civan \& Michel, 2013). The effects of Marcellus shale pore sizes on gas condensate critical properties will be investigated in this research. 


\subsection{Unconventional Hydrocarbon Resources}

Marcellus shale is one of the biggest unconventional hydrocarbon recourses in the United States. According to the literature, there is no specific definition of unconventional resources in petroleum industry. The definition of conventional and unconventional resources changes over the time based on the economic advantages (Natgas, 2013). However, the term unconventional resources refer to the hydrocarbon resources (oil or gas) that cannot be extracted from the underground formation by the use of the conventional methods of production such as vertical wells. In other word, unconventional resources represent the hydrocarbon reserves which are trapped within low permeability formations such as shale rock, sandstone, and coal seams. As a result, these hydrocarbon resources within these kinds of formation require special production techniques to be extracted (Burwen \& Flegal, 2013). The importance of studying the unconventional resources comes from that only a third of the total oil and gas reserves are conventional whereas the balance of the other reserves are unconventional recourses. The unconventional resources are classified into many different types of resources which includes; tight gas, coalbed methane (CBM), shale gas, shale oil, have oil (tar sand) and methane hydrates (Unconventional Resources, n.d.). Fig. 1 depicts the worldwide hydrocarbon resources and the percentage of each resource.

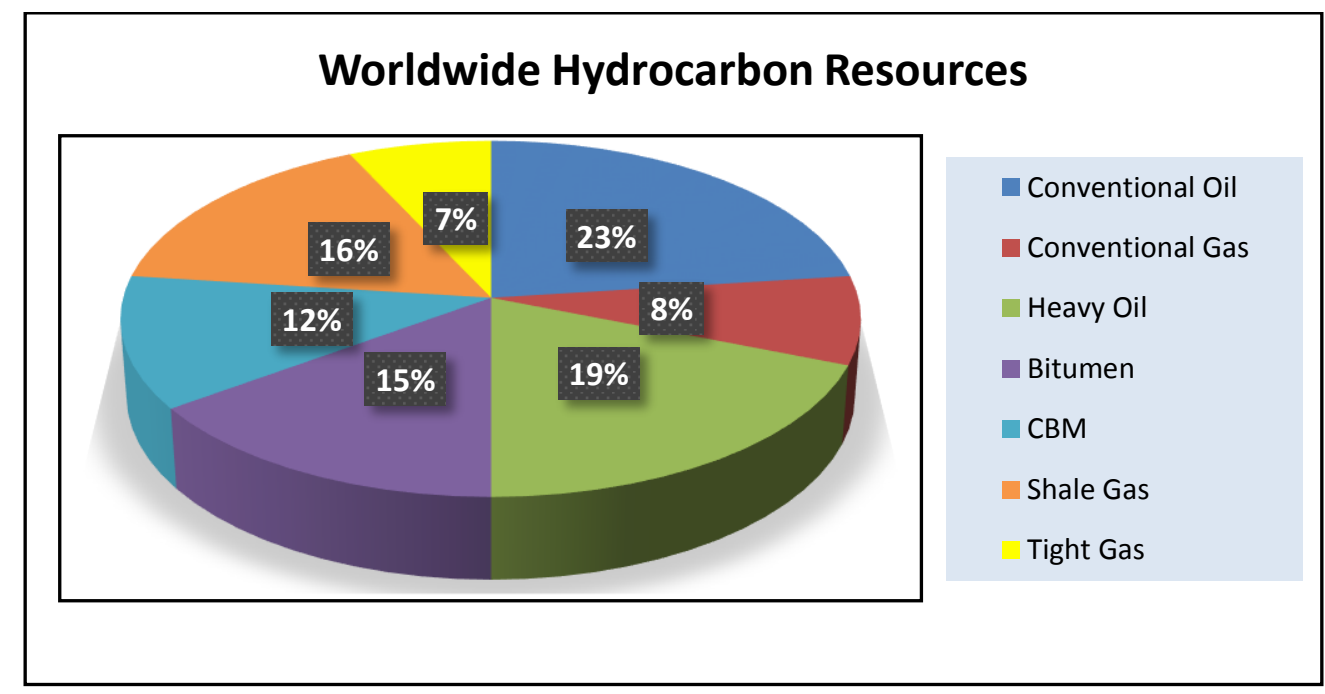

Fig. 1 worldwide hydrocarbon resources (Unconventional Resources, n.d.) 
Currently, the most common techniques that are used to produce the unconventional hydrocarbon resources are horizontal drilling and well stimulation which includes both hydraulic fracturing and acidizing. Horizontal drilling starts by drilling a vertical hole similar to conventional vertical wells, when the vertical hole reaches the target formation, an arc has to be built in order to penetrate the target formation horizontally. The purpose of using horizontal wells is to increase the production of the well by increasing the contact with the producing zone. Even though the cost of drilling a horizontal well is two or three times more than the vertical well, the initial production of this kind of wells is usually three or four times more than the vertical wells (Burwen \& Flegal, 2013).The second technique that is mostly used to produce the unconventional hydrocarbon resources is hydraulic fracturing. This technique is accomplished by injecting huge volume of water, proppant, and chemicals into the producing formation (mostly shale or sandstone). The injected water at high pressure results in fracturing the formation and the purpose of using proppant is to maintain the fractures to be opened after releasing fracturing pressure. Consequently, the created fractures will enable the hydrocarbon (oil or gas) within the tight formations to flow toward the wellbore to be produced. Fig. 2 shows the unconventional hydrocarbon production methods.

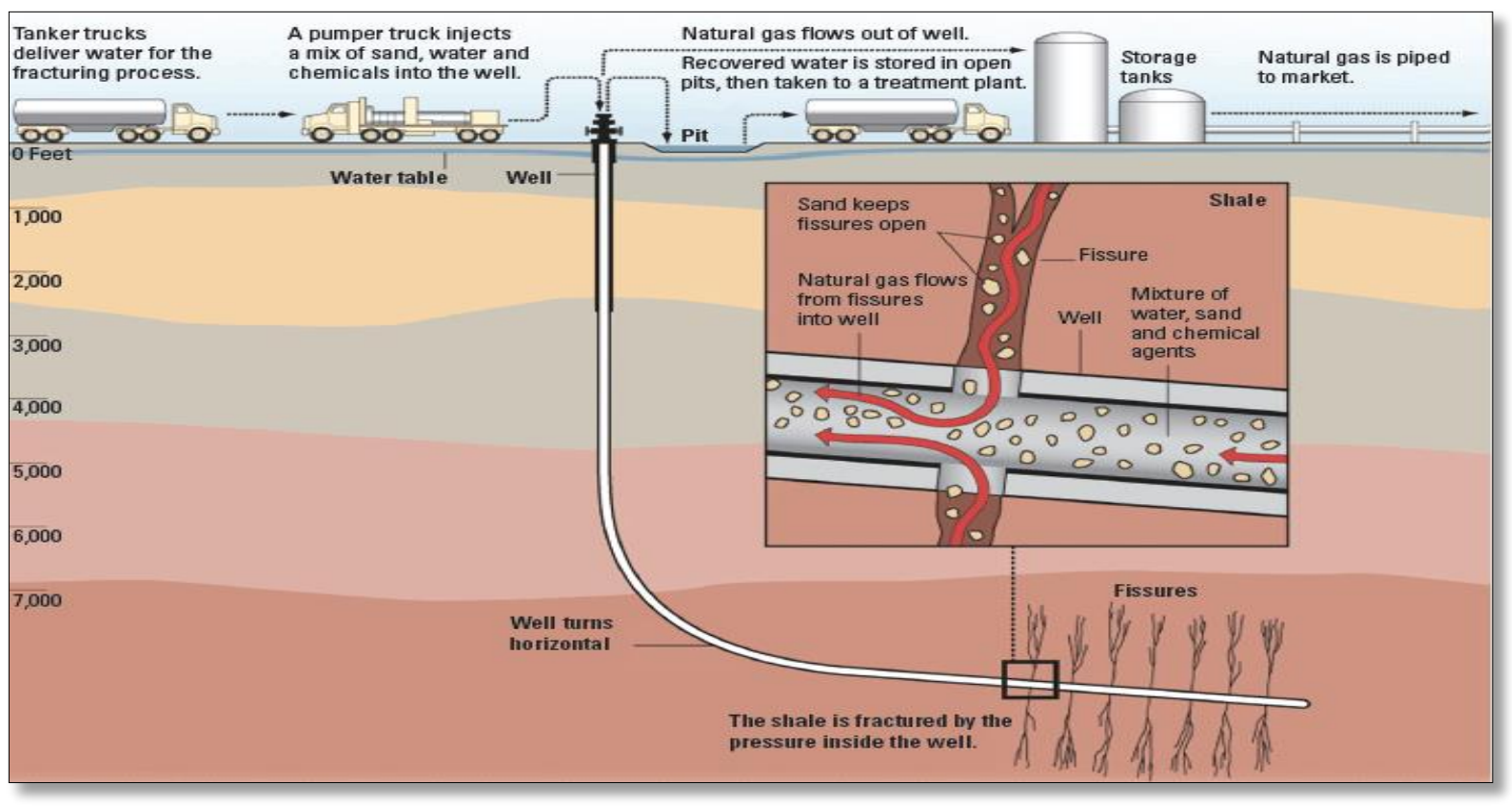

Fig. 2 unconventional Gas Production Methods (Burwen \& Flegal, 2013) 


\subsection{Marcellus Shale}

The shale term usually refers to the rock that originally formed from mud or clay consolidation due to geological conditions such as high pressure and temperature. Marcellus shale is considered one of the valuable unconventional resources in the United States, which is named after the town of Marcellus in New York. This formation is believed to be formed approximately 350- 415 million years ago during the Devonian era. The area of the Marcellus shale was estimated to be around 54, 000 square miles with a distance approximated by 600 miles starting from New York and ending by Ohio and West Virginia (Sumi, 2008)(Fig. 3 depicts Marcellus shale extent). The Marcellus shale is considered the deepest formation among Hamilton group formations. Consequently, it is the oldest formation of this group and it is considered slightly radioactive due to the little uranium content (Hart, 2008). The main reason of the high interest in this formation is because it contains a vast volume of the recoverable hydrocarbon (especially methane gas) which has a significant economic advantages. In addition, the location of the Marcellus shale, in the eastern United States, gives this source of the gas more importance because it is near to the high population areas such as New Jersey, New York, and New England. Moreover, the availability of transportation pipelines provide another advantage in the market (King, n.d.). According to the U.S. Energy Information Agency (EIA), the recoverable gas reserves of Marcellus shale were approximately estimated to be around 400 trillion cubic feet (TCF) in 2011 (Newell, 2011).

The natural gas in the Marcellus shale is believed to exist in three forms. The first form is the natural gas inside the pore spaces of the shale formation. The second form of the natural gas is within the natural fractures (joints) which exist in the shale formation. The last form of the natural gas in the Marcellus shale is the adsorbed gas on mineral grains and organ material. The first form of the natural gas, within pore spaces, is considered the most recoverable gas during production process even though it is difficult for this gas to flow through the tight formations (King, n.d.). 


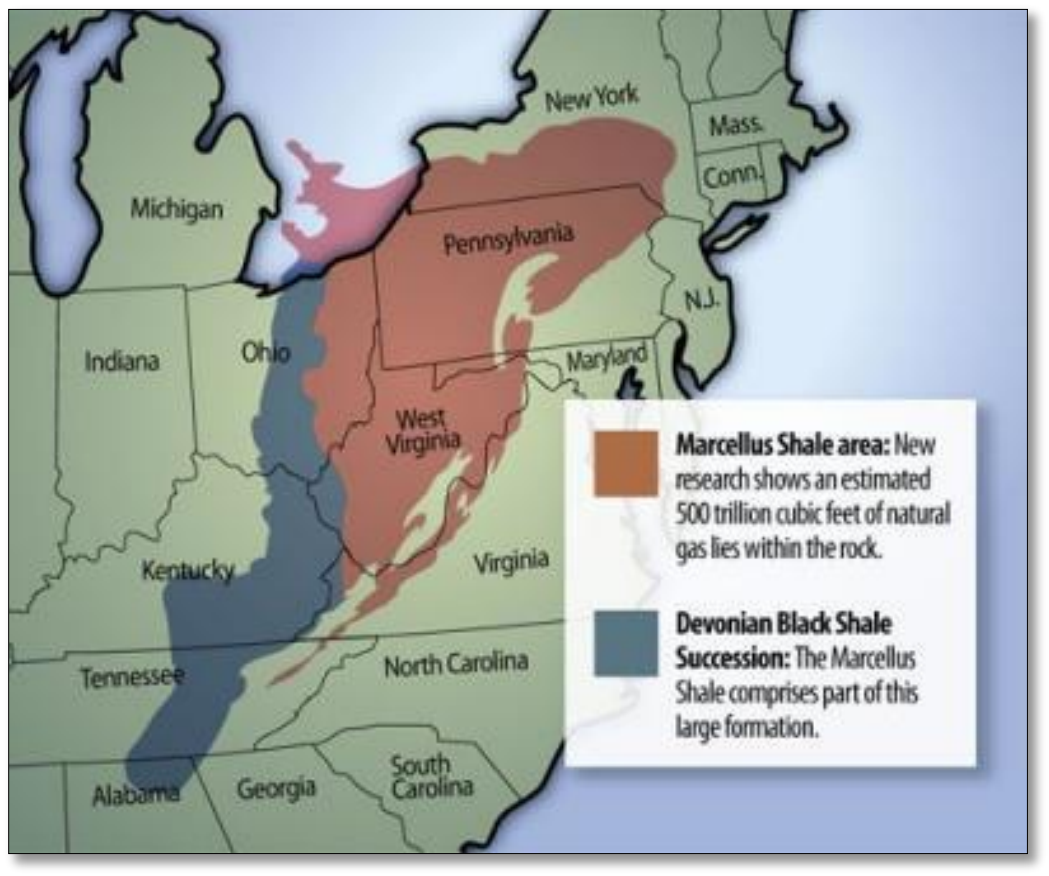

Fig. 3 Marcellus shale extent (Hoffman, 2012)

\subsection{Marcellus Shale Geology}

Marcellus Shale has been found to have appropriate mineralogy which is important to be considered as an economic source of hydrocarbon. Moreover, Marcellus shale is classified as a low density rock with appropriate porosity; therefore, it is believed to contain more hydrocarbon such as condensate or free gas (Sumi, 2008). Marcellus shale is a sedimentary rock which is commonly called as clastic rock since it was formed by fragments consolidation. The majority of the fragments contain silicon dioxide, which is also found in quartz, glass, and sand. In addition, it contains limestone (calcium carbonate) and pyrite (iron hydroxide) within rock fragments. The Marcellus shale is recognized as a black shale rock which indicates that it contains more than one carbon percent. It was found that Marcellus shale was formed in water environment with a lack of oxygen; therefore, the carbon compounds, iron and sulfur were chemically reduced in this formation (Curtis, 2011).

The Marcellus shale is considered a heterogeneous formation because its properties change with the location of the formation. The western part of the Marcellus shale is identified by its high organic 
content comparing with the other parts, even though this part is shallower and thinner. Conversely, the eastern part of the Marcellus shale is deeper and thicker, but it has less organic content. The northern part of the Marcellus shale is geopressured, whereas the southern part is underpressure. In addition, Marcellus shale depth is not constant throughout the entire formation. It is shallow in some areas such as New York, where it appears on the surface (outcrop) and it is deep in the most other parts, between 5000 to 9000 feet below the surface (Sumi, 2008). In deep parts of Marcellus shale, it was found that it extents between two of Hamilton group formations, Mahantango, and Onondoga. The Mahantango formation is the Tully limestone formation that works as a cap rock to prevent natural gas leakage through shale fractures, while the Onondoga is a limestone formation below the Marcellus shale (Hart, 2008). Fig. 4 depicts the sequence of the Mahantango, Marcellus shale, Onondoga, and other formations.

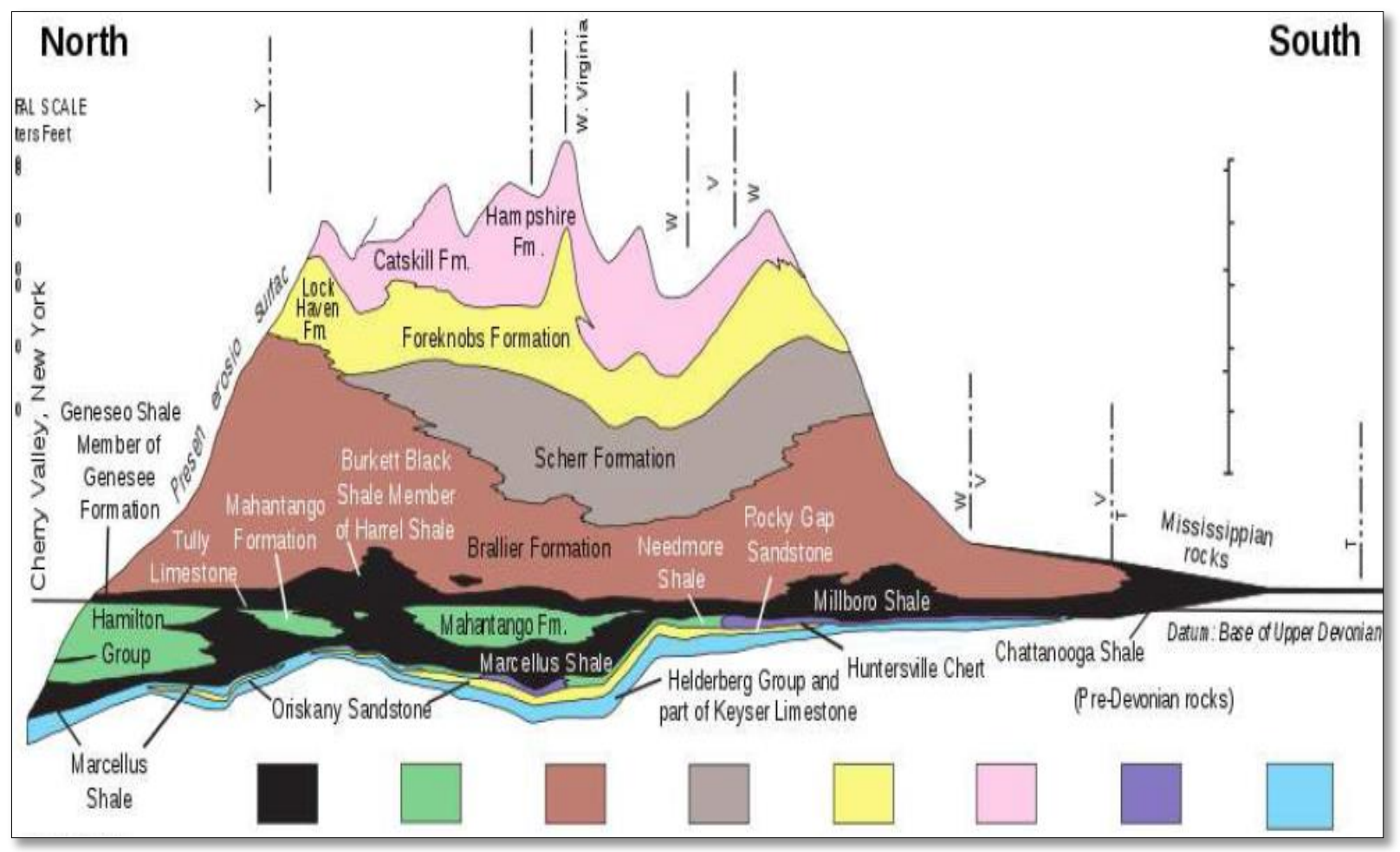

Fig. 4 the sequence of the formations above and below the Marcellus shale (Curtis, 2011) 


\subsection{Deposition Environment of the Marcellus Shale}

In general, shale rocks have formed due to weathering conditions. As rocks are subjected to the chemical weathering, little particles are formed as a result of rocks breaking down. Then, rainstorms carry the resulted clay minerals and other particles from the weathering process to create muddy streams which keep flowing until entering places which minimize streams speed as lakes, swamps and oceans. Consequently, mud starts to settle and later the accumulated mud forms the sedimentary rocks if there is no disturbance, and these sedimentary rocks is usually called by (mudstone) (King, n.d.).

As mentioned in the above outlined, the Marcellus shale is a sedimentary rock that was formed due to mud particles deposition and compression in the middle of Devonian era. According to (Curtis, 2011), the most parts of the Appalachian Mountains were a very shallow area that was surrounded by higher areas in the middle of the Devonian era. That shallow area represented the Appalachian Basin, which was a shallow sea at that time. To the east of the Appalachian Basin is the Arcadian Mountains and between them is the Catskill Delta. Fig. 5 shows the geography of the Marcellus shale in the Devonian era. During the Devonian era, sediments broke down from the Arcadian Mountains because of the weathering conditions and settled down in the Catskill Delta. Coarse sediments accumulated around the shore area, whereas fine fragments moved farther and settled in the bottom of the Appalachian Basin.

Over the time, the fine fragments were accumulating along with the algae and the other marine organisms deep in the Appalachian Basin. Due to the accumulation of more sediments, the organisms decomposed tardily since there was no enough oxygen for the decomposition process. This process of deposition happened many times and as a result, different Marcellus shale layers with different properties were created (Hart, 2008). Beside sediment accumulation over the time, an increase of the temperature and pressure resulted in oil and gas generation from the accumulated organic 
substance by different chemical reactions. In that time, these chemical reactions needed more pore spaces but they did not have the ability to expand during Marcellus shale deposition. Consequently, the resulted organic matters or kerogen (oil and gas) caused the pore pressure to increase and caused the shale rock to be cracked. More chemical reactions resulted in pressure increase and as a result the shale cracks grow until they reached each other and generated joins which are commonly known as natural fractures (Engelder \& Lash, 2008). Fig. 6 depicts the natural fractures within the Marcellus shale.

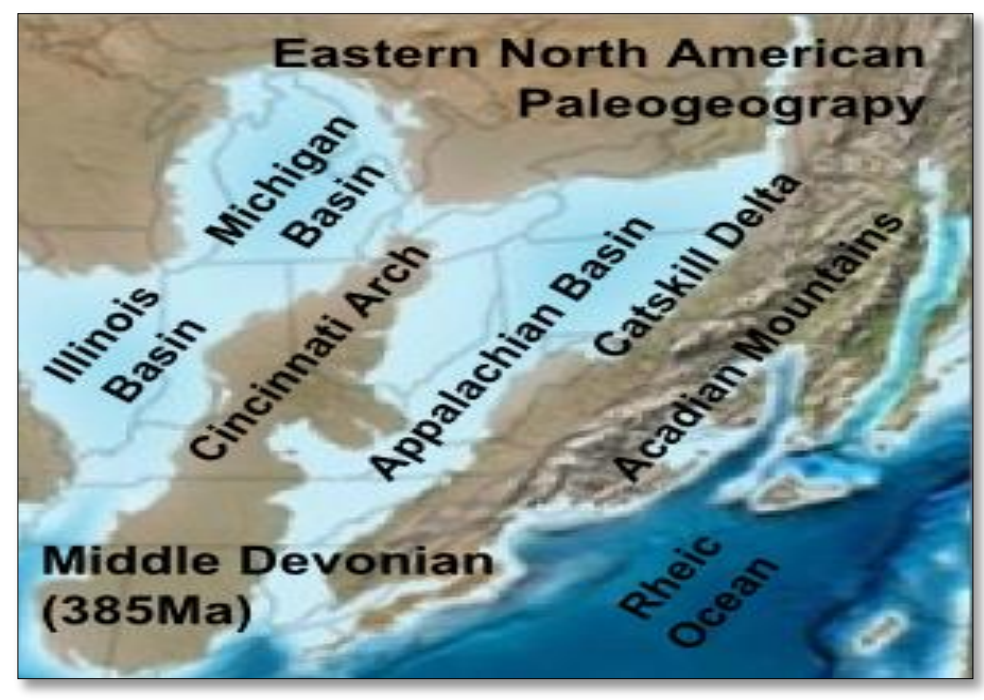

Fig. 5 Marcellus shale geography during the Devonian era (Curtis, 2011)
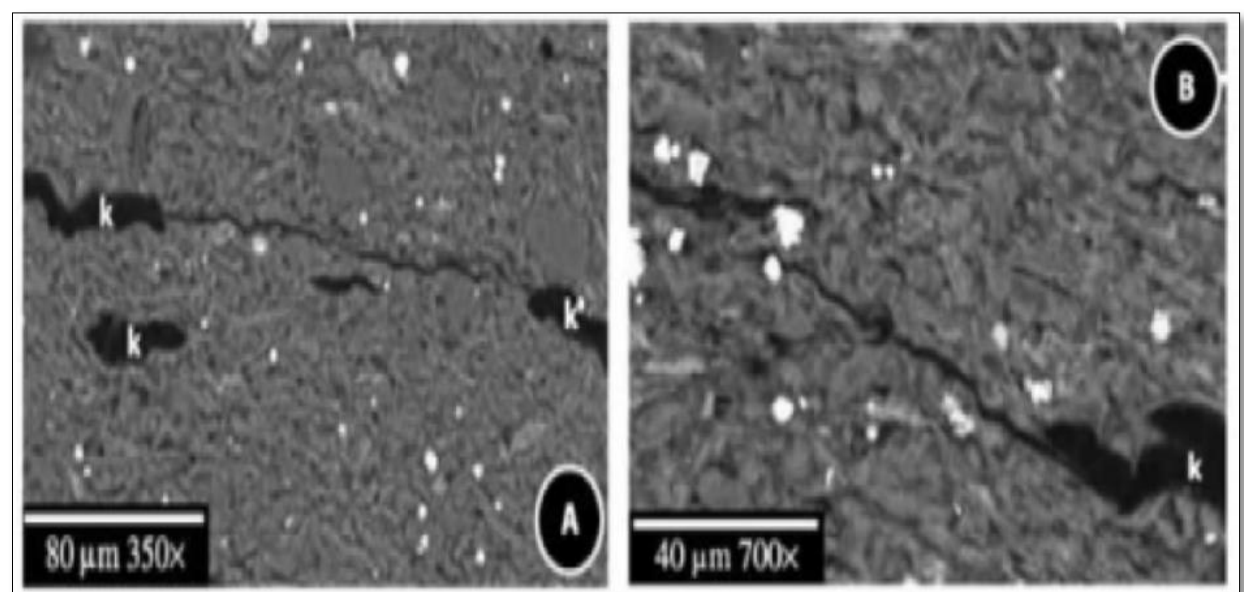

Fig. 6 the resulted natural fracture due to the chemical reaction in the Marcellus shale (Engelder \& Lash, 2008) 


\subsection{Marcellus Shale Characteristics}

\subsubsection{Thickness}

As mentioned before in this research, the Marcellus shale does not have a consistent thickness. According to (Hart, 2008), the Marcellus shale has a thickness of 900 feet in New Jersey while has a thickness of 40 feet near Canada. Generally, the Marcellus shale is thicker in the eastern part and has a thickness value of 250 feet (Sumi, 2008). For instance, the Marcellus shale thickness is 200 feet in West Virginia, where most of the wells are being drilled there. Fig. 7 shows the Marcellus shale thickness map.

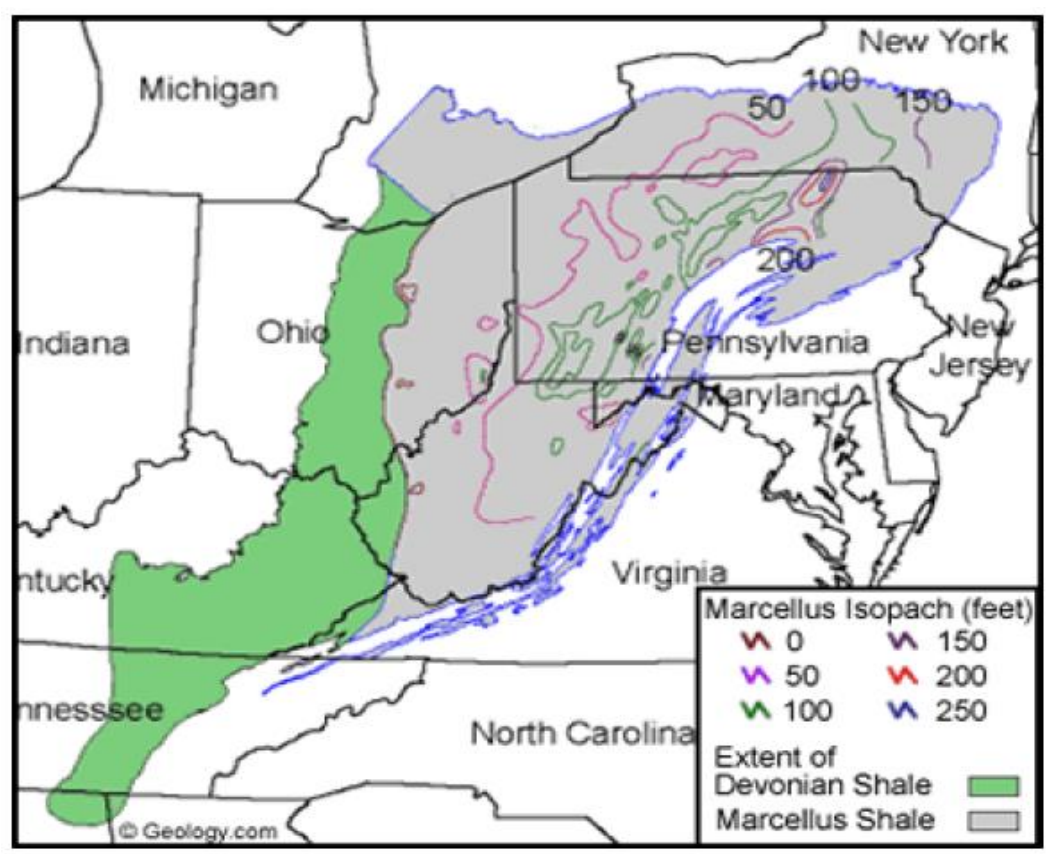

Fig. 7 Marcellus shale thickness map (King, n.d.)

\subsubsection{Depth}

Most of the economic shale gas reserves in the United States were discovered at a depth between 500 and 11,000 feet. The Marcellus shale is known to not have a consistent depth. Despite the fact, the Marcellus shale is shallow in Ohio and deep in Pennsylvania, it outcrops in New York. Fig. 8 shows the contour map of the Marcellus shale. Overall, the depth of the major parts of Marcellus shale ranges between more 5000 to 9000 feet (Sumi, 2008). 


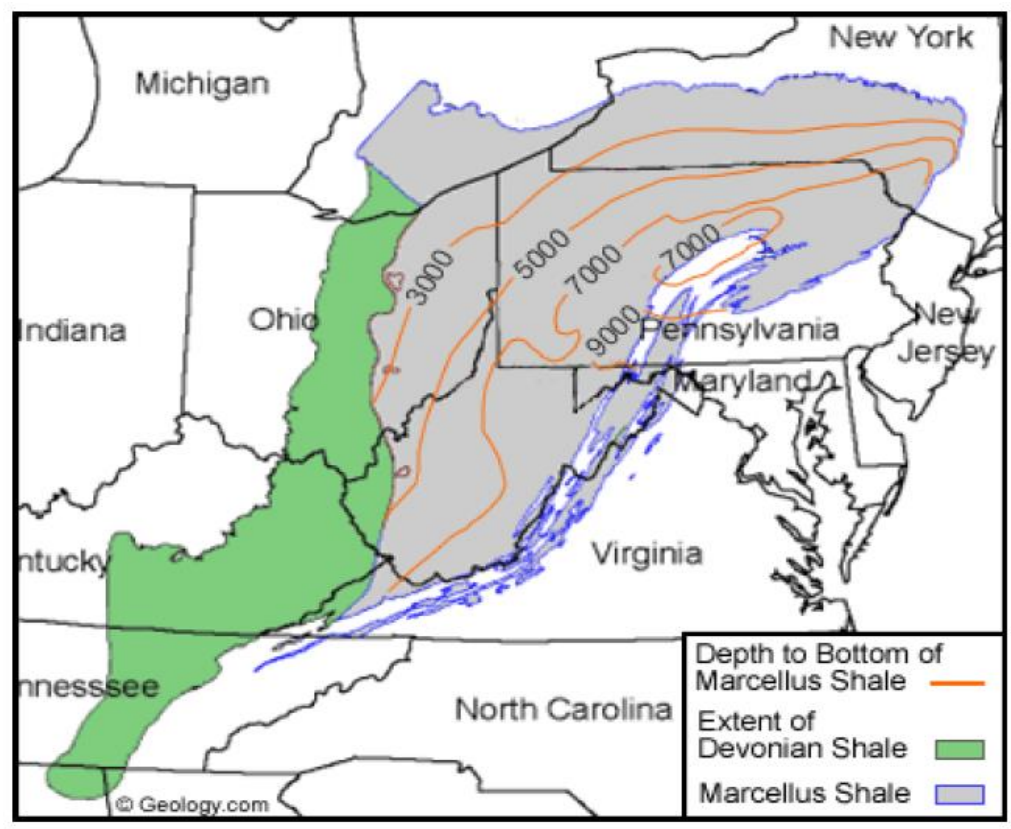

Fig. 8 Marcellus shale base depth in feet (Sumi, 2008)

\subsubsection{Porosity}

In general, shale reservoirs have a low porosity value which is commonly less than $10 \%$. Marcellus shale is known to have a porosity value that varies between 0.5 to $5.0 \%$; however, the porosity value was found to be equal to $9 \%$ in West Virginia. Since matrix pore spaces in Marcellus shale are not well connected, most of the commercial gas production is based on natural fractures porosity (Lee, Herman, Elsworth, Kim, \& Lee, 2011).

\subsubsection{Permeability}

The Marcellus shale has a very low permeability value which is not enough to provide commercial production. Consequently, hydraulic fracturing techniques have to be used in order to produce economic gas volume out of the Marcellus shale. According to (Lee, Herman, Elsworth, Kim, \& Lee, 2011), the permeability value of the Marcellus shale ranges between $10^{-21}$ and $10^{-17} \mathrm{~m}^{2}$, nonetheless, it has a value of $10^{-14}$ in West Virginia core samples. 


\subsubsection{Water Saturation}

The produced gas from the Marcellus shale has a percent of water that could cause many issues during the transportation process. The water content in the Marcellus shale produced gas was found to be around 1,100 $\mathrm{mg} \mathrm{H}_{2} \mathrm{O} / \mathrm{m}^{3}$ gas. Water treatment is important to meet transportation companies' specifications (Lee, Herman, Elsworth, Kim, \& Lee, 2011).

\subsection{Marcellus Shale Organic Content}

The Total Organic Carbon (TOC) represents rock richness in term of the organic substances; in the other word, it is the amount of organic carbon (kerogen and bitumen) within a rock sample (Quantity of Organic Matter, n.d.). Marcellus shale is one of most important hydrocarbon sources in the United State based on its rich total organic content (TOC). According to many researchers' estimations, the Marcellus black shale has a total carbon content ranges between 1.4 to $12 \%$. The total organic content by weight of the Marcellus shale was estimated to be $1.40-4.30 \%$ by Milici and Swezey (2006), 4.27\% by Lash (2008), 4-6\% Gottschling, 2007), 2-10\% (Wrightstone, 2008), 3.87-11.05\% by Hill and others (2004), and 10-12\% (Engelder, 2008a) (Bruner \& Smosna, 2011). The majority of the oil and gas producers have more concerned in producing oil and gas from the thickest section of the Marcellus shale due to the high presence of Total Organic Carbon (TOC) which results in producing more of the trapped gas in the Marcellus shale (Hart, 2008). However, the 50 feet of the bottom of the Marcellus shale are believed to be the richest part in term of Total Organic Carbon (TOC). The bottom of the Marcellus shale has a TOC of $5.19 \%$ to $8.81 \%$, whereas the top of the Marcellus shale has a TOC of 1.64\% in one of the wells in West Virginia (Bruner \& Smosna, 2011). 


\section{Chapter 2 - Literature Review}

\subsection{Previous work}

As mentioned previously in the introduction of this research, gas condensate reservoirs are considered an interesting topic of research due to the continuous change in composition and because of the economic importance of the produced condensate. For this reason, many researchers have studied the behavior of gas condensate reservoirs and they have investigated various techniques to improve gas condensate production and to overcome production issues.

The impact of using different well configurations, for instance, vertical, horizontal and hydraulically fractured wells in gas condensate reservoirs, on well productivity were studied by Hashemi and his fellow researchers (Hashemi \& Gringarten, 2005). They have found that if the lateral length of the horizontal well is bigger than the permeability ratio $\left(\mathrm{hk}_{\mathrm{h}} / \mathrm{k}_{\mathrm{v}}\right)$, the horizontal well is considered to be effective, whereas if the lateral length is equal to the relative permeability ratio, the horizontal well behaves as a vertical well. Furthermore, they found that the affectivity of the hydraulic fracture is a function of fracture length and fracture conductivity which is equal to the product of the fracture permeability and its width.

Ahmed and other researchers investigated condensate blockage issues in gas condensate reservoir and discussed the mechanism of the gas injection process and the effectiveness of lean gas, $\mathrm{N}_{2}$, and $\mathrm{Co}_{2}$ (Huff ' $n$ ' Puff) technique as a solution to overcome condensate blockage problems (Ahmed, Evans, Kwan, \& Vivian, 1998). Al-Lamki tried to study the near wellbore effects in order to invent new methods for calculating well productivity in gas condensate reservoirs using well test data (Al-Lamki, Daungkaew, Mott, Whittle, \& Gringarten, 2000).

Even though various researches have investigated the behavior of gas condensate reservoirs, few researchers have studied the effect of the pore size on the critical properties of gas condensate in tight formations. 
Bustos investigated the impact of contact angle hysteresis and fluid-solid system wettability on gas condensate distribution and relative permeability through three dimensional pore network model (Bustos \& Toledo, 2003). In addition, they found that the gas relative permeability shows two different regimes. In the first regime, when the condensate saturation is less than $20 \%$, the relative permeability of the gas phase decreases slowly, whereas it decreases faster in the second regime (condensate saturation above 20\%).

Singh and other researchers studied the effects of confinement on thermophysical properties of nalkanes (critical temperature, pressure, and density) in the graphite and mica slit pores (Singh, Sinha, Deo, \& Singh, 2009). They found that the critical temperature of alkanes decreases due to the confinement in the carbon nanotube, while the critical density increases because of the confinement. In addition, Singh proposed equations that calculate the shift in the critical pressure and temperature due to confinement in the tight formations. Singh's equations calculate the shift in the critical pressure and temperature based on the shifted bulk pressure and temperature values. Singh's equations are shown below:

$$
\begin{aligned}
\Delta \mathrm{P}_{\mathrm{c}} & =\frac{\mathrm{P}_{\mathrm{cb}}-\mathrm{P}_{\mathrm{cp}}}{\mathrm{P}_{\mathrm{cp}}} \\
\Delta \mathrm{T}_{\mathrm{c}} & =\frac{\mathrm{T}_{\mathrm{cb}}-\mathrm{T}_{\mathrm{cp}}}{\mathrm{T}_{\mathrm{cp}}}
\end{aligned}
$$

Finally, Devagowda et. al investigated the changes in the phase diagram, density, viscosity and surface tension of the hydrocarbon components within different pore sizes and the other changes due to the absorbed components layers compared with the bulk systems. Moreover, Devagowda et. al. extended the work of Singh 2009 of the nanopores and proposed equations to calculate the shift in the critical temperature and pressure of the heavier compounds to model gas condensate mixtures based on the corresponding molecular weight in order to study changes in the critical properties within the nanopores of $2 \mathrm{~nm}, 4 \mathrm{~nm}$, and $5 \mathrm{~nm}$ size (Devagowda, Sapmanee, Civan, \& Sigal, 2012). 
Devagowda's et. al proposed equations are as follows:

$$
\begin{aligned}
& \Delta \mathrm{P}_{\mathrm{c} 2 \mathrm{~nm}}=0.085 \mathrm{Ln}(\mathrm{MW})-0.0693 \\
& \Delta \mathrm{P}_{\mathrm{c} 4 \mathrm{~nm}}=-0.085 \mathrm{Ln}(\mathrm{MW})+0.1193 \\
& \Delta \mathrm{P}_{\mathrm{c} 5 \mathrm{~nm}}=-0.077 \mathrm{Ln}(\mathrm{MW})-0.041 \\
& \Delta \mathrm{T}_{\mathrm{c} 2 \mathrm{~nm}}=0.0636 \mathrm{Ln}(\mathrm{MW})^{0.2129} \\
& \Delta \mathrm{T}_{\mathrm{c} 4 \mathrm{~nm}}=0.0229 \mathrm{Ln}(\mathrm{MW})^{0.2329} \\
& \Delta \mathrm{T}_{\mathrm{c} 5 \mathrm{~nm}}=0.0153 \mathrm{Ln}(\mathrm{MW})^{0.241}
\end{aligned}
$$

\subsection{Gas Condensate Behavior}

In reservoir initial conditions, a gas condensate reservoir commonly contains a single phase fluid, which is gas as long as reservoir pressure is above the dew point pressure. In the beginning of the production process, production stream consists of two phase fluid, gas and condensate. Even though there is only gas in the reservoir at the initial conditions, the condensate generates as the gas enters the wellbore or reaches the surface due to pressure drop.

As the formation pressure or the near wellbore pressure drops below the dew point pressure, condensate starts to accumulate throughout the reservoir. After a while of the production with a bottomhole pressure lower than the dew point pressure, three different regions in the reservoir with different condensate saturation will appear. The first region, around the wellbore, contains two phase fluid, gas and condensate, and both of them are mobile, that is being said two phase flow exists in this region. After the first region is the second region, which also has gas and condensate but condensate saturation in this region is lower comparing with the first region. As a result, the gas is flowing, whereas the condensate is not flowing since its saturation is lower than the critical saturation. The third region only contains the original gas of the reservoir and it is farther from the wellbore. The reason of the formation of these different three regions is the pressure drop is not equal throughout the entire reservoir. It was found that the first region is the main reason of gas 
deliverability reduction even though the fluid composition is constant in this region. The first region usually exists if the flowing bottomhole pressure is lower than the dew point pressure (Fevang \& Whitson, 1996).

The highest pressure drop occurs around the wellbore region; therefore the condensate first accumulates in this region forming (condensate bank or ring). Moreover, the vast gas volume flowing through the near wellbore region enhances the formation of the condensate ring in this region (Bamum, Brinkman, Richardson, \& Spillette, 1995). The condensate ring around the wellbore causes many gas flow issues. Once the saturation of the condensate increases, gas saturation decreases and gas relative permeability decreases too. As a result, gas deliverability reduction occurs (Ahmed, Evans, Kwan, \& Vivian, 1998). The biggest drop of gas relative permeability happens near the wellbore region since condensate saturation is high in this region. Fig. 9 shows the condensate distribution in the three regions throughout the reservoir.

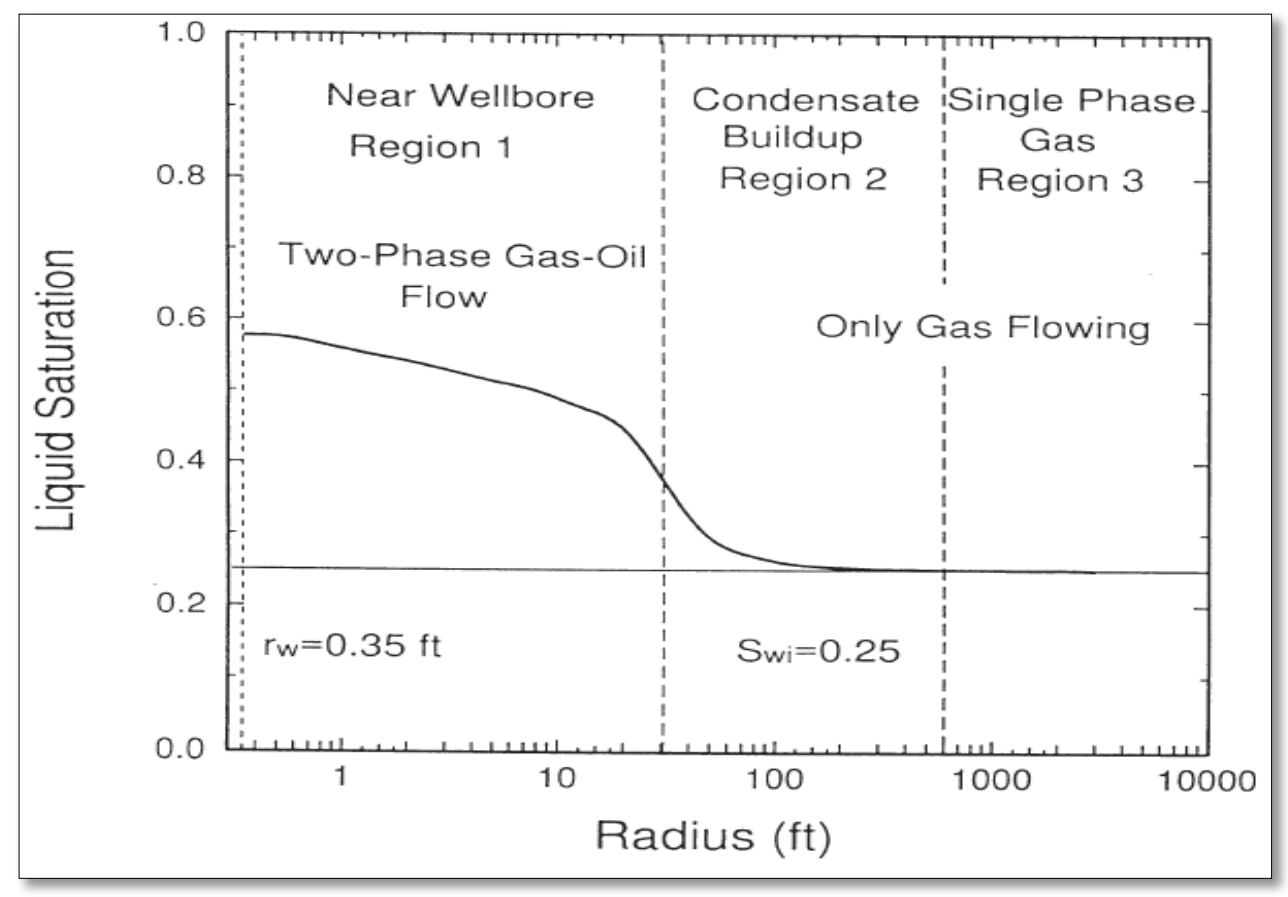

Fig. 9 gas condensate distribution in the reservoir, (Fevang \& Whitson, 1996) 


\subsection{Gas Condensate Reservoirs Modeling}

Reservoir simulation models are usually utilized in order to study the performance of oil and gas reservoirs and provide optimum development plans to obtain the maximum economic advantages. Fluid properties and reservoir data have to be available for the reservoir models to perform simulation processes (Fan, et al., 2005/2006). Gas condensate reservoir calculations and modeling have been considered one of the most difficult processes in petroleum industry because of the continuous composition change and due to the unique thermodynamic behavior (Fevang \& Whitson, 1996). Composition change and permeability reduction are usually caused by condensate accumulation during the production with formation pressure below the dew point pressure. In addition, condensate accumulation results in gas deliverability reduction due to blocking gas flow channels and the decrease in the permeability values. A significant change in composition and permeability mostly happens around the wellbore since condensate saturation is the highest in this region; therefore, near wellbore region modeling is usually difficult and requires more calculations. Fig. 10 depicts the relationship between condensate saturation and gas and condensate relative permeability around the wellbore region.

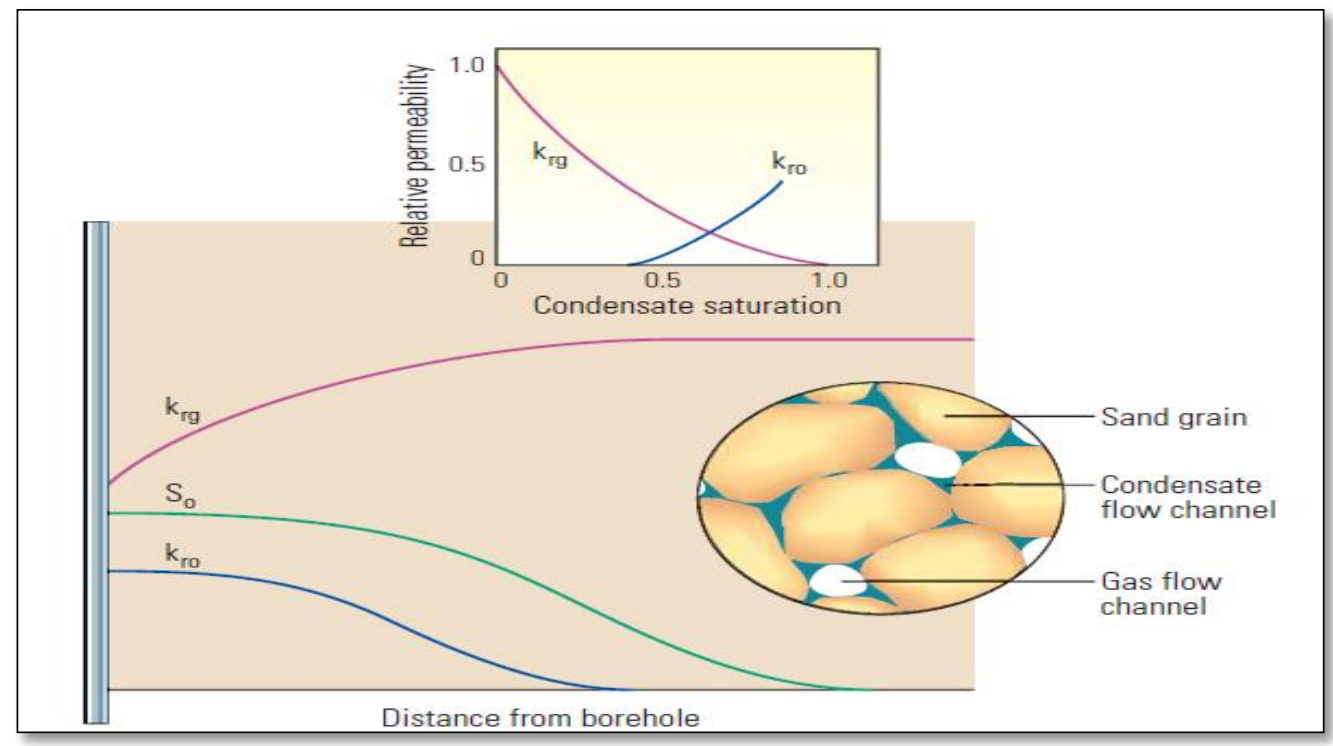

Fig. 10 relative permeability and condensate saturation relationship (Fan, et al., 2005/2006) 
Using a typical grid block size of a full-field model (FFM) is not appropriate to model the condensate bank zone and that may result in overestimate results. Consequently, the best method to study the flow behavior of a zone with an accumulated condensate is by use of a full-field model with local grid refinement (LGR) method or by use of a single well model that has fine grids around it (Fan, et al., $2005 / 2006)$. Local grid refinement method is provided by most of reservoir simulation models such as CMG (Computer Modeling Group) software and ECLIPSE. The local grid refinement method is described by generating a small grid cell perpendicularly to the direction of the fracture and the wellbore (Computer Modeling Group Ltd). The purpose of this process is to minimize the size of gridblocks and bring it near to the size of the actual fracture width. Even though, this method is one of the most accurate methods of modeling the near well behavior of gas-condensate reservoirs, the cost of the simulation and the competition time are further comparing to the case of not using local grid refinement.

Gas condensate reservoirs can also be modeled by using single well model. Commonly, radial symmetric well is used in this case and that helps to treat the well model as a two dimensional model which has height and radial dimension only. In this case of modeling, the grid-blocks around the wellbore have to be smaller in the size comparing to the grid blocks that are farther from the wellbore. Using small size grid blocks helps to increase the precision of the simulation and that enhances the ability of studying the gas condensate behavior at high flow rates and complex saturation conditions in the near wellbore region (Fan, et al., 2005/2006).

Another method to model the gas condensate reservoir is by using black oil model. This kind of simulator considers that there is only two hydrocarbon components which is oil and gas. This method of simulation is not applicable when the change in the composition is huge such as gas injection. Finally, a full-field model can be utilized to model the gas condensate reservoirs, but it has to be incorporated with pseudopressure method. In the pseudopressure method, the gas flow equation has 
to be in pseudopressure term which is represented by an integral over pressure value and this method has been incorporated with spreadsheet format (Fan, et al., 2005/2006). In this research, the first method of simulation with local grid refinement will be used to perform the simulation in order to study the effect of pore sizes on gas condensate behavior and how that will impact the reservoir performance.

\subsection{Equation of State}

The hydrocarbon reservoir fluids have quite complicated thermodynamic behavior. Equations of state depict that these reservoir fluids have unique performance in phase behavior calculations. An equation of state (EOS) is a mathematical relationship that relates the pressure to volume and temperature in hydrocarbon systems and can provide a description of the phase behavior of the fluid. The equations of state are usually classified into two different kinds; cubic equation and noncubic equation. The noncubic equations are commonly used to investigate the volumetric behavior of pure substances, whereas they are not appropriate for complex hydrocarbon mixtures. The first proposed equation of state was in 1873, which was proposed by Van der Waals. Later, many different equations of state were proposed by different researchers to be used in reservoir engineering to perform reservoir fluid calculations. The most popular equations of state in oil and gas industry are Esmaeilzadeh-Roshanfekr (ER), Peng-Robinson (PR), Patel-Teja (PT), Schmit-Wenzel (SW), and Soave-Redlich-Kwong (SRK). In this research, the Peng-Robinson equation of state will be used to perform the phase behavior calculations since it is the most common equation of state (Ashour, ALRawahi, Fatemi, \& Nezhaad, 2011).

\section{Peng-Robinson Equation of State}

The Peng-Robinson equation of state is the most well-known equation of state for natural gas systems in oil and gas industry (Adewumi, 2014). The Peng-Robinson equation of state is a cubic equation and it is considered one of the Van der Waals equation of state forms. This equation was improved 
by Peng and Robinson in 1976 in order to enhance density prediction of reservoir fluid systems (Ashour, AL-Rawahi, Fatemi, \& Nezhaad, 2011). Peng-Robinson EOS provides the ability to identify the phase of a substance by calculating vapor pressure based on the temperature and molar parameters. Peng-Robinson EOS exploits interaction coefficients of mixtures to find out the effect of the miscibility between components on the Pressure-Volume-Temperature (PVT) behavior of the mixed composition (Peng \& Robinson, 1976). According to the literature, the Peng-Robinson EOS is simpler in calculations and provides more reliable results comparing with the other proposed equations of state. Nonetheless, Peng-Robinson EOS is not able to represent the volumetric behavior around the critical point. The final developed Peng-Robinson EOS in term of molar volume $\left(\mathrm{V}_{\mathrm{m}}\right)$ is shown as the following:

$$
P=\frac{R T}{V_{m}-b}-\frac{a(T)}{V_{m}\left(V_{m}+b\right)+b\left(V_{m}-b\right)}
$$

Where

$$
\begin{gathered}
a\left(T_{c}\right)=0.45724 \frac{\left(R T_{C}\right)^{2}}{P_{C}} \\
b=0.07780 \frac{\left(R T_{C}\right)}{P_{C}}
\end{gathered}
$$

The Peng-Robinson EOS is generally used to estimate gas and condensate reserves by performing compositional simulation. Moreover, the Peng-Robinson EOS is quite important for gas condensate reservoirs development including production plans and how to achieve the maximum economic advantages out of these kinds of reservoirs. The required data to perform the compositional simulation include the dew point pressure, liquid volume, gas compressibility factor, and produced gas (Constant Volume Depletion, CVD data) which are usually obtained by the use of the equation of state (Hosein, Dawe, \& Amani, 2011). In this research, the Peng-Robinson EOS is used to obtain the required results using the CMG (Computer Modeling Group) software since this equation is one of the provided equations by this software. 


\subsection{Components Lumping}

The critical properties data of the gas condensate fluid (critical pressure, and critical temperature, etc.) have to be provided in order to investigate condensate behavior by use of the Peng-Robinson EOS via CMG software (Marir \& Tiab, 2006). EOS-based compositional modeling is usually utilized to model changing composition systems such as reservoirs, production flow lines, compressors, and surface processes. Mostly, the modeling process of these systems necessitates large CPU time, especially reservoirs modeling which may take hours or even days.

In order to minimize the CPU time in compositional reservoir modeling, the number of the components of the hydrocarbon mixtures in the equation of state (EOS) that provide the fluid phase behavior should be reduced to a reasonable number (Alavian, Whitson, \& Martinsen, 2014). Diminishing the number of the components is usually accomplished by use of lumping method. Lumping method is applied to increase the precision of the simulation process and minimize the time of the computation by combined some of mixture components in less number of components.

A typical EOS model mostly has 20 to 40 components in which the first 10 components representing pure components such as $\mathrm{H}_{2} \mathrm{~S}, \mathrm{CO}_{2}, \mathrm{~N}_{2}, \mathrm{C}_{1}, \mathrm{C}_{2}, \mathrm{C}_{3}, \mathrm{i}-\mathrm{C}_{4}, \mathrm{n}-\mathrm{C}_{4}, \mathrm{i}-\mathrm{C}_{5}$, and n- $\mathrm{C}_{5}$. The other components in the EOS model are a split of the heavy components such as single-carbon number (SCN) fractions, $\mathrm{C}_{6}, \mathrm{C}_{7}$, $\mathrm{C}_{8}$ and $\mathrm{C}_{9}$, or combinations of $\mathrm{SCN}$ fractions such as $\mathrm{C}_{10}-\mathrm{C}_{12}, \mathrm{C}_{13}-\mathrm{C}_{19}, \mathrm{C}_{20}-\mathrm{C}_{29}$ and $\mathrm{C}_{30}+$ (Alavian, Whitson, \& Martinsen, 2014). According to the literature, there is no specific method to choose the optimum lumping scheme that provides precise results similar to the single carbon number results. Nonetheless, to obtain precise results, trial and error method could be used or algorithms designed might be carried out to select the best number of lumping schemes (Hosein, Dawe, \& Amani, 2011). In this research, the lumping method is used with data that have many components in order to reduce simulation time. 


\subsection{CMG (Computer Modeling Group) Software}

CMG is one of the commercial reservoir simulators that is mostly utilized in petroleum industry for reservoir development planning. Reservoir simulation models are used to predict oil and gas reservoirs production and to find the optimum scenario for developing a reservoir in order to increase economic advantages. CMG has provided three reservoir simulators IMEX, a black oil simulator, GEM, a compositional simulator, and STARS, which is a thermal compositional simulator. Moreover, CMG has developed reservoir simulation tools and software such as CMOST, iSEGWELL, and WinProp, etc. GEM software will be used in this research since the objective is to study the impact of pore size on gas condensate critical properties, and it is obvious that the process of producing gas condensate reservoir accompanies with many changes in compositions and phases. Besides GEM, WinProp program is utilized in this research to model the phase behavior and the properties of gas condensate (Computer Modeling Group Ltd).

\subsubsection{GEM Software}

GEM is one of the most popular simulators that is used for compositional and unconventional reservoirs modeling. GEM is a sophisticated combination of equations of state (EOS) compositional reservoir simulator, which is commonly utilized to model recovery processes where the change in fluid composition has a significant impact on the recovery process (University of Waterloo). Furthermore, GEM provides the ability to model the laboratory scale process and field scale projects. GEM has the ability to effectively perform many processes and calculations such as; modeling complex oil and gas reservoirs, studying fluid properties and behavior, simulating naturally and hydraulically fractured reservoirs, improving field and surface operating conditions in order to increase the effectiveness of production, and optimizing the estimation of net present value (NPV) by precisely modeling of reservoirs phase behavior (Computer Modeling Group Ltd). 


\subsubsection{WinProp Program}

WinProp is one of CMG programs which is considered to be CMG's equation of state (EOS) that is mostly used for multiphase equilibrium and properties estimation (Computer Modeling Group Ltd). WinProp is an important program for reservoir engineers that provides the ability to model and investigate the phase behavior and properties of reservoir fluid in the laboratory and in the field conditions. Moreover, WinProp is a fluid property characterization program that helps to establish fluid property models for CMG simulators (IMEX, GEM and STARS). WinProp program can be used in different applications in reservoir simulation area to accomplish many processes such as, tuning the Equation of state in order to forecast fluid behavior, studying phase's distribution in a reservoir system during different conditions of depletion, and optimizing reservoir development planning (Computer Modeling Group Ltd). 


\section{Chapter 3 - Methodology}

The purpose of this study is to investigate the impact of the pore sizes on the critical properties of confined gas condensate in Marcellus shale and then study reservoir performance under this effect. To approach the objectives of this study, reservoir and fluid data are required to be available in order to carry out phase behavior calculations and to construct fluid and reservoir models. Once the reservoir model is built, numerous simulation runs will be performed in order to achieve the objectives of this research.

\subsection{Data Acquisition}

To accomplish the objectives of this research, accurate fluid and reservoir data must be available. The provided fluid data include, reservoir fluid composition and properties, separator gas composition, constant composition expansion data at reservoir temperature, and constant volume depletion study using an equation of state. The following tables and figures depict some of the given data for this research:

Table 1 Constant Composition Expansion at 130 F (Coleman, 2014)

\begin{tabular}{|c|c|c|c|c|c|c|}
\hline $\begin{array}{c}\text { Pressure } \\
\text { (psia) }\end{array}$ & & $\begin{array}{l}\text { Relative } \\
\text { Volume }\end{array}$ & $\begin{array}{c}\text { Gas } \\
\text { Density }\end{array}$ & $\begin{array}{c}\text { Liquid } \\
\text { Volume \% }\end{array}$ & $\begin{array}{l}\text { Deviation } \\
\text { Factor (Z) }\end{array}$ & $\begin{array}{c}\text { Correlated } \\
\text { Gas } \\
\text { Viscosity }\end{array}$ \\
\hline 4500 & & 0.665 & 0.292 & & 0.893 & 0.0353 \\
\hline 4000 & & 0.702 & 0.277 & & 0.839 & 0.0326 \\
\hline 3800 & Reservior & 0.72 & 0.27 & & 0.817 & 0.0315 \\
\hline 3500 & & 0.753 & 0.258 & & 0.788 & 0.0296 \\
\hline 3000 & & 0.831 & 0.234 & & 0.744 & 0.262 \\
\hline 2400 & & 0.991 & 0.196 & & 0.71 & 0.0219 \\
\hline 2375 & Saturation & 1 & 0.194 & 0 & 0.709 & 0.0217 \\
\hline 2300 & & 1.028 & & 0.08 & 0.706 & \\
\hline 2200 & & 1.075 & & 0.16 & 0.706 & \\
\hline 2000 & & 1.192 & & 0.25 & 0.712 & \\
\hline 1800 & & 1.348 & & 0.36 & 0.725 & \\
\hline 1600 & & 1.554 & & 0.81 & 0.743 & \\
\hline 1400 & & 1.83 & & 1.82 & 0.765 & \\
\hline 1200 & & 2.205 & & 2.41 & 0.79 & \\
\hline 1014 & & 2.692 & & 2.35 & 0.815 & \\
\hline
\end{tabular}


Table 2 EOS input parameters (Coleman, 2014)

\begin{tabular}{|c|c|c|c|c|c|c|c|}
\hline Component & Mole \% & $\begin{array}{c}\text { Molecular } \\
\text { Weight }\end{array}$ & $\begin{array}{c}\text { Liquid } \\
\text { Density } \\
\text { Gms/cc }\end{array}$ & $\begin{array}{c}\text { Critical } \\
\text { Temp. (F) }\end{array}$ & $\begin{array}{c}\text { Critical } \\
\text { Pres. } \\
\text { (psia) }\end{array}$ & $\begin{array}{c}\text { Accentric } \\
\text { Factor }\end{array}$ & $\begin{array}{c}\text { Normal } \\
\text { Tb (F) }\end{array}$ \\
\hline N2 & 0.442 & 28.01 & & -232.51 & 492.32 & 0.04 & -320.35 \\
\hline CO2 & 0.15 & 44.01 & & 87.89 & 1069.87 & 0.225 & -109.3 \\
\hline C1 & 74.177 & 16.04 & & -116.59 & 667.2 & 0.008 & -258.79 \\
\hline C2 & 14.82 & 30.07 & & 90.05 & 708.35 & 0.098 & -127.39 \\
\hline C3 & 5.39 & 44.1 & & 205.97 & 615.76 & 0.152 & -43.69 \\
\hline Ic4 & 0.707 & 58.12 & & 274.91 & 529.06 & 0.176 & 10.85 \\
\hline$n c 4$ & 1.545 & 58.12 & & 305.69 & 551.1 & 0.193 & 31.19 \\
\hline$i c 5$ & 0.426 & 72.15 & & 369.05 & 490.85 & 0.227 & 82.13 \\
\hline$n c 5$ & 0.517 & 72.15 & & 385.61 & 489.38 & 0.251 & 96.89 \\
\hline$c 6$ & 0.549 & 86.18 & 0.664 & 453.65 & 430.59 & 0.296 & 155.75 \\
\hline$c 7$ & 0.425 & 97.37 & 0.698 & 505.28 & 410.49 & 0.342 & 197.51 \\
\hline$c 8$ & 0.357 & 109.6 & 0.722 & 518.86 & 328.43 & 0.383 & 242.15 \\
\hline$c 9$ & 0.172 & 121.79 & 0.755 & 456.28 & 284.34 & 0.423 & 288.05 \\
\hline$c 10$ & 0.114 & 134.63 & 0.779 & 448.56 & 267.03 & 0.465 & 330.53 \\
\hline$c 11$ & 0.07 & 147 & 0.79 & 511.16 & 251.66 & 0.505 & 369.05 \\
\hline$c 12$ & 0.047 & 161 & 0.801 & 581.16 & 237.32 & 0.549 & 407.03 \\
\hline$c 13$ & 0.032 & 175 & 0.812 & 641.83 & 225.65 & 0.592 & 441.05 \\
\hline$c 14$ & 0.021 & 190 & 0.823 & 703.35 & 215.31 & 0.638 & 475.61 \\
\hline$c 15$ & 0.013 & 206 & 0.833 & 772.12 & 206.04 & 0.686 & 510.53 \\
\hline$c 16$ & 0.009 & 222 & 0.84 & 853.5 & 198.02 & 0.733 & 541.13 \\
\hline$c 17$ & 0.006 & 237 & 0.848 & 914.43 & 191.84 & 0.776 & 571.73 \\
\hline$c 18-45$ & 0.011 & 271.27 & 0.86 & 1096.53 & 180.22 & 0.874 & 635.06 \\
\hline & & & & & & & \\
\hline
\end{tabular}

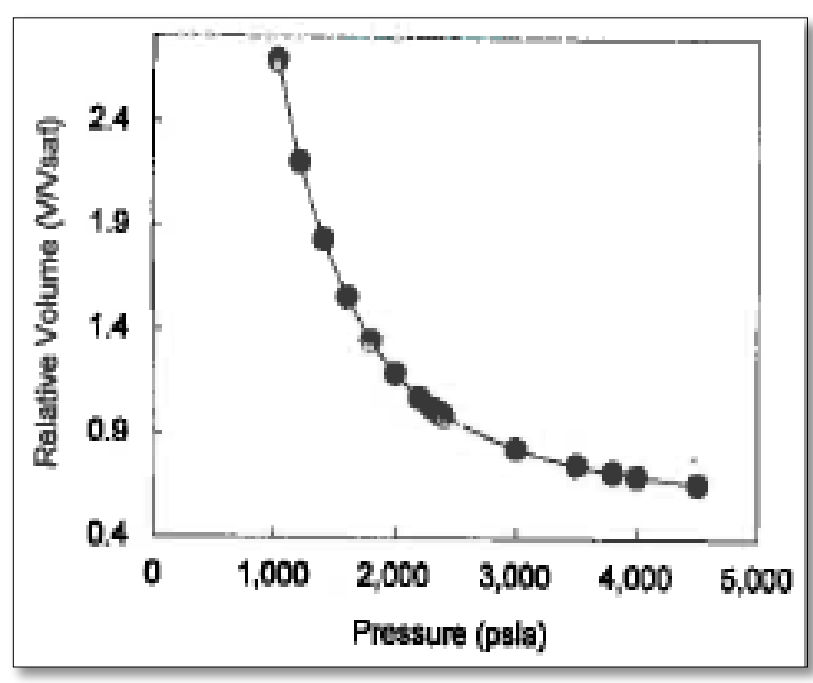

Fig. 11 pressure and volume relations (Coleman, 2014) 


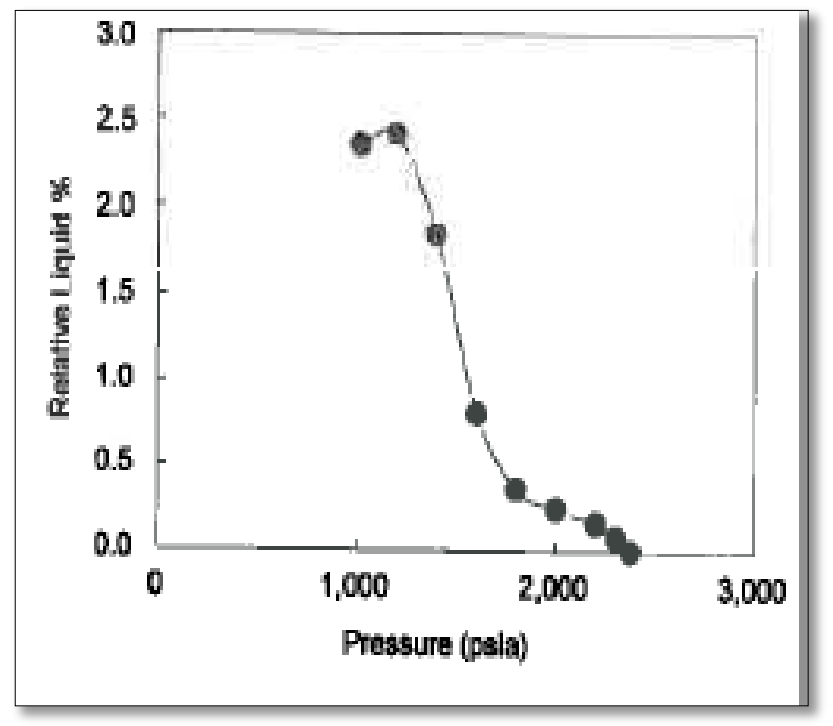

Fig. 12 retrograte liquid volume (Coleman, 2014)

The above given data have been used to construct the fluid models which then imported into the reservoir models in order to investigate the impact of the confinement on reservoir performance. Prior to studying the impact of the confinement on the critical properties of the reservoir fluid, the fluid model that was built with WinProp software has to be history matched with the provided laboratory results in order to enable the fluid model to reflect the real behavior of the reservoir fluid. Regression calculations were performed in order to obtain the optimum matched with laboratory analysis results.

\subsection{Fluid Models History Matching}

The provided fluid data for this research have been used to construct reservoir models for both confined and unconfined cases. To obtain a reliable fluid model that reflects the real reservoir fluid behavior, the built fluid models have to be history matched. Constant composition expansion (CCE) calculations were performed in order to investigate the PVT behavior of the fluid reservoir. Constant composition expansion calculations provide the data regarding, the relative volume, produced liquid, dew point pressure, compressibility factor, and gas viscosity, etc. The first obtained results of constant composition expansion calculations from the built fluid model did not match the provided 
fluid data, therefore, regression calculations were used to match the fluid model results with laboratory results. As mentioned before in this research, regression calculation is a tool in WinProp software that is used to tune the equation of state to match the real laboratory measurement. In this research, specific regression algorithm has been used to tune the Equation of State to enable the fluid model to provide optimum results that match the provided experimental measurements. The following table depicts fluid composition input for the fluid model and the other figures show the results of the constant composition expansion for both the non-tuned fluid model and the tuned fluid model which is used in this research.

Table 3 reservoir fluid composition and properties

\begin{tabular}{|c|c|c|c|c|}
\hline Component & Mole \% & M.WT & Pc(atm) & $T c(k)$ \\
\hline N2 & 0.442 & 28.013 & 33.5 & 126.2 \\
\hline CO2 & 0.15 & 44.01 & 72.8 & 304.2 \\
\hline CH4 & 74.177 & 16.043 & 45.4 & 190.6 \\
\hline C2H6 & 14.82 & 30.07 & 48.2 & 305.4 \\
\hline C3H8 & 5.39 & 44.097 & 41.9 & 369.8 \\
\hline IC4 & 0.707 & 58.124 & 36 & 408.1 \\
\hline NC4 & 1.545 & 58.124 & 37.5 & 425.2 \\
\hline IC5 & 0.426 & 72.151 & 33.4 & 460.4 \\
\hline NC5 & 0.517 & 72.151 & 33.3 & 469.6 \\
\hline FC6 & 0.549 & 86 & 32.46 & 507.5 \\
\hline FC7 & 0.425 & 96 & 30.97 & 543.2 \\
\hline FC8 & 0.357 & 107 & 29.12 & 570.5 \\
\hline FC9 & 0.172 & 121 & 26.94 & 598.5 \\
\hline FC10 & 0.114 & 134 & 18.1703 & 504.6 \\
\hline FC11 & 0.071 & 147 & 17.1244 & 539.4 \\
\hline FC12 & 0.047 & 161 & 16.1486 & 578.2 \\
\hline C13+ & 0.091 & 204.737 & 16.9722 & 728.2 \\
\hline
\end{tabular}


Table 4 constant composition expansion results of the tuned fluid model

\begin{tabular}{|c|c|c|c|c|c|c|c|}
\hline & p, psia & $\begin{array}{l}\text { relative } \\
\text { tot vol }\end{array}$ & $\begin{array}{r}0 i 1 \\
\text { vis, cp }\end{array}$ & $\begin{array}{r}\text { gas } \\
\text { vis, } \mathrm{cp}\end{array}$ & Z-factor & $\begin{array}{c}\text { IFT } \\
\text { dyne/cm }\end{array}$ & $\begin{array}{c}\text { liquid } \\
\text { vol (\% } \\
\text { of } \mathrm{CV} @ \text { sat) }\end{array}$ \\
\hline \multirow[t]{2}{*}{$\begin{array}{l}1 \\
2 \\
3 \\
4 \\
5 \\
6 \\
7\end{array}$} & $\begin{array}{l}---\cdot-- \\
4500.00 \\
4000.00 \\
3800.00 \\
3500.00 \\
3000.00 \\
2400.00 \\
2375.00\end{array}$ & $\begin{array}{l}---1-- \\
0.6869 \\
0.7244 \\
0.7426 \\
0.7746 \\
0.8463 \\
0.9897 \\
0.9980\end{array}$ & $--1-1$ & $\begin{array}{l}---1-- \\
0.03728 \\
0.03461 \\
0.03349 \\
0.03174 \\
0.02855 \\
0.02409 \\
0.02389\end{array}$ & $\begin{array}{l}---1-- \\
0.8399 \\
0.7873 \\
0.7667 \\
0.7366 \\
0.6899 \\
0.6454 \\
0.6440\end{array}$ & 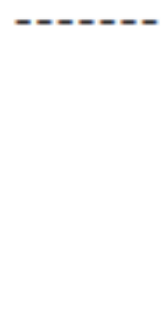 & $\begin{array}{l}0.0000 \\
0.0000 \\
0.0000 \\
0.0000 \\
0.0000 \\
0.0000 \\
0.0000\end{array}$ \\
\hline & 2368.98 & 1.0000 & 0.1141 & 0.02384 & 0.6437 & 0.4530 & 0.0000 \\
\hline $\begin{array}{r}8 \\
9 \\
10 \\
11 \\
12 \\
13 \\
14 \\
15\end{array}$ & $\begin{array}{l}2300.00 \\
2200.00 \\
2000.00 \\
1800.00 \\
1600.00 \\
1400.00 \\
1200.00 \\
1014.00\end{array}$ & $\begin{array}{l}1.0255 \\
1.0667 \\
1.1684 \\
1.3060 \\
1.4980 \\
1.7733 \\
2.1701 \\
2.6998\end{array}$ & $\begin{array}{l}0.1141 \\
0.1140 \\
0.1131 \\
0.1101 \\
0.1029 \\
0.0927 \\
0.0907 \\
0.0963\end{array}$ & $\begin{array}{l}0.02323 \\
0.02232 \\
0.02048 \\
0.01863 \\
0.01681 \\
0.01513 \\
0.01375 \\
0.01278\end{array}$ & $\begin{array}{l}0.6408 \\
0.6375 \\
0.6349 \\
0.6390 \\
0.6523 \\
0.6779 \\
0.7145 \\
0.7536\end{array}$ & $\begin{array}{l}0.5069 \\
0.5976 \\
0.8338 \\
1.1630 \\
1.5866 \\
2.0762 \\
2.8238 \\
3.8611\end{array}$ & $\begin{array}{l}0.0718 \\
0.1676 \\
0.3373 \\
0.5041 \\
0.7549 \\
1.2850 \\
1.9422 \\
2.2974\end{array}$ \\
\hline
\end{tabular}

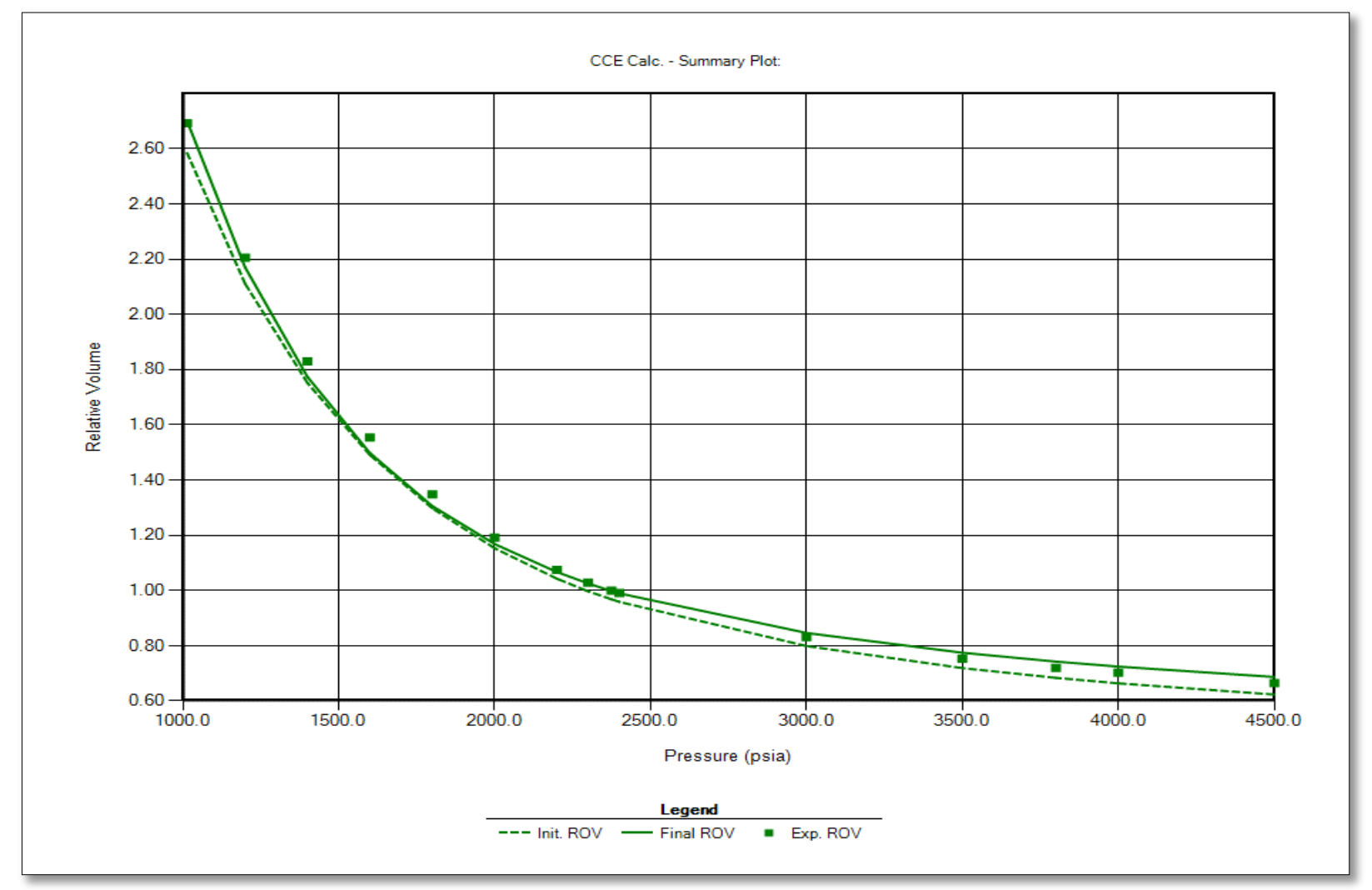

Fig. 13 pressure and volume relation based on constant composition expansion 


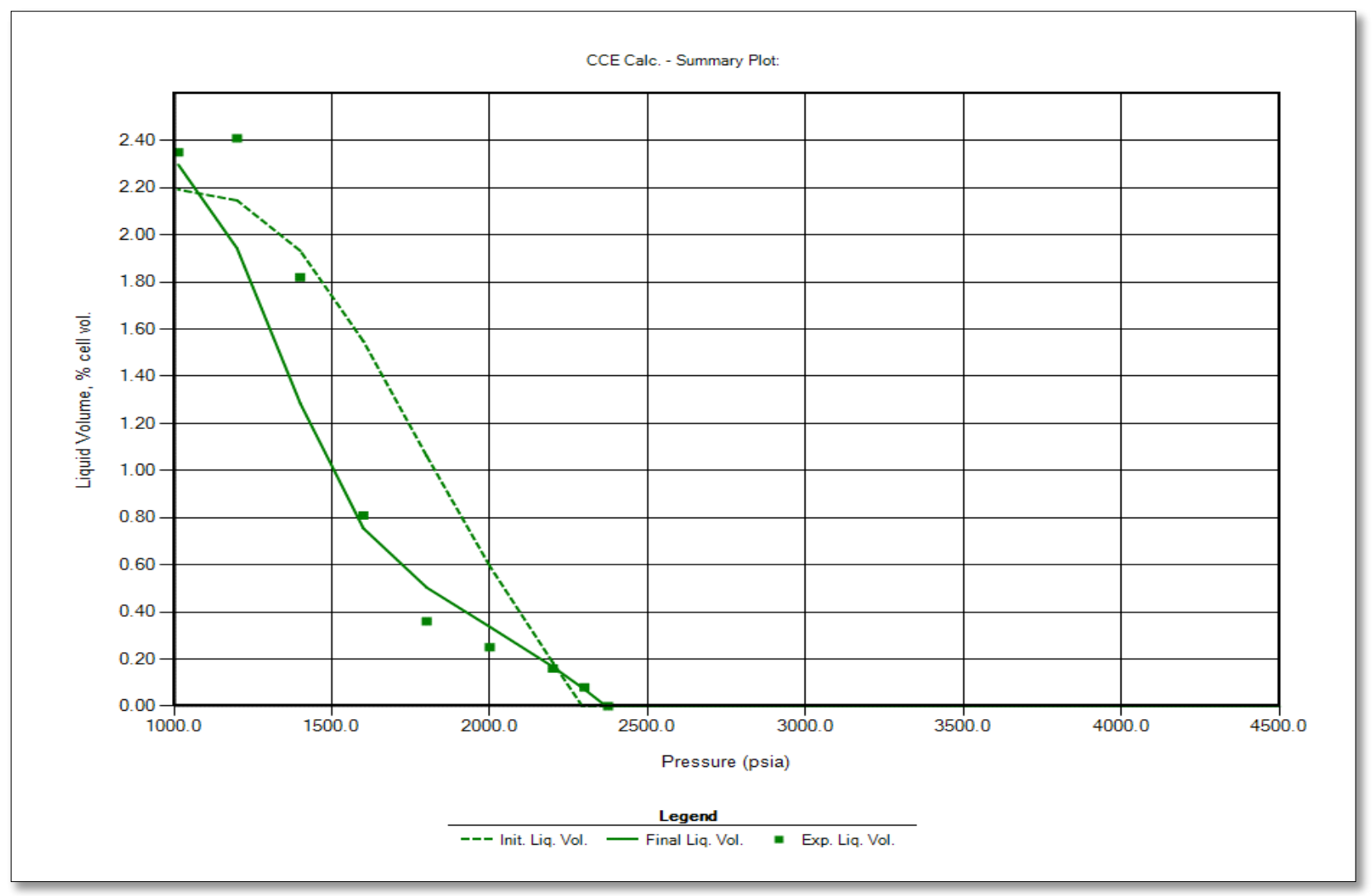

Fig. 14 retrograde liquid calculation based on constant composition expansion

\subsection{Critical Properties Calculations}

After performing the history matching calculations for the given fluid data, the relative shift in the critical properties (critical pressure and temperature) due to pore size is calculated. The relative shift in the bulk pressure and temperature of each component in the gas condensate fluid is calculated using Devagowda's et. al equations' which are mentioned in the literature review of this research. Once the relative shift in the bulk pressure and temperature is calculated based on the molecular weight of each component, Singh's equations, which are also mentioned previously in this research are used to calculate the modified critical pressure and temperature values due to pore size effects in the formation. Finally, these obtained values are used to construct the fluid models using WinProp program. The shift in the critical pressure and temperature values is shown in Table 5. 
Table 5 the shift in the Critical pressure and temperature values of the given fluid data at different pore sizes

\begin{tabular}{|c|c|c|c|c|c|c|}
\hline \multirow{2}{*}{ Component } & \multicolumn{2}{|c|}{ Pore Size $2 \mathrm{~nm}$} & \multicolumn{2}{c|}{ Pore Size 4 $\mathrm{nm}$} & \multicolumn{2}{c|}{ Pore Size $5 \mathrm{~nm}$} \\
\cline { 2 - 7 } & $\Delta \mathrm{PC}$ & $\Delta \mathrm{TC}$ & $\Delta \mathrm{PC}$ & $\Delta \mathrm{TC}$ & $\Delta \mathrm{PC}$ & $\Delta \mathrm{TC}$ \\
\hline N2 & 0.21398 & 0.04513 & -0.16398 & 0.01770 & -0.29762 & 0.01229 \\
\hline CO2 & 0.25238 & 0.05124 & -0.20238 & 0.02010 & -0.33240 & 0.01395 \\
\hline CH4 & 0.16660 & 0.03758 & -0.11660 & 0.01474 & -0.25470 & 0.01023 \\
\hline C2H6 & 0.22000 & 0.04609 & -0.17000 & 0.01807 & -0.30307 & 0.01255 \\
\hline C3H8 & 0.25254 & 0.05127 & -0.20254 & 0.02011 & -0.33255 & 0.01396 \\
\hline IC4 & 0.27602 & 0.05501 & -0.22602 & 0.02157 & -0.35382 & 0.01498 \\
\hline NC4 & 0.27602 & 0.05501 & -0.22602 & 0.02157 & -0.35382 & 0.01498 \\
\hline IC5 & 0.29439 & 0.05794 & -0.24439 & 0.02272 & -0.37046 & 0.01578 \\
\hline NC5 & 0.29439 & 0.05794 & -0.24439 & 0.02272 & -0.37046 & 0.01578 \\
\hline FC6 & 0.30932 & 0.06031 & -0.25932 & 0.02365 & -0.38398 & 0.01642 \\
\hline FC7 & 0.31867 & 0.06180 & -0.26867 & 0.02424 & -0.39245 & 0.01683 \\
\hline FC8 & 0.32789 & 0.06327 & -0.27789 & 0.02482 & -0.40081 & 0.01723 \\
\hline FC9 & 0.33834 & 0.06494 & -0.28834 & 0.02547 & -0.41028 & 0.01768 \\
\hline FC10 & 0.34702 & 0.06632 & -0.29702 & 0.02601 & -0.41813 & 0.01806 \\
\hline FC11 & 0.35489 & 0.06757 & -0.30489 & 0.02650 & -0.42526 & 0.01840 \\
\hline FC12 & 0.36262 & 0.06880 & -0.31262 & 0.02698 & -0.43227 & 0.01874 \\
\hline C13+ & 0.38305 & 0.07206 & -0.33305 & 0.02826 & -0.45077 & 0.01962 \\
\hline & & & & & & \\
\hline
\end{tabular}

\subsection{Fluid Models Construction}

Once calculating the modified critical values of the pressure and the temperature of the gas condensate fluid components, fluid models are constructed based on these values to investigate the impact of the pore size on the critical properties of the gas condensate fluid. To construct the fluid models, CMG WinProp program is used to build four fluid models, three models for the confinement cases with pore size of $(2,4$, and $5 \mathrm{~nm})$ and the last model represents the unconfined case. Reservoir pressure, reservoir temperature, and gas condensate composition data are imported to the CMG WinProp program. After importing all the required data to the program, the Peng-Robinson (EOS) will be used in order to perform two phase envelop calculations to construct the phase envelope curves for each case. Once, the phase envelop curves are constructed, then the fluid models have to be validated in order to be employed in building reservoir models in CMG GEM software. 
Lumping method calculations are performed to ease the process of simulation by combining the hydrocarbon substance in the mixtures into fewer components and then facilitate the process of matching the constructed fluid model with the experimental measurements.

The fluid models are built based on the given reservoir temperature of $130^{\circ} \mathrm{F}$ and reservoir pressure of 3800 Pisa. The modified critical pressure and temperature values which were calculated based on the different pore sizes and then imported into the fluid models are shown in Table 6.

Table 6 the modified critical pressure and temperature values due to confinement effects

\begin{tabular}{|c|c|c|c|c|c|c|}
\hline \multirow{2}{*}{ Component } & \multicolumn{2}{|c|}{ Pore Size $2 \mathrm{~nm}$} & \multicolumn{2}{c|}{ Pore Size $4 \mathrm{~nm}$} & \multicolumn{2}{c|}{ Pore Size 5 $\mathrm{nm}$} \\
\cline { 2 - 7 } & Pc(atm) & $T c(k)$ & Pc(atm) & $T c(k)$ & Pc(atm) & Tc(k) \\
\hline N2 & 27.595 & 120.751 & 40.071 & 124.005 & 47.695 & 124.668 \\
\hline CO2 & 58.130 & 289.372 & 91.271 & 298.207 & 109.047 & 300.014 \\
\hline CH4 & 38.917 & 183.697 & 51.392 & 187.832 & 60.915 & 188.669 \\
\hline C2H6 & 39.508 & 291.946 & 58.072 & 299.978 & 69.161 & 301.615 \\
\hline C3H8 & 33.452 & 351.765 & 52.542 & 362.511 & 62.776 & 364.708 \\
\hline IC4 & 28.213 & 386.821 & 46.513 & 399.481 & 55.712 & 402.077 \\
\hline NC4 & 29.388 & 403.030 & 48.451 & 416.220 & 58.033 & 418.925 \\
\hline IC5 & 25.804 & 435.187 & 44.203 & 450.171 & 53.055 & 453.249 \\
\hline NC5 & 25.726 & 443.883 & 44.071 & 459.167 & 52.896 & 462.306 \\
\hline FC6 & 24.792 & 478.632 & 43.825 & 495.773 & 52.693 & 499.299 \\
\hline FC7 & 23.486 & 511.583 & 42.347 & 530.345 & 50.976 & 534.209 \\
\hline FC8 & 21.930 & 536.551 & 40.326 & 556.686 & 48.599 & 560.837 \\
\hline FC9 & 20.129 & 562.005 & 37.855 & 583.636 & 45.682 & 588.100 \\
\hline FC10 & 13.489 & 473.191 & 25.847 & 491.781 & 31.228 & 495.621 \\
\hline FC11 & 12.639 & 505.212 & 24.635 & 525.425 & 29.795 & 529.605 \\
\hline FC12 & 11.851 & 541.015 & 23.493 & 563.045 & 28.444 & 567.604 \\
\hline C13+ & 12.272 & 679.287 & 25.447 & 708.220 & 30.902 & 714.220 \\
\hline
\end{tabular}

The last step is to run the fluid models in the WinProp program in order to obtain the results. The results of the simulation runs are the PVT curves of each pore size and from the PVT curves it is obvious to notice the change in the dew pressure and the shape of curves with the pore size. Fig. 17 shows the PVT curves of the four fluid models. 


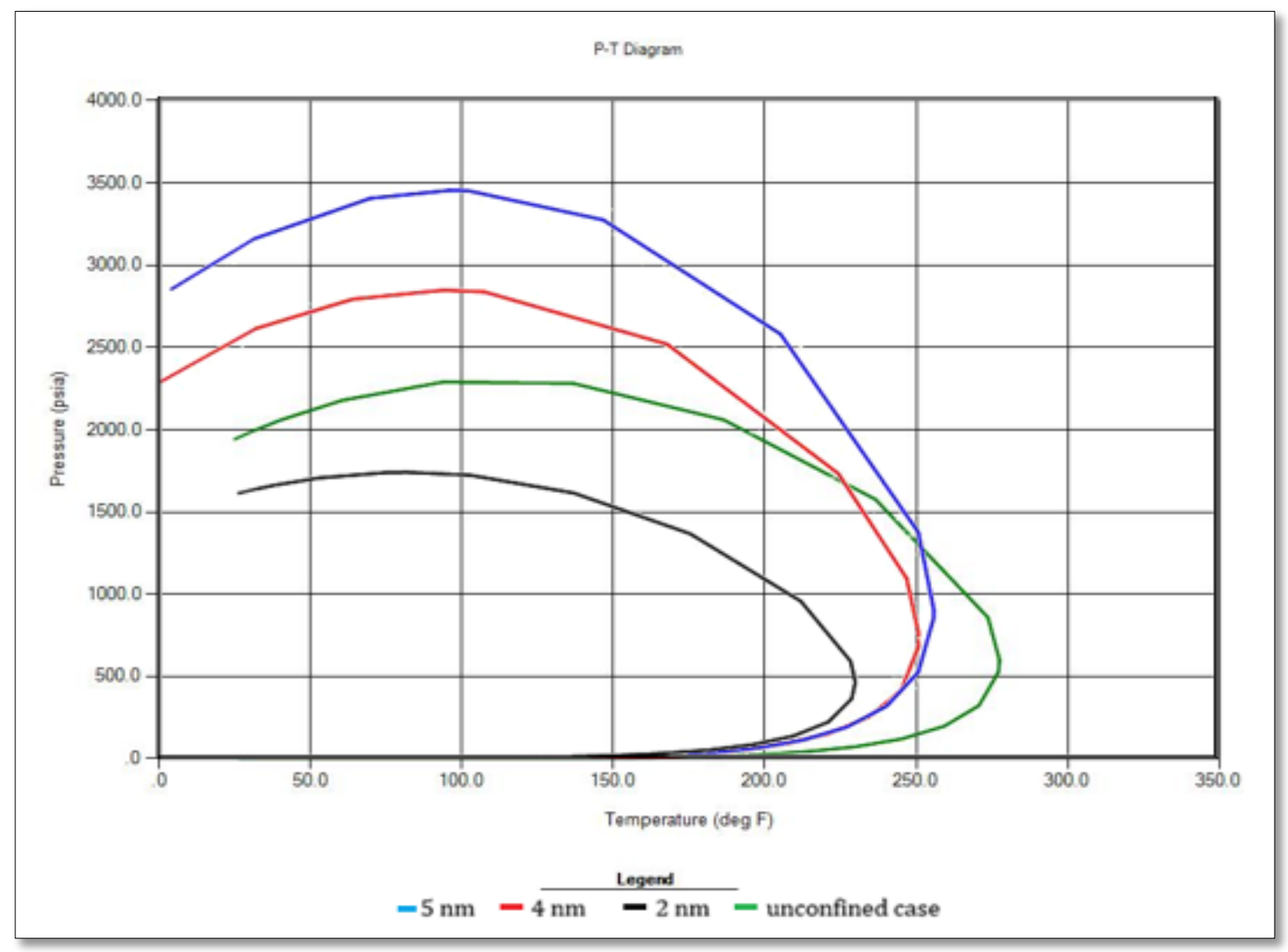

Fig. 15 PVT curves of the four fluid models based on different pore sizes

In addition, the results of fluid models simulation runs show the effect of each confinement case on the PVT behavior. This effect includes the change in the produced volume of the gas and liquid for each confinement case. This part of the calculations are obtained by performing the constant volume depletion test (CVD) and the results of these simulation run will be presented in the next chapter.

\subsection{Base Models Building}

Once the fluid models were constructed and all the reservoir data were obtained, four base models will be built by the use of the CMG GEM software. The purpose of this research is to investigate the impact of pore confinement on gas and condensate production from Marcellus shale; therefore four reservoir models were constructed in order to study three confinement cases with pore size of $2 \mathrm{~nm}$, 
$4 \mathrm{~nm}$, and $5 \mathrm{~nm}$, as well as the fourth model which represents the unconfined case. The four built reservoir models use the Peng-Robinson (EOS). Fig. 18 shows the reservoir base model.

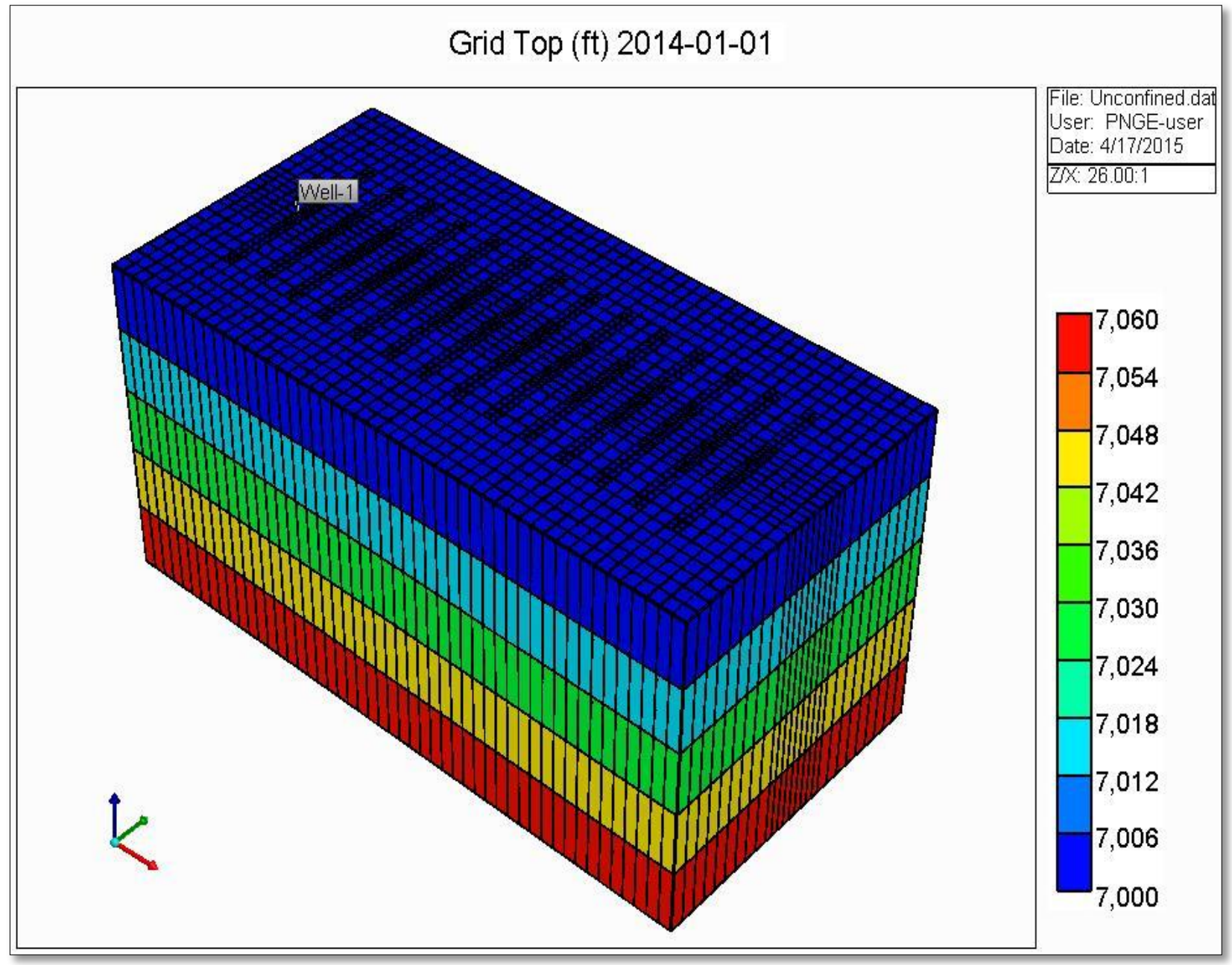

Fig. 16 reservoir base model

\subsection{Reservoir Models Construction}

The four constructed reservoir models are identical in everything except the part of fluid properties due to the use of four different fluid models. To construct the reservoir models, GEM software was used and the constructed fluid models were incorporated into these models. 
The first step is to build the base models 50 grid blocks in I direction and 27 grid blocks in J direction ( $9=86 \mathrm{ft}$., $9=50 \mathrm{ft}$. and $9=86 \mathrm{ft}$.). The reservoir models have dimensions of $2000 \mathrm{ft}$ width, $4000 \mathrm{ft}$ length, and net pay of $75 \mathrm{ft}$ within 5 layers, each layer is $15 \mathrm{ft}$ in thickness. A horizontal fractured well with a lateral length of $3000 \mathrm{ft}$ is placed in the third layer of the reservoir model. Smaller grid blocks were used around the horizontal well in order to improve the ability of the reservoir model to study the significant changes in composition and fluid phases around the wellbore area due to the high velocity and the high pressure drop.

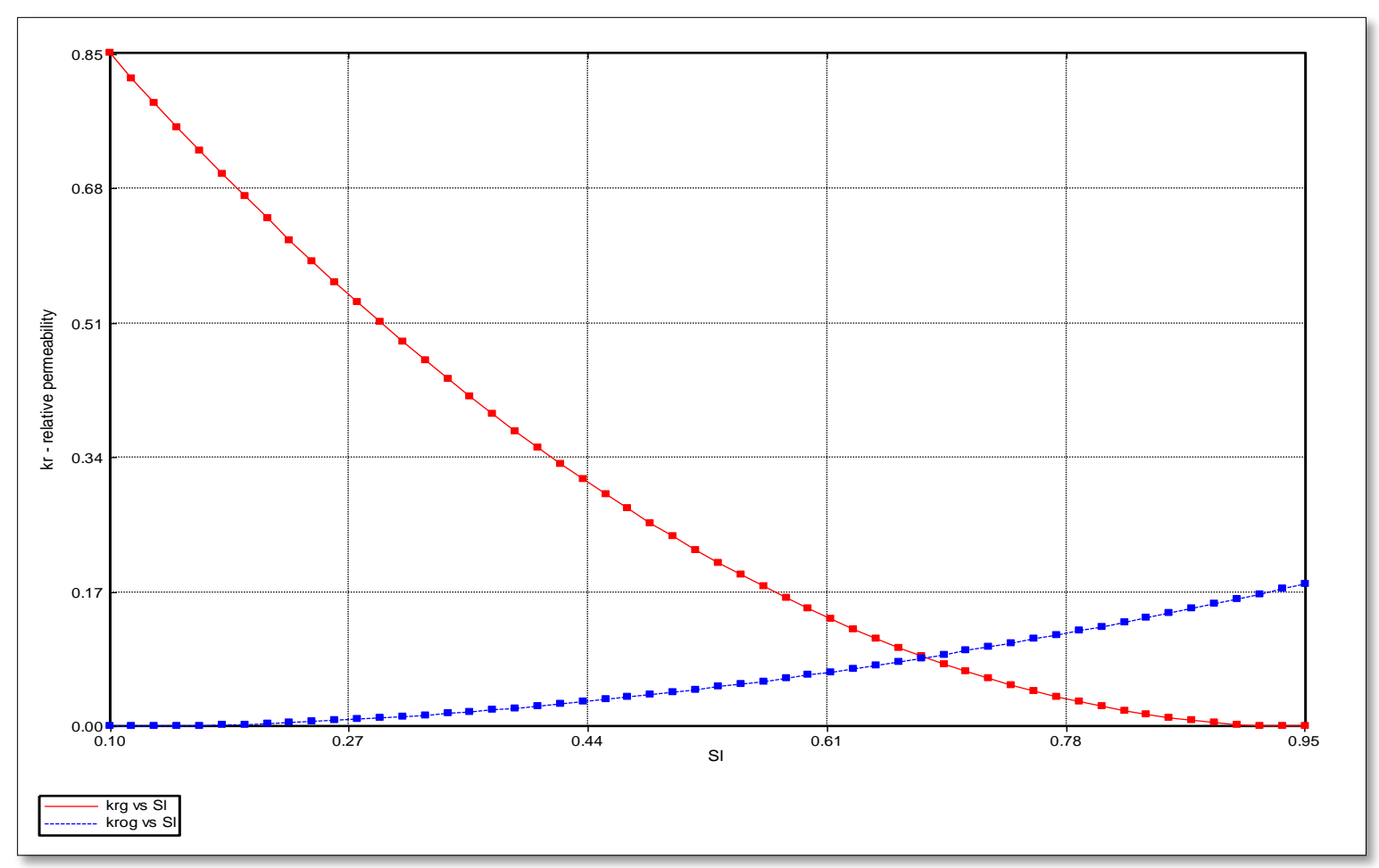

Fig. 17 relative permeability curves (Hooks, 2013)

The reservoir models are considered to be a single porosity model and the permeability was assumed to be homogeneous in both I and J directions. The vertical permeability was considered to be equal to $1 / 10$ of the horizontal permeability. Fig. 19 show the used relative permeability curves in the reservoir models. 
Fourteen hydraulic fracture stages were used in the reservoir model around the wellbore. The fractures spacing was $214 \mathrm{ft}$. and hydraulic each fracture has a width of $0.1 \mathrm{in}$. Moreover, the permeability of the hydraulic fractures was assumed to be equal to $2000 \mathrm{md}$. The natural fracture permeability is equal to $0.002 \mathrm{md}$ in I and J directions, while it is equal to $0.0002 \mathrm{md}$ in the k direction. Other reservoir data such as, reservoir temperature, reservoir pressure, porosity, water saturation, permeability, and reservoir depth were imported to the reservoir models which reflect the properties of the Marcellus shale (Table 7 depicts some of the reservoir models characteristics).

Table 7 reservoir models characteristics

\begin{tabular}{|c|c|}
\hline \multicolumn{2}{|c|}{ Reservoir Models Characteristics } \\
\hline Reservoir Temperature & $130 \mathrm{~F}$ \\
\hline Reservoir Pressure & 3800 Psia \\
\hline Saturation Pressure & 2375 Psia \\
\hline Rock Density & 150 \\
\hline Reservoir Porosity & $5 \%$ \\
\hline Reservoir Bottom Depth & $7075 \mathrm{ft}$ \\
\hline Reservoir Permeability I and J & $0.0004 \mathrm{md}$ \\
\hline Reservoir Permeability K & $0.00004 \mathrm{md}$ \\
\hline Natural fractures Permeability I and J & $0.002 \mathrm{md}$ \\
\hline Natural fractures Permeability K & $0.0002 \mathrm{md}$ \\
\hline
\end{tabular}

Local grid refinement (LGR) method is utilized with the built reservoir models with the all three layers around the hydraulic fractures. In reservoir models, 3 grid blocks in I direction, 3 grid blocks in J direction, and only one block in K direction were refined. Fig. 20 shows fracture stages with the local grid refinement. As mentioned previously in the literature review of this research, the LGR helps to increase the precision of the simulation to obtain reliable results even though the simulation run will take longer time. Finally, each reservoir model has to be run in order to study the effect of the 
pore size and the change in the phase behavior on condensate and gas production and reservoir performance in general.

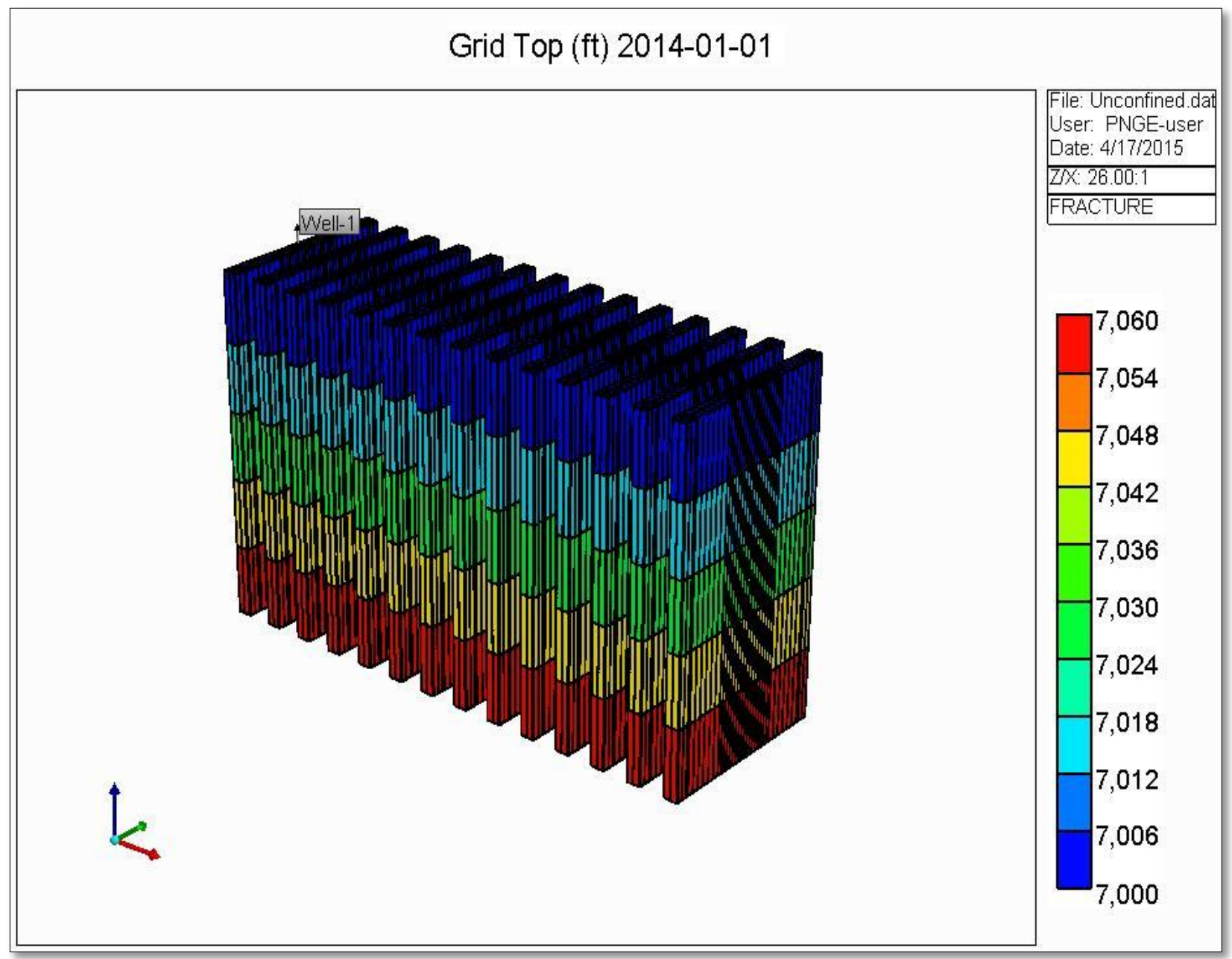

Fig. 18 the 14 fracture stages in the reservoir model. 


\section{Chapter 4 - Results and Discussion}

Several simulation runs were carried out for the fluid and reservoir models to investigate the impact of the pore confinement on reservoir performance. In this chapter, confinement effects on phase behavior, reservoir performance, and gas recovery factor are presented as follow:

\subsection{Confinement effects on the gas phase behavior}

The phase behavior of the gas condensate was studied by the use of the Constant Volume Depletion (CVD) Calculations. CVD calculations provide an insight regarding the generated liquid under different pressure values to reflect the behavior of the fluid in the reservoir during the process of the reservoir depletion. Three confined cases with pore size of $2 \mathrm{~nm}, 4 \mathrm{~nm}$, and $5 \mathrm{~nm}$, were investigated by CVD calculations, as well as the unconfined case, the results of the CVD calculations for each case are presented as follows:

\subsubsection{Unconfined case}

Table 8 CVD calculations of the unconfined case

\begin{tabular}{|c|c|c|c|c|c|c|c|c|}
\hline \multirow[b]{2}{*}{ Component } & \multicolumn{4}{|c|}{ Gas composition (mole \%) at } & \multicolumn{4}{|c|}{ Pressure Levels ( psia) } \\
\hline & 2293.4 & 2375.0 & 2100.0 & 1700.0 & 1300.0 & 900.0 & 600.0 & 600.0 \\
\hline $\begin{array}{l}\mathrm{N} 2 \\
\mathrm{CO} 2 \\
\mathrm{CH} 4 \\
\mathrm{C} 2 \mathrm{H} 6 \\
\mathrm{CHH} 8 \\
\text { IC4 } \\
\text { NC4 } \\
\text { IC5 } \\
\text { NC5 } \\
\text { FC6 } \\
\text { FC7 } \\
\text { FC8 } \\
\text { FC9 } \\
\text { FC10 } \\
\text { FC10 } \\
\text { FC11 } \\
\text { FC12 } \\
\text { C13+ }\end{array}$ & $\begin{array}{r}0.44 \\
0.15 \\
74.18 \\
14.82 \\
5.39 \\
0.71 \\
1.55 \\
0.43 \\
0.52 \\
0.55 \\
0.43 \\
0.36 \\
0.17 \\
0.11 \\
0.07 \\
0.05 \\
0.09\end{array}$ & $\begin{array}{r}0.44 \\
0.15 \\
74.18 \\
14.82 \\
5.39 \\
0.71 \\
1.55 \\
0.43 \\
0.52 \\
0.55 \\
0.43 \\
0.36 \\
0.17 \\
0.11 \\
0.07 \\
0.05 \\
0.09\end{array}$ & $\begin{array}{r}0.44 \\
0.15 \\
74.33 \\
14.82 \\
5.37 \\
0.70 \\
1.53 \\
0.42 \\
0.51 \\
0.54 \\
0.41 \\
0.34 \\
0.16 \\
0.11 \\
0.07 \\
0.04 \\
0.05\end{array}$ & $\begin{array}{r}0.45 \\
0.15 \\
74.77 \\
14.81 \\
5.32 \\
0.69 \\
1.49 \\
0.40 \\
0.48 \\
0.49 \\
0.35 \\
0.27 \\
0.11 \\
0.10 \\
0.06 \\
0.03 \\
0.01\end{array}$ & $\begin{array}{r}0.45 \\
0.15 \\
75.25 \\
14.83 \\
5.27 \\
0.67 \\
1.45 \\
0.38 \\
0.45 \\
0.43 \\
0.28 \\
0.19 \\
0.07 \\
0.08 \\
0.04 \\
0.02 \\
0.00\end{array}$ & $\begin{array}{r}0.45 \\
0.15 \\
75.35 \\
14.91 \\
5.30 \\
0.67 \\
1.44 \\
0.37 \\
0.43 \\
0.39 \\
0.23 \\
0.14 \\
0.04 \\
0.07 \\
0.03 \\
0.01 \\
0.00\end{array}$ & $\begin{array}{r}0.45 \\
0.15 \\
75.01 \\
15.00 \\
5.41 \\
0.70 \\
1.50 \\
0.39 \\
0.46 \\
0.42 \\
0.24 \\
0.14 \\
0.04 \\
0.07 \\
0.03 \\
0.01 \\
0.00\end{array}$ & $\begin{array}{r}0.03 \\
0.06 \\
13.36 \\
9.43 \\
8.75 \\
2.20 \\
6.13 \\
3.16 \\
4.55 \\
8.54 \\
10.70 \\
12.42 \\
7.60 \\
2.43 \\
2.34 \\
2.13 \\
6.17\end{array}$ \\
\hline $\begin{array}{l}\text { Equilibrium Gas } \\
Z \text { Z-Factor }\end{array}$ & 0.6984 & 0.7002 & 0.7004 & 0.7224 & 0.7681 & 0.8281 & 0.8791 & \\
\hline $\begin{array}{l}\text { Gas Produced, } \\
\text { cum. mole \% of } \\
\text { original fluid }\end{array}$ & & 0.00 & 8.60 & 27.80 & 47.44 & 65.74 & 78.16 & \\
\hline $\begin{array}{l}\text { Liquid, vol \% of } \\
\text { original fluid }\end{array}$ & & 0.00 & 0.38 & 1.24 & 1.76 & 1.71 & 1.48 & \\
\hline $\begin{array}{c}\text { MW of components } \\
1 \text { to } 1\end{array}$ & & 28.0 & 28.0 & 28.0 & 28.0 & 28.0 & 28.0 & 28.0 \\
\hline $\begin{array}{r}\text { Note : } \\
\text { first co } \\
\text { last colv }\end{array}$ & $\begin{array}{l}\text { lumn }=s \\
\text { umn }=\end{array}$ & $\begin{array}{l}\text { aturate } \\
600.0\end{array}$ & $\begin{array}{l}\text { reservo } \\
\text { psia equ }\end{array}$ & $\begin{array}{l}\text { ir fluid } \\
\text { ilibrium }\end{array}$ & & & & \\
\hline
\end{tabular}




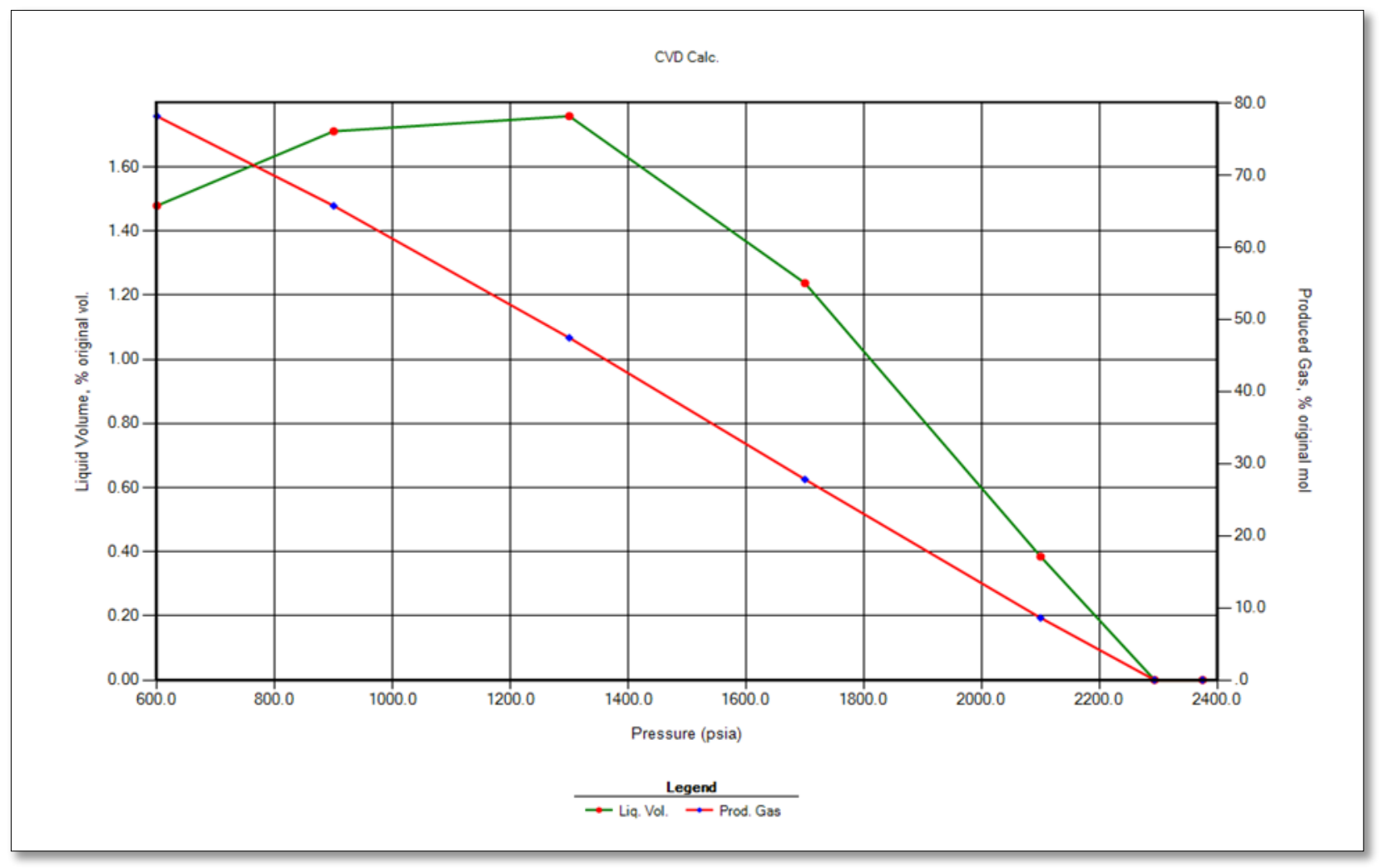

Fig. 19 the volume of the produced liquid and gas for the unconfined case based on CVD

The above results of the CVD calculations for the unconfined case depict that the liquid starts to generate at pressure value of 2293 Psia. This case is compared with the other confined cases in order to show the effect of the confinement on the phase behavior and liquid generation.

\subsubsection{Confined case with pore size of $2 \mathrm{~nm}$}

The CVD calculations in this case of the confinement $(2 \mathrm{~nm})$ show that the liquid does not start to generate until reaching a pressure value of 1635 Psia. In addition, the volume of the generated liquid is less than the generated liquid volume in the unconfined case. Consequently, the produced condensate on the surface will increase due to increase the time of the production with a pressure value higher than the dew point pressure. In addition, the produced gas in this case has more heavy 
components and this enhances condensate production. Fig 20 and Table 9 show the results of the CVD calculations of the $2 \mathrm{~nm}$ pore size.

Table 9 CVD calculations of the $2 \mathrm{~nm}$ pore size

\begin{tabular}{|c|c|c|c|c|c|c|c|c|}
\hline \multirow[b]{2}{*}{ Component } & \multicolumn{8}{|c|}{ Gas Composition (mole \%) at Pressure Levels ( psia) } \\
\hline & 1635.7 & 2375.0 & 2100.0 & 1700.0 & 1300.0 & 900.0 & 600.0 & 600.0 \\
\hline N2 & 0.44 & 0.44 & 0.44 & 0.44 & 0.44 & 0.45 & 0.44 & 0.05 \\
\hline $\mathrm{CO} 2$ & 0.15 & 0.15 & 0.15 & 0.15 & 0.15 & 0.15 & 0.15 & 0.07 \\
\hline $\mathrm{CH} 4$ & 74.18 & 74.18 & 74.18 & 74.18 & 74.43 & 74.67 & 74.64 & 16.53 \\
\hline $\mathrm{C} 2 \mathrm{H} 6$ & 14.82 & 14.82 & 14.82 & 14.82 & 14.82 & 14.85 & 14.88 & 9.62 \\
\hline $\mathrm{C} 3 \mathrm{H} 8$ & 5.39 & 5.39 & 5.39 & 5.39 & 5.37 & 5.36 & 5.38 & 7.86 \\
\hline IC4 & 0.71 & 0.71 & 0.71 & 0.71 & 0.70 & 0.70 & 0.70 & 1.83 \\
\hline NC4 & 1.55 & 1.55 & 1.55 & 1.55 & 1.53 & 1.51 & 1.52 & 4.93 \\
\hline IC 5 & 0.43 & 0.43 & 0.43 & 0.43 & 0.42 & 0.41 & 0.41 & 2.41 \\
\hline NC5 & 0.52 & 0.52 & 0.52 & 0.52 & 0.50 & 0.49 & 0.49 & 3.43 \\
\hline $\mathrm{FC} 6$ & 0.55 & 0.55 & 0.55 & 0.55 & 0.53 & 0.50 & 0.50 & 6.48 \\
\hline FC7 & 0.43 & 0.43 & 0.43 & 0.43 & 0.40 & 0.36 & 0.35 & 8.86 \\
\hline FC8 & 0.36 & 0.36 & 0.36 & 0.36 & 0.32 & 0.27 & 0.25 & 11.78 \\
\hline FC9 & 0.17 & 0.17 & 0.17 & 0.17 & 0.15 & 0.11 & 0.09 & 8.58 \\
\hline FC10 & 0.11 & 0.11 & 0.11 & 0.11 & 0.11 & 0.10 & 0.10 & 1.84 \\
\hline FC11 & 0.07 & 0.07 & 0.07 & 0.07 & 0.07 & 0.06 & 0.05 & 2.08 \\
\hline FC12 & 0.05 & 0.05 & 0.05 & 0.05 & 0.04 & 0.03 & 0.02 & 2.44 \\
\hline $\mathrm{C} 13+$ & 0.09 & 0.09 & 0.09 & 0.09 & 0.03 & 0.01 & 0.00 & 11.22 \\
\hline \multicolumn{9}{|l|}{ Equilibrium Gas } \\
\hline Z-Factor & 0.7419 & 0.7548 & 0.7429 & 0.7403 & 0.7673 & 0.8208 & 0.8728 & \\
\hline \multicolumn{9}{|l|}{ Gas Produced, } \\
\hline $\begin{array}{l}\text { cum. mole } \% \text { of } \\
\text { original fluid }\end{array}$ & & 0.00 & 0.00 & 0.00 & 22.94 & 49.78 & 68.31 & \\
\hline \multicolumn{9}{|l|}{ Liquid, vol \% of } \\
\hline original fluid & & 0.00 & 0.00 & 0.00 & 0.50 & 0.77 & 0.72 & \\
\hline \multicolumn{9}{|l|}{ MW of components } \\
\hline 1 to 1 & & 28.0 & 28.0 & 28.0 & 28.0 & 28.0 & 28.0 & 28.0 \\
\hline
\end{tabular}

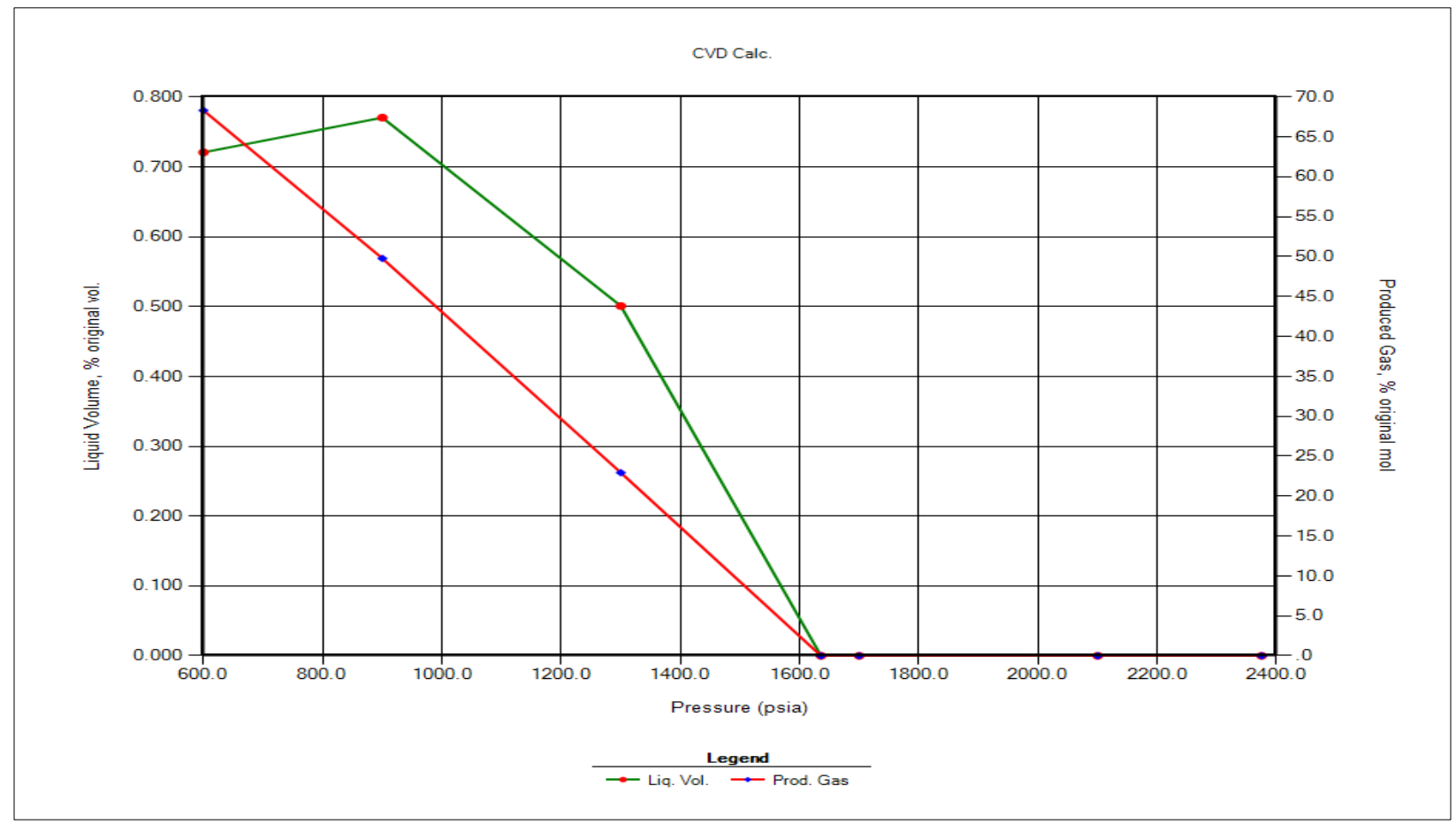

Fig. 20 the volume of the produced liquid and gas for the $2 \mathrm{~nm}$ pore size based on CVD 


\subsubsection{Confined case with pore size of $4 \mathrm{~nm}$}

The CVD calculations for this pore size case show that the confinement has an opposite impact compared with the $2 \mathrm{~nm}$ pore size. This case of the confinement shows that the liquid starts to generate at a pressure value of 2772 Psia, which is higher than the unconfined case. Fig 21 and Table 10 depict the CVD calculations results for the $4 \mathrm{~nm}$ pore size.

Table 10 CVD calculations of the $4 \mathrm{~nm}$ pore size

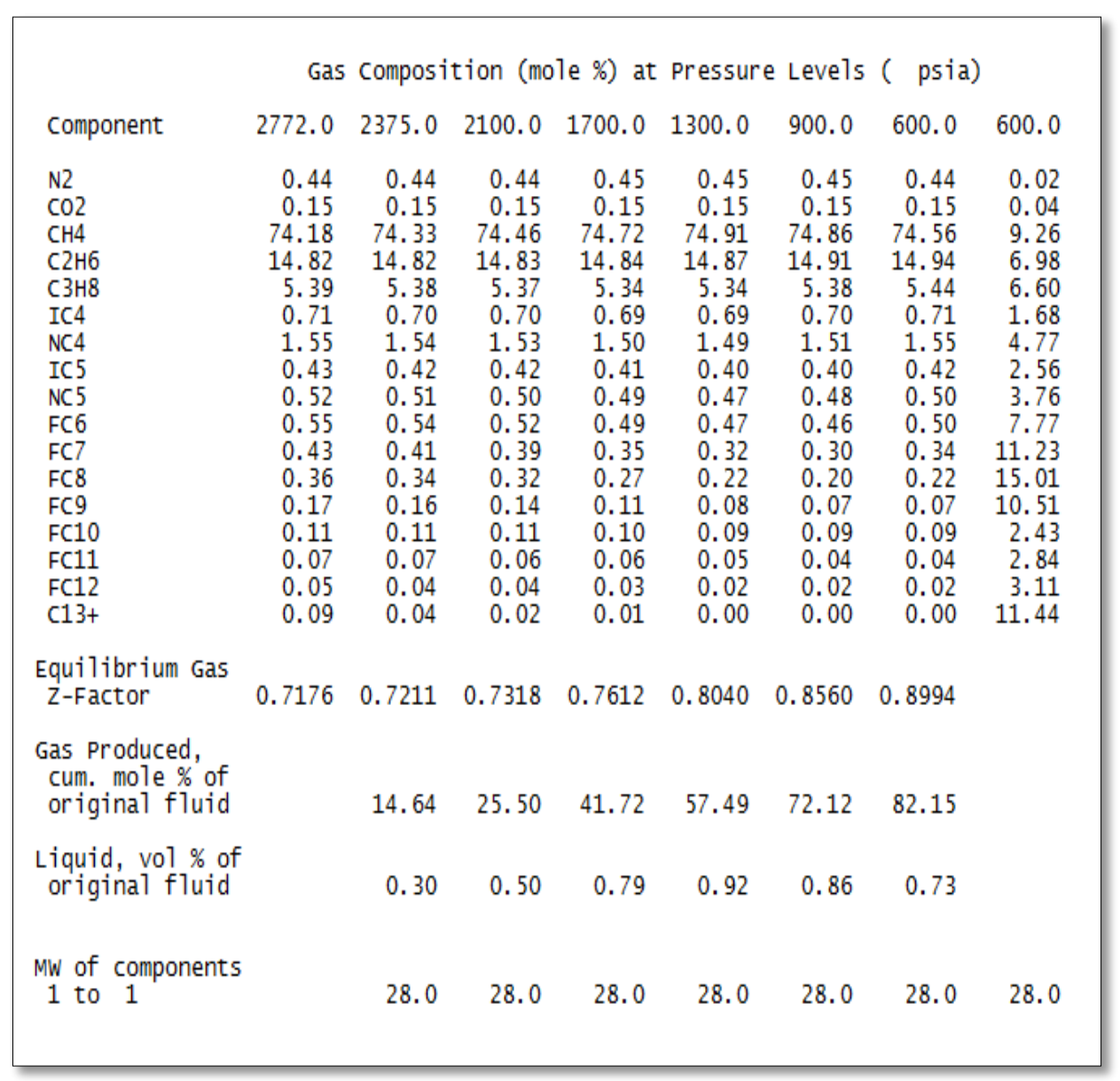




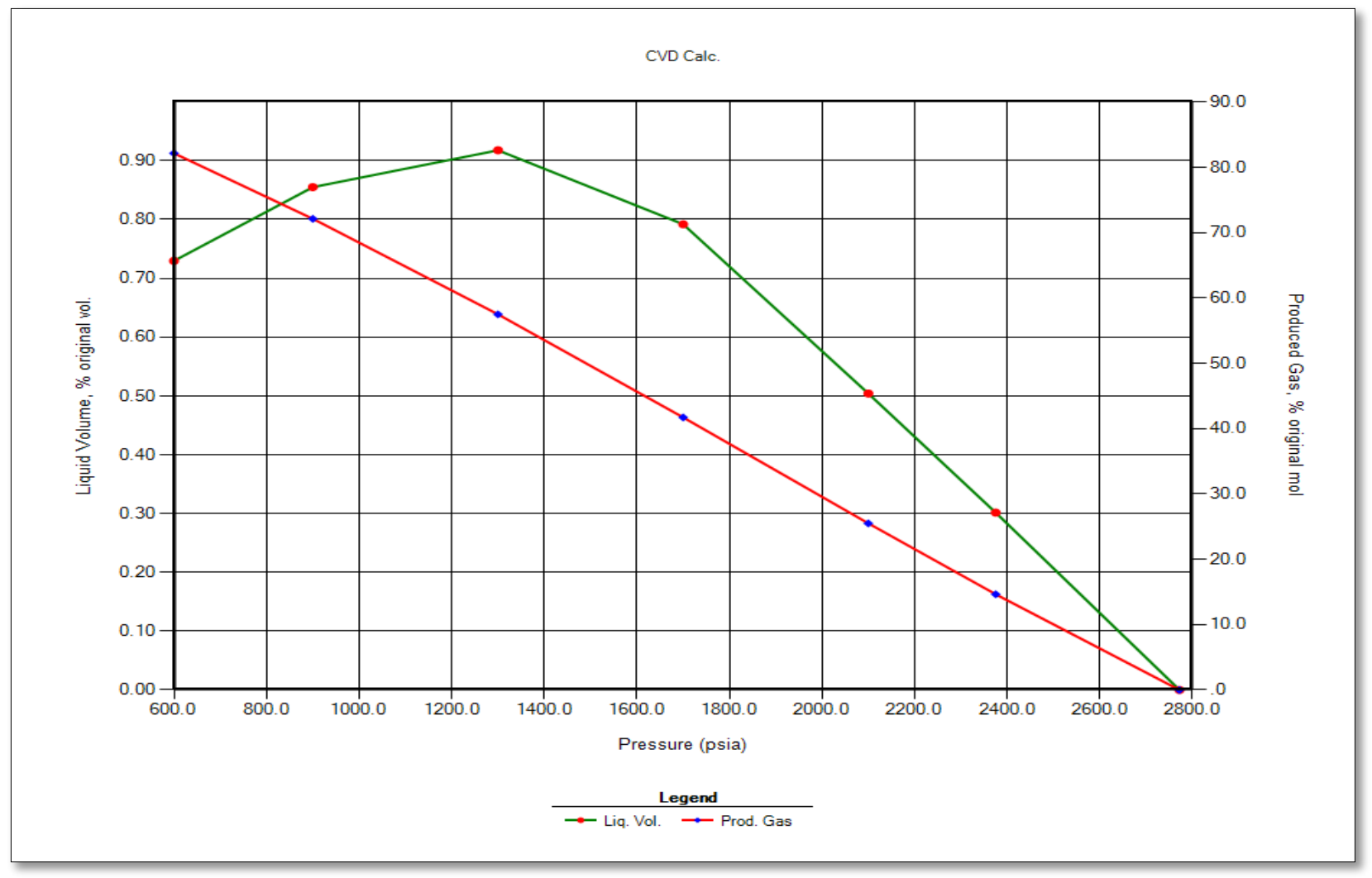

Fig. 21 the volume of the produced liquid and gas for the $4 \mathrm{~nm}$ pore size based on CVD

\subsubsection{Confined case with pore size of $5 \mathrm{~nm}$}

The CVD calculations results show that the confined case with $5 \mathrm{~nm}$ pore size has the same impact on the phase behavior with the $4 \mathrm{~nm}$ pore size. In this case, the liquid starts to generate at a pressure value higher than the pressure value of the unconfined case and the $4 \mathrm{~nm}$ pore size case. From Fig 22 and Table 11, it can be seen that the liquid starts to generate at a pressure value of 3368 Pisa.

The impact of the change in the phase behavior due to the pore confinement will be used in the second part of the results to investigate the impact on the gas and condensate production for the unconfined and confined cases. 
Table 11 CVD calculations of the $5 \mathrm{~nm}$ pore size

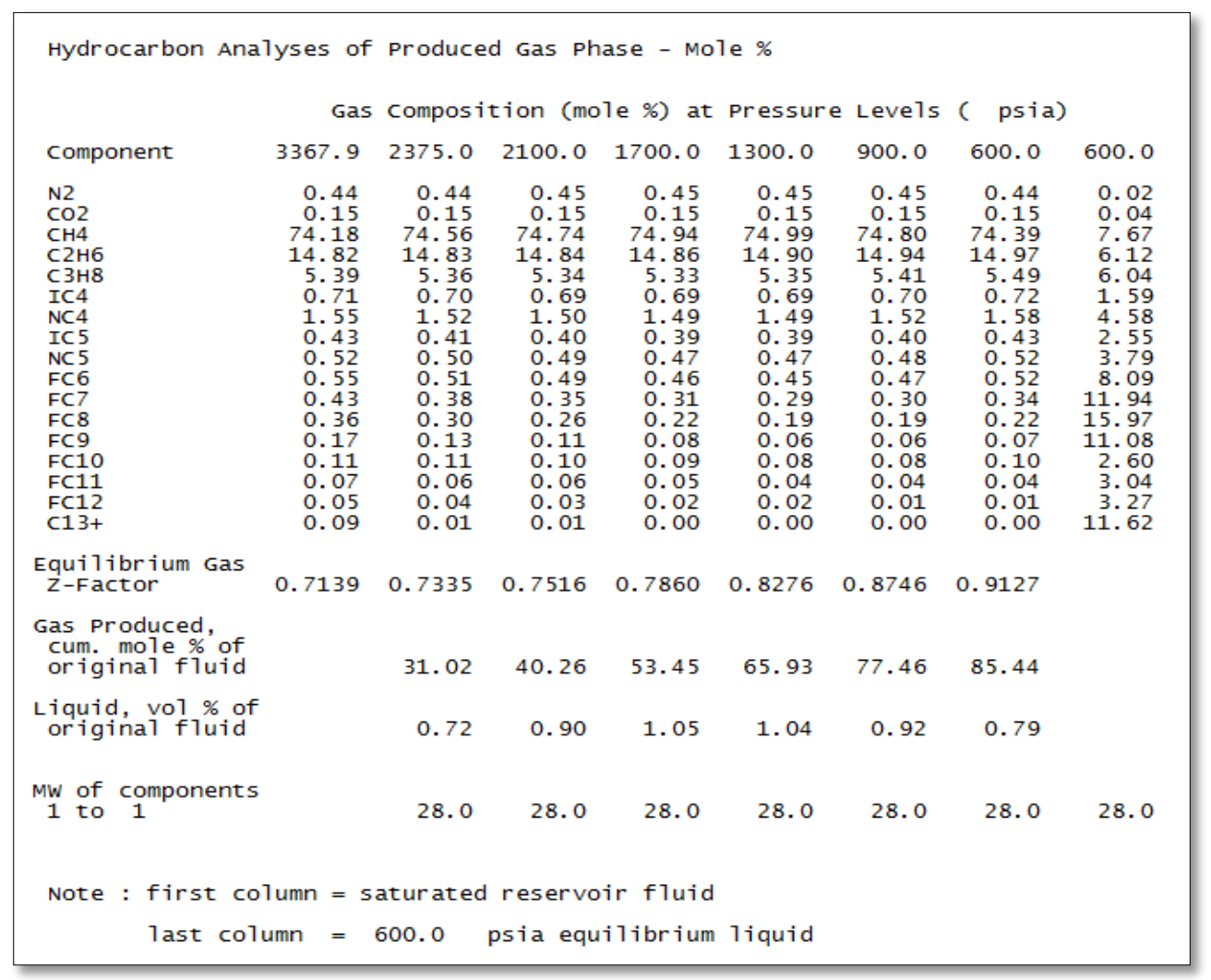

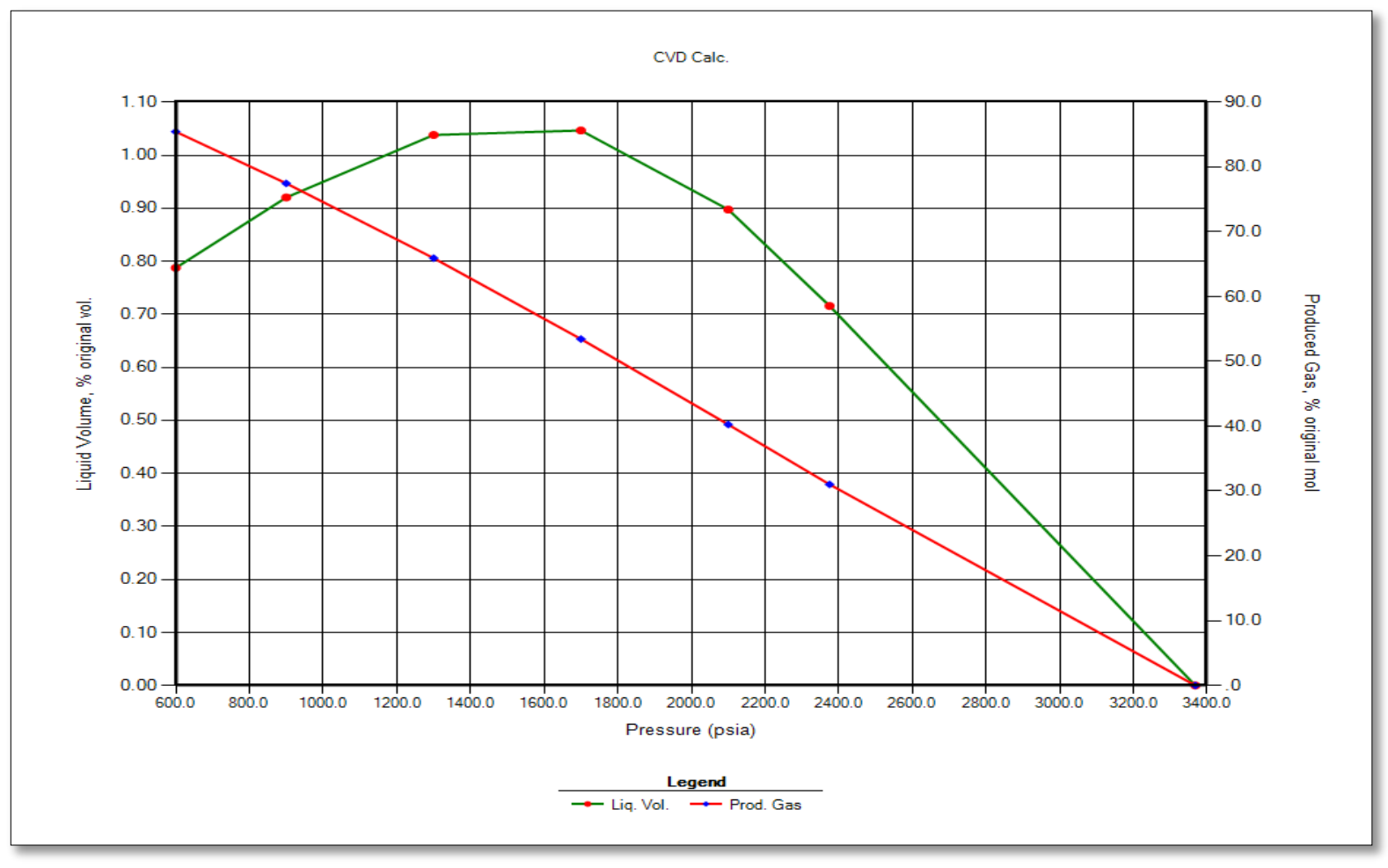

Fig. 22 the volume of the produced liquid and gas for the $5 \mathrm{~nm}$ pore size based on CVD 


\subsection{Confinement Effects on Gas and Condensate Production}

After constructing the four reservoir models which represent the unconfined case and the three confined cases with different pore size, several simulation run were carried out in order to investigate the reservoir performance under confinement effects. The main focus in the simulation runs results was on the gas and condensate production. The cumulative gas and condensate production are presented in this chapter, as well as, the daily production of the gas and condensate for 30 years.

\subsubsection{Unconfined case}

The unconfined reservoir model was simulated for 30 years to investigate gas and condensate production. Two kinds of constrains were used to run all of the four reservoir models for both unconfined and confined cases. The first constrain was the bottom hole pressure, and it was set to be equal to 1500 Psia. The second constrain was the gas production rate and it was set to be equal to 4 MMCF for the first 4 months , 3 MMCF for the second 4 months , and $2 \mathrm{MMCF}$ for the remaining time of the production.

Under these sets of constrains, the confined reservoir model provided cumulative gas production of $4194 \mathrm{MMCF}$ and $8069 \mathrm{bbl}$. of cumulative condensate production. It was found that the unconfined case could sustain the gas production of $4 \mathrm{MMCF}$ for the first four months. However, for the second four months, the gas production rate of $3 \mathrm{MMCF}$ could not be sustained and it dropped after three months. The production rate of $2 \mathrm{MMCF}$ was also not sustained more than 6 months and gas production started to gradually incline later.

Table 12 oil and gas production of the unconfined case.

\begin{tabular}{|c|c|c|}
\hline Time (Years) & Cumulative Oil Production (bbl.) & Cumulative Gas Production (SCF) \\
\hline 2 & 4787 & $1.595 \mathrm{e}+9$ \\
\hline 5 & 6095 & $2.44 \mathrm{e}+9$ \\
\hline 10 & 7045 & $3.112 \mathrm{e}+9$ \\
\hline 30 & 8069 & $4.194 \mathrm{e}+9$ \\
\hline
\end{tabular}


Moreover, it was found that the daily condensate production rate in the first four months inclined even though the gas production rate was constant. This is attributed to the reservoir pressure drop because as the reservoir pressure passes the dew point pressure, the condensate will start to accumulate in the reservoir and the produced gas will be leaner and will contain less heavy components (Find the pressure and saturations figures in the Appendix for more details).

The above obtained results will be compared with the obtained results from the confined reservoir models with the three different pore sizes and will be shown in this chapter. Figures 23, 24, and 25 depicts the simulation runs results for the unconfined reservoir model.

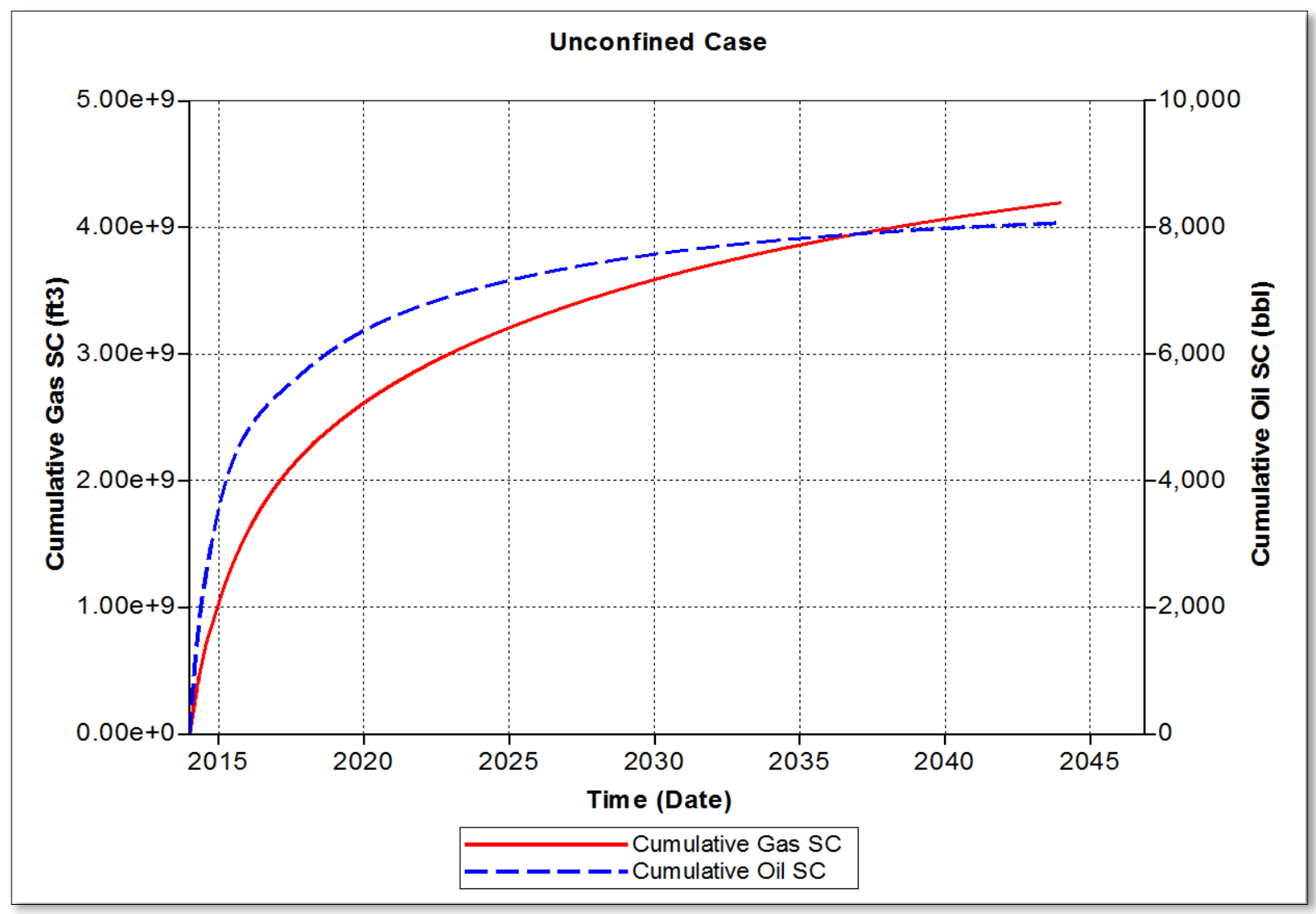

Fig. 23 cumulative gas and oil prouction for the unconfine case for $\mathbf{3 0}$ years 


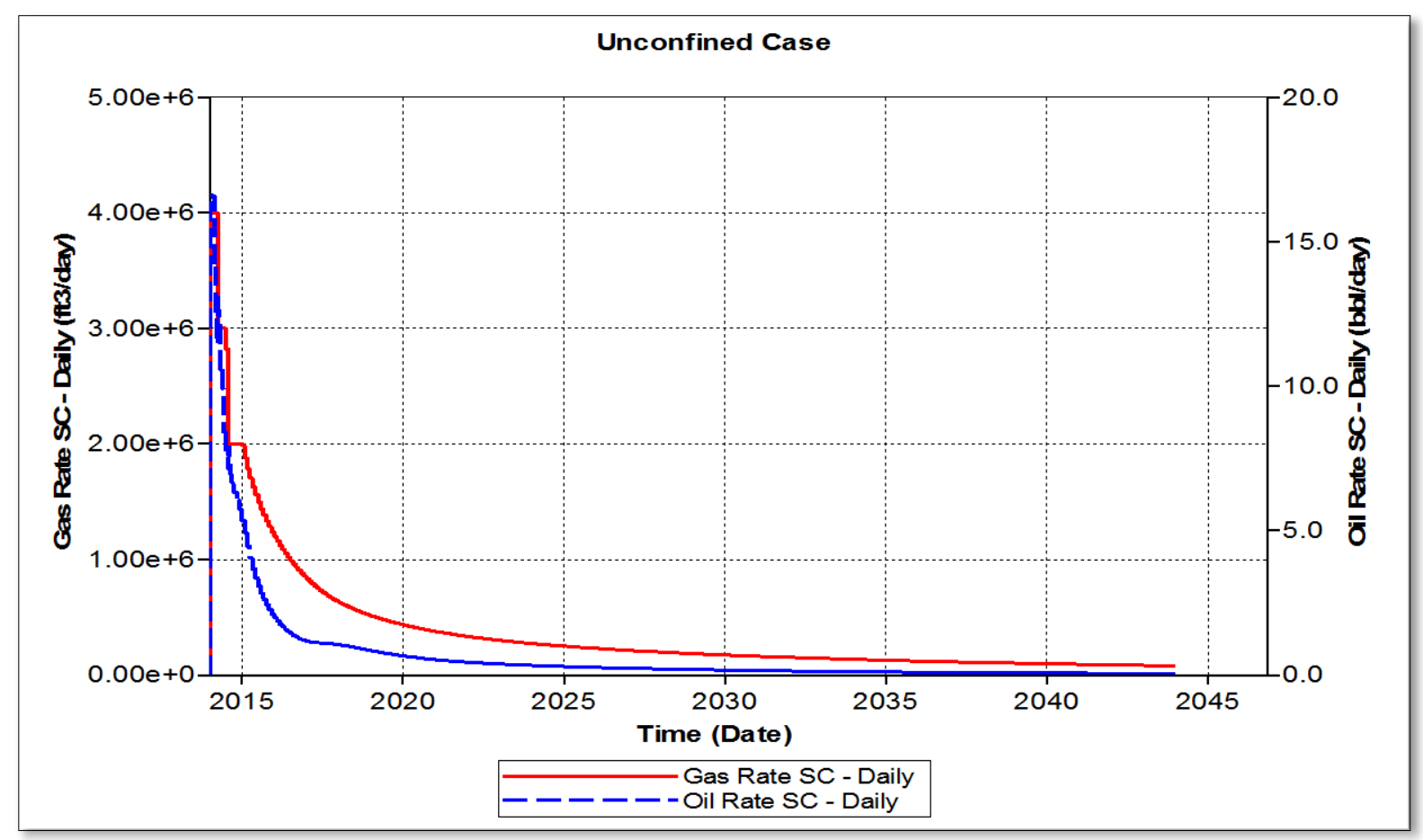

Fig. 24 gas and oil daily production of the unconfined case for 30 years

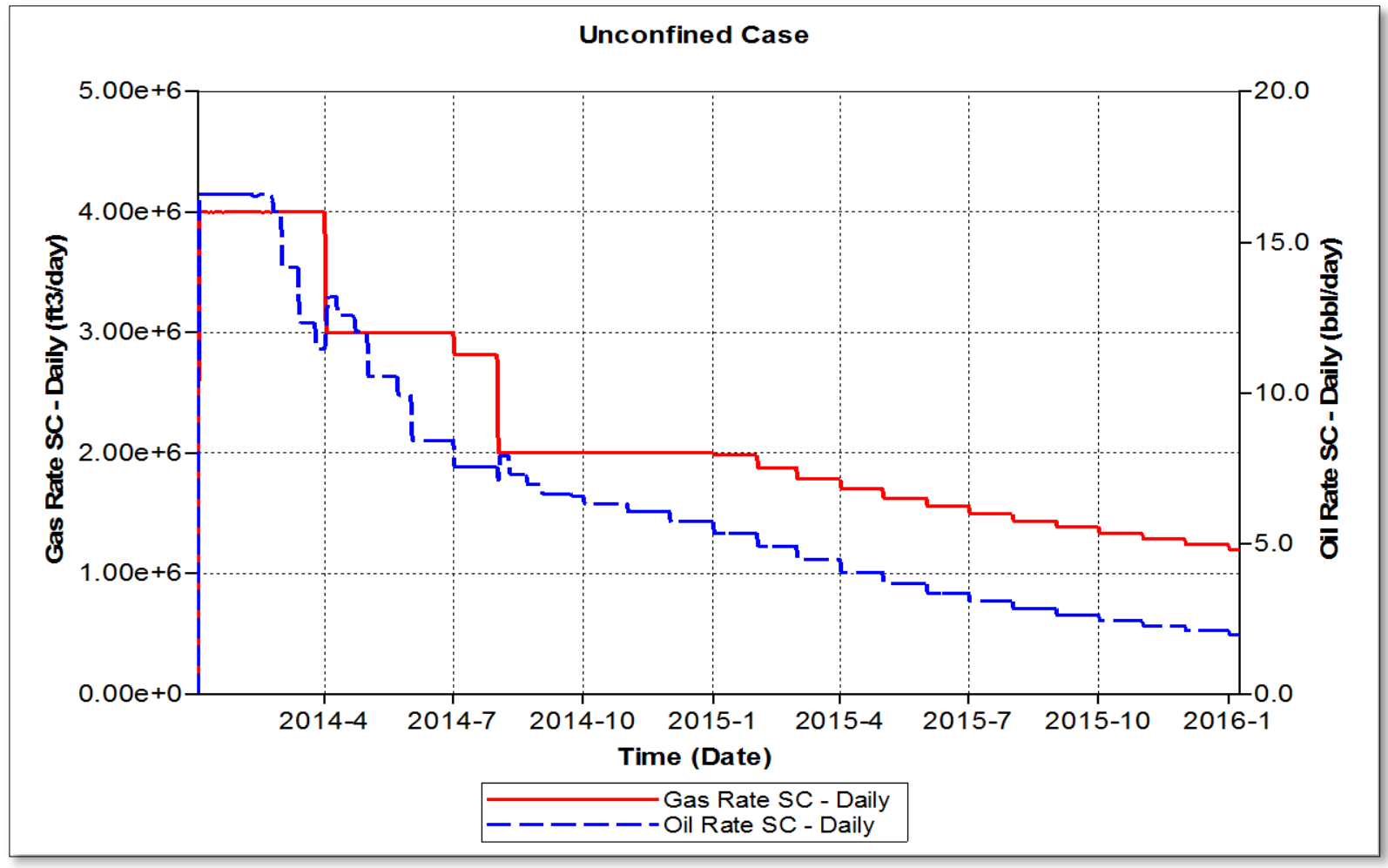

Fig. 25 gas and oil daily production of the unconfined case for the first two years 


\subsubsection{Confined case with pore size of $2 \mathrm{~nm}$}

The first investigated case of the confinement was the case of $2 \mathrm{~nm}$ pore size. The results of the reservoir model of this case showed that the cumulative condensate production has increased compared with the unconfined case. Furthermore, it was found that the condensate production rate was constant relative to the gas production rate. The reason of this trend is because the $2 \mathrm{~nm}$ pore size changes the phase behavior of the gas condensate and retards the condensate generation in the reservoir due to lowering the value of the dew point pressure; therefore, more condensate was produced and the gas production rate was sustained for longer time compared with the unconfined case. The change in the gas condensate phase behavior due to $2 \mathrm{~nm}$ pore size was discussed earlier in this chapter.

The $2 \mathrm{~nm}$ pore size case provided higher gas production rate in the beginning of the production, especially in the first two years. Moreover, the gas production rates of the 4 MMCF and 3 MMCF were found to be sustained for the first and second four months without a drop in the gas rate (Fig 27 and 28). Also the production rate of the $2 \mathrm{MMCF}$ was found to be sustained for more than seven months, which is longer than the unconfined case. This increase in the gas production rate in the beginning of the production is due to the delay in the reservoir pressure drop below the dew point pressure which results in retarding condensate accumulation around the wellbore and the hydraulic fractures. On the other hand, it was found that the cumulative gas production after 30 years is lower than the unconfined case because the smaller size of the pore results in a slight drop of the permeability and the initial gas in place is less compared with the unconfined case (Figures 26, 27, 28 and Table 13).

Table 13 oil and gas production under confinement effects with $2 \mathrm{~nm}$ pore size.

\begin{tabular}{|c|c|c|}
\hline Time (Years) & Cumulative Oil Production (bbl.) & Cumulative Gas Production (SCF) \\
\hline 2 & 5494 & $1.605 \mathrm{e}+9$ \\
\hline 5 & 7811 & $2.395 \mathrm{e}+9$ \\
\hline 10 & 9444 & $2.926 \mathrm{e}+9$ \\
\hline 30 & 11,770 & $3.77 \mathrm{e}+9$ \\
\hline
\end{tabular}




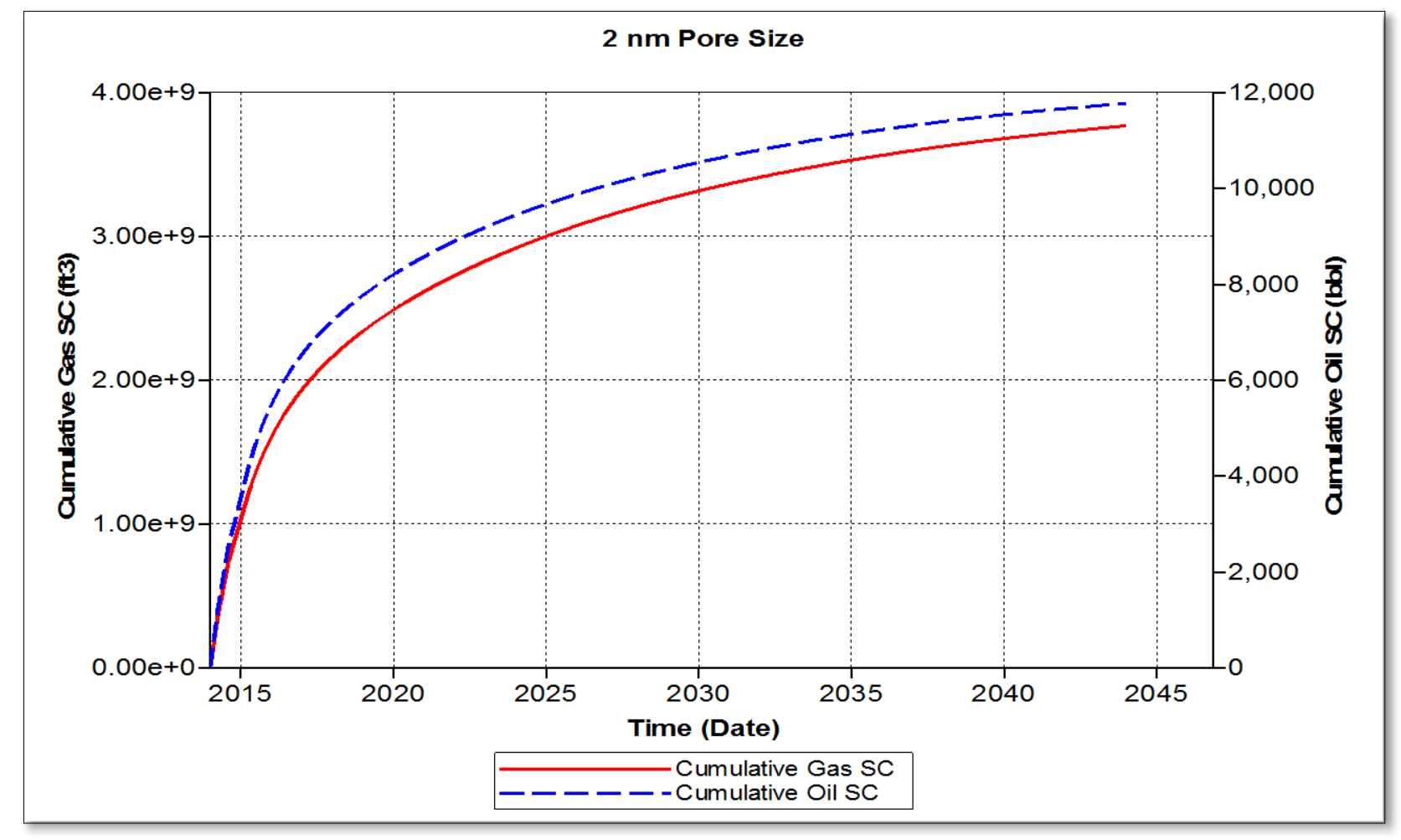

Fig. 26 cumulative gas and oil production for the confine case with $2 \mathrm{~nm}$ pore size for 30 years

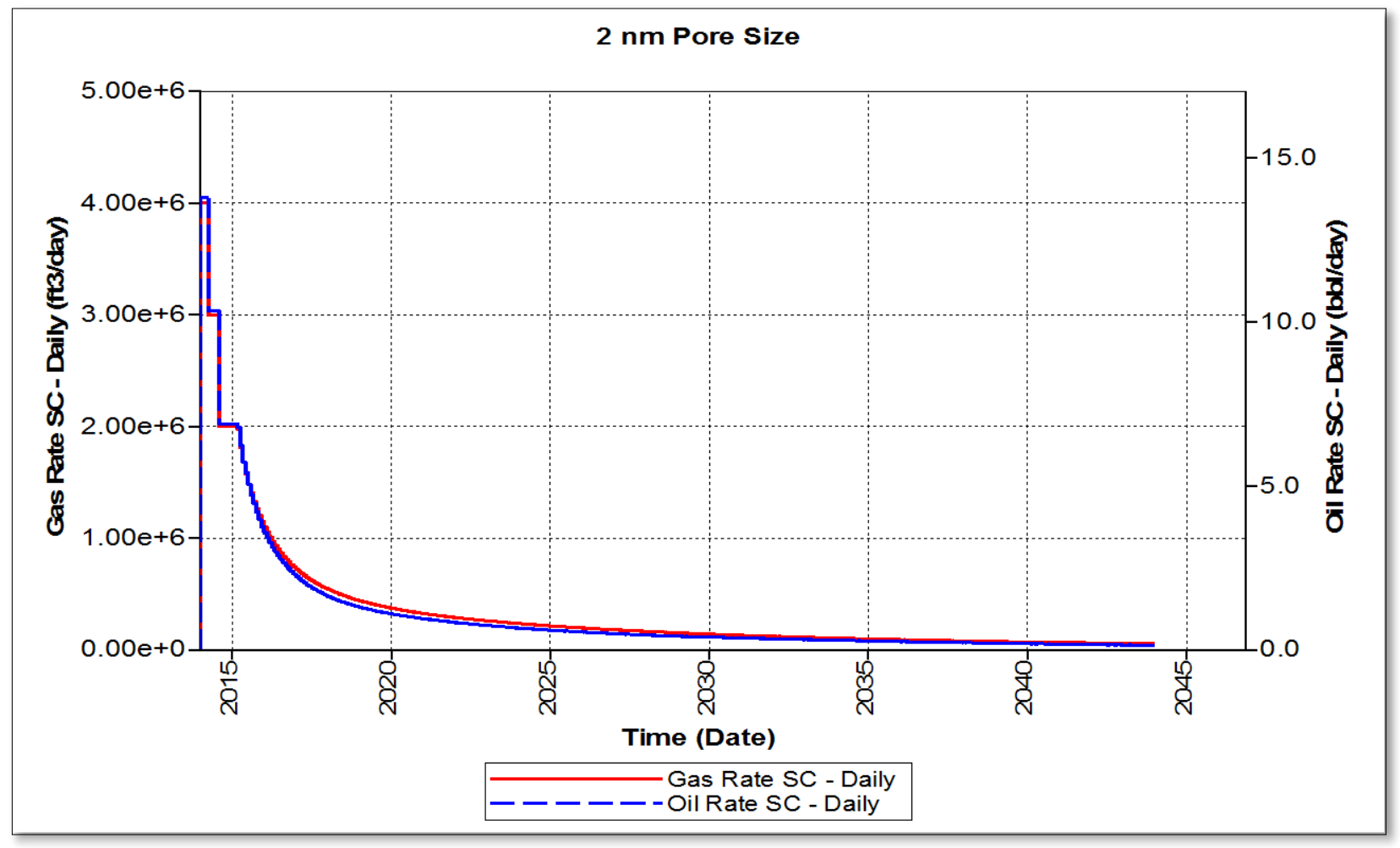

Fig. 27 gas and oil daily production of the confined case with pore size of $2 \mathbf{n m}$ for 30 years 


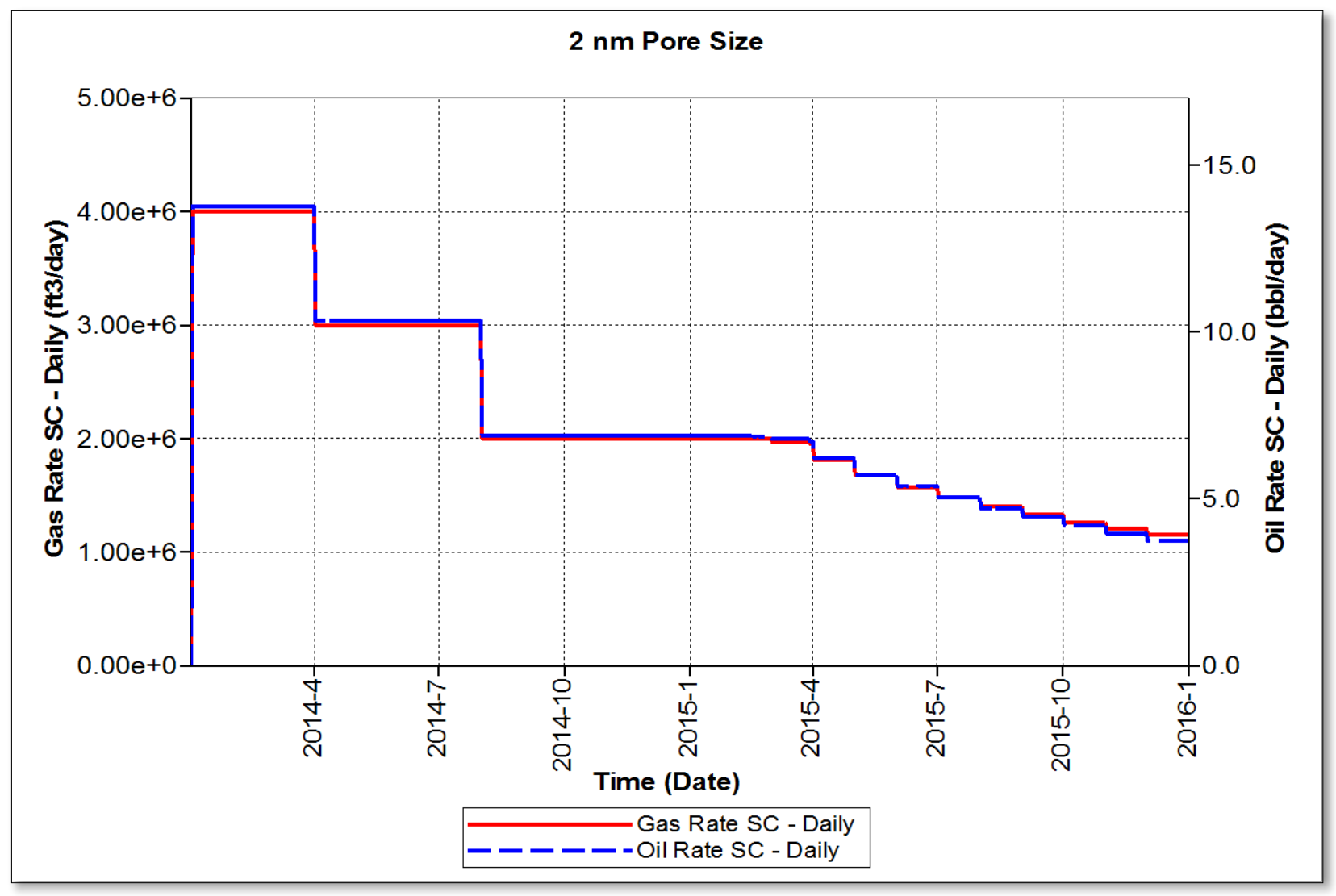

Fig. 28 gas and oil daily production of the confined case with pore size of $\mathbf{2} \mathbf{n m}$ for the first two years

\subsubsection{Confined case with pore size of $4 \mathrm{~nm}$}

The second case of the confinement which studied in this research is the case of the $4 \mathrm{~nm}$ pore size. The simulation results of this case show that it has an opposite impact on the gas and condensate production compared with the $2 \mathrm{~nm}$ pore size. This case of the confinement was found to have a significant negative effect on the condensate production. The cumulative condensate production after 30 years was found to be equal to $1520 \mathrm{bbl}$. which is less than the unconfined case and confined case of the $2 \mathrm{~nm}$ pore size. This behavior can be attributed to the effect of the $4 \mathrm{~nm}$ pore size on the phase behavior which hastens condensate generation in the reservoir in the early time of the production and this resulted in producing leaner gas which has less heavy components. Moreover, the liquid accumulation in the reservoir resulted in gas deliverability reduction in the beginning of 
the production because of the condensate blockage which reduced the value of the gas relative permeability and blocked gas flow channels in the reservoir; therefor, the 4 MMCF and 3 MMCF production rate could not be sustained for the same time with the confined case and $2 \mathrm{~nm}$ pore size case. However, the cumulative produced gas after 30 years was found to be higher than the unconfined case and the $2 \mathrm{~nm}$ pore size case due to the more initial gas in place compared with both cases. Figures 29, 30, 31 and Table 14 depict the produced gas and the condensate for the $2 \mathrm{~nm}$ pore size case.

Table 14 oil and gas production under confinement effects with $4 \mathrm{~nm}$ pore size.

\begin{tabular}{|c|c|c|}
\hline Time (Years) & Cumulative Oil Production (bbl) & Cumulative Gas Production (SCF) \\
\hline 2 & 836 & $1.507 \mathrm{e}+9$ \\
\hline 5 & 1130 & $2.4 \mathrm{e}+9$ \\
\hline 10 & 1308 & $3.166 \mathrm{e}+9$ \\
\hline 30 & 1520 & $4.475 \mathrm{e}+9$ \\
\hline
\end{tabular}

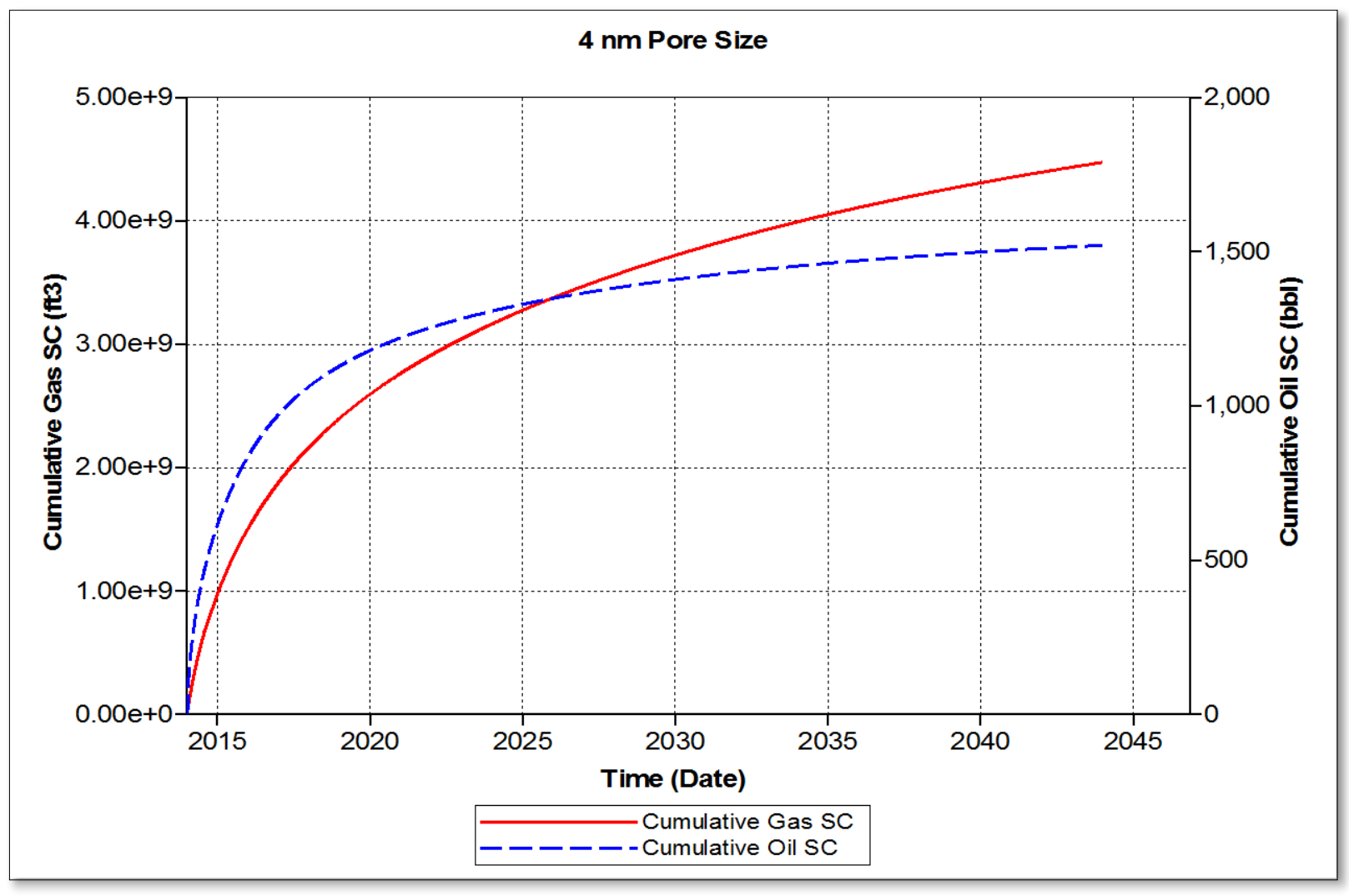

Fig. 29 cumulative gas and oil production for the confine case with $4 \mathrm{~nm}$ pore size for 30 years 


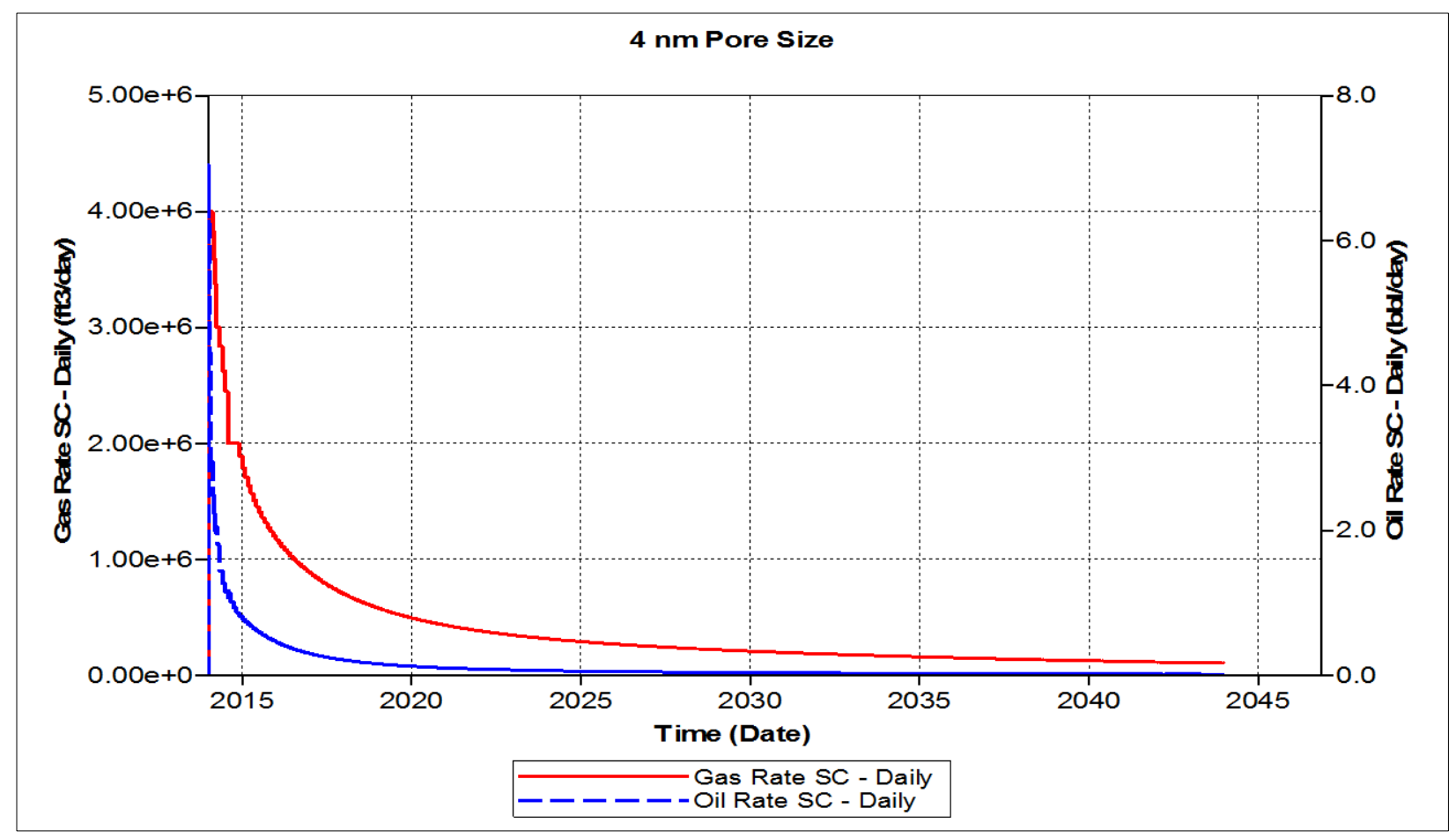

Fig. 30 gas and oil daily production of the confined case with pore size of $4 \mathbf{n m}$ for 30 years.

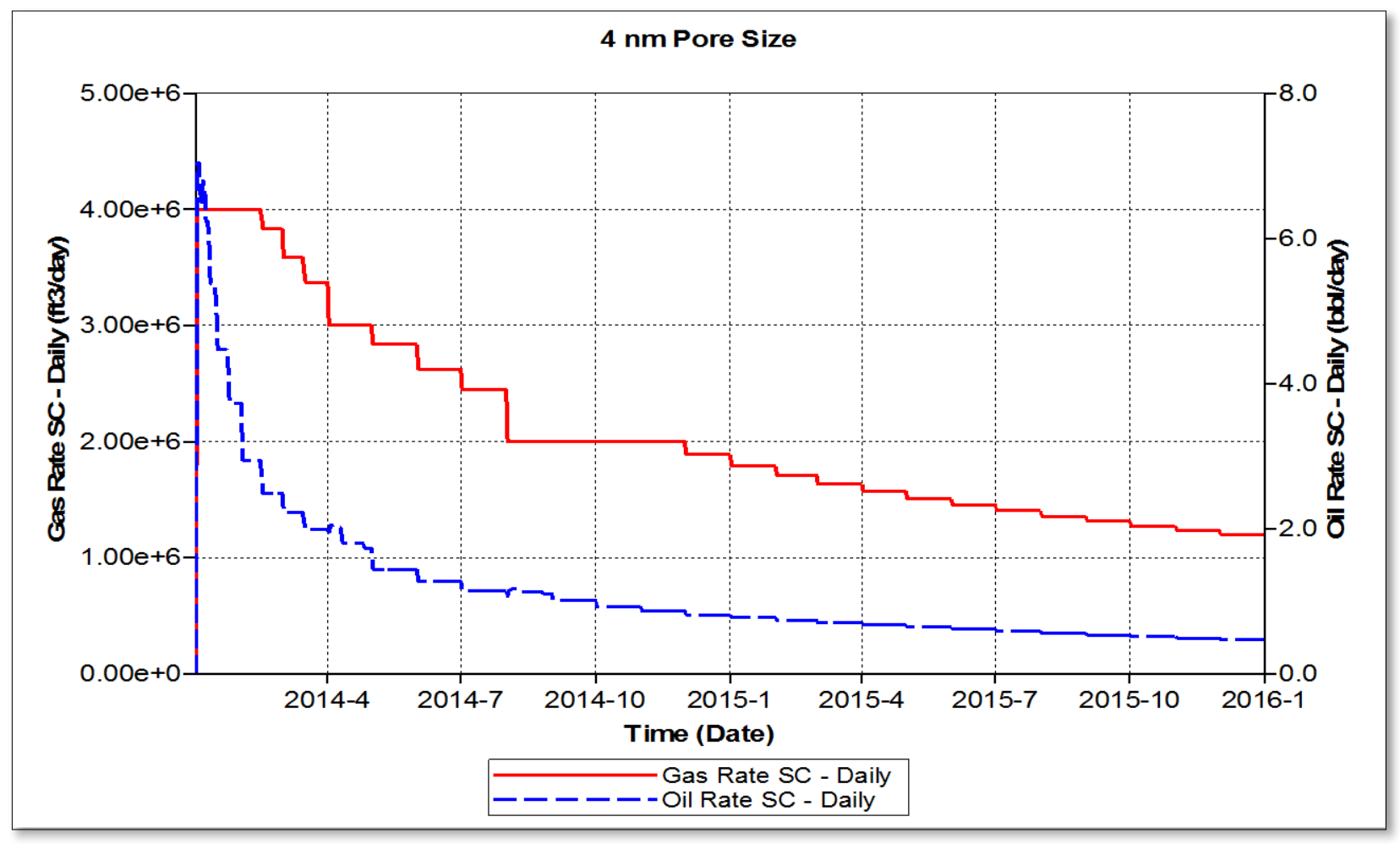

Fig. 31 gas and oil daily production of the confined case with pore size of $4 \mathrm{~nm}$ for the first two years 


\subsubsection{Confined case with pore size of $5 \mathrm{~nm}$}

The simulation results of the last confinement case with $5 \mathrm{~nm}$ pore size show that it has a similar effect with the $4 \mathrm{~nm}$ pore size on the gas and condensate production. Like the case of the $4 \mathrm{~nm}$ pore size, condensate production was less than the other cases because the $5 \mathrm{~nm}$ pore size changed the gas condensate phase behavior and hastened the reaching to the dew point pressure and condensate accumulation in the reservoir. Consequently, gas deliverability reduction happened and it was higher compared with all of the other cases. On the other hand, the cumulative gas production after 30 years of the production was higher than the other cases for the same reason that was mentioned in the case of $4 \mathrm{~nm}$ pore size (Find Figures 32, 33, 34 and Table 15 show the gas and condensate production).

Table 15 oil and gas production under confinement effects with $5 \mathrm{~nm}$ pore size.

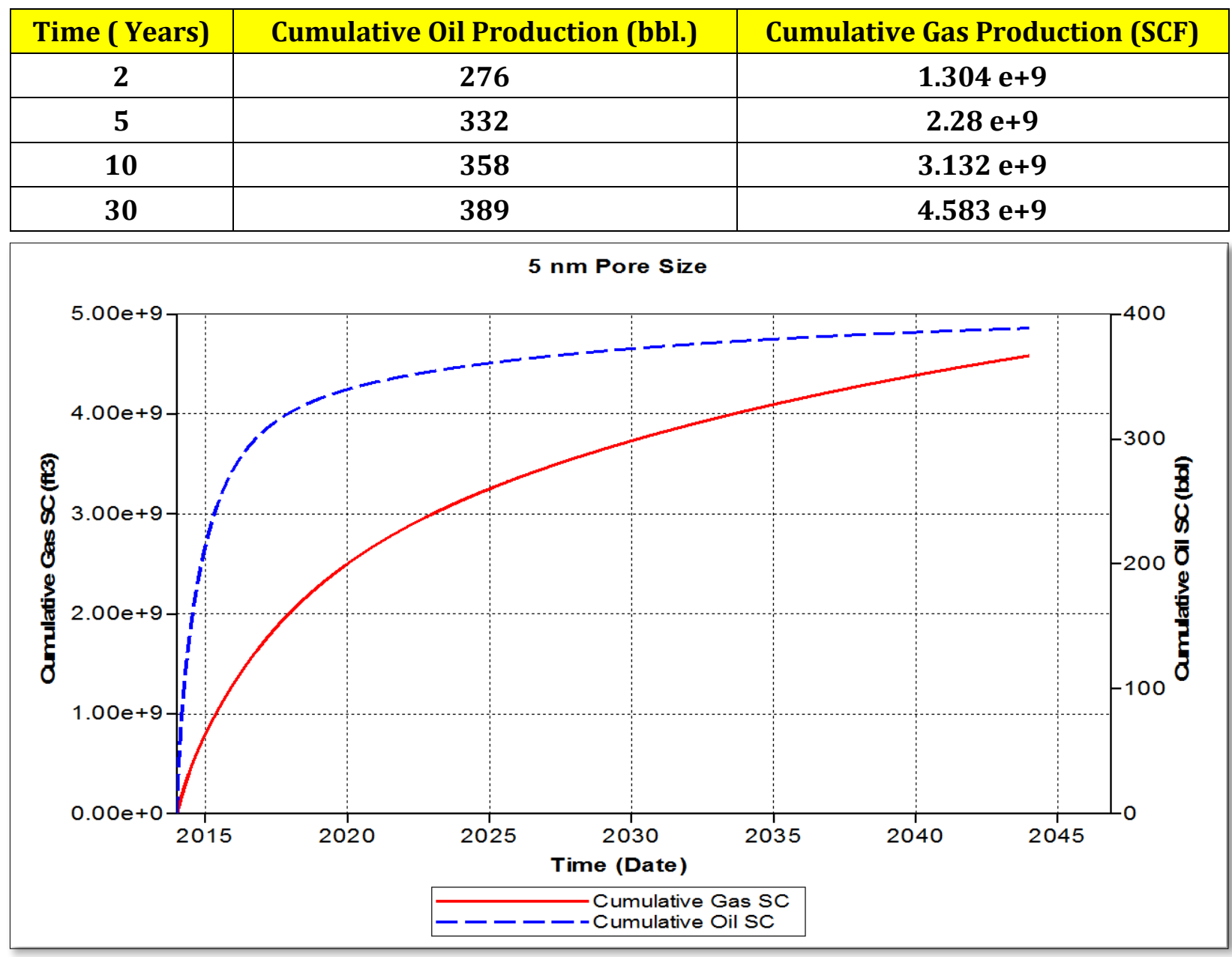

Fig. 32 cumulative gas and oil production for the confine case with $5 \mathrm{~nm}$ pore size for 30 years. 


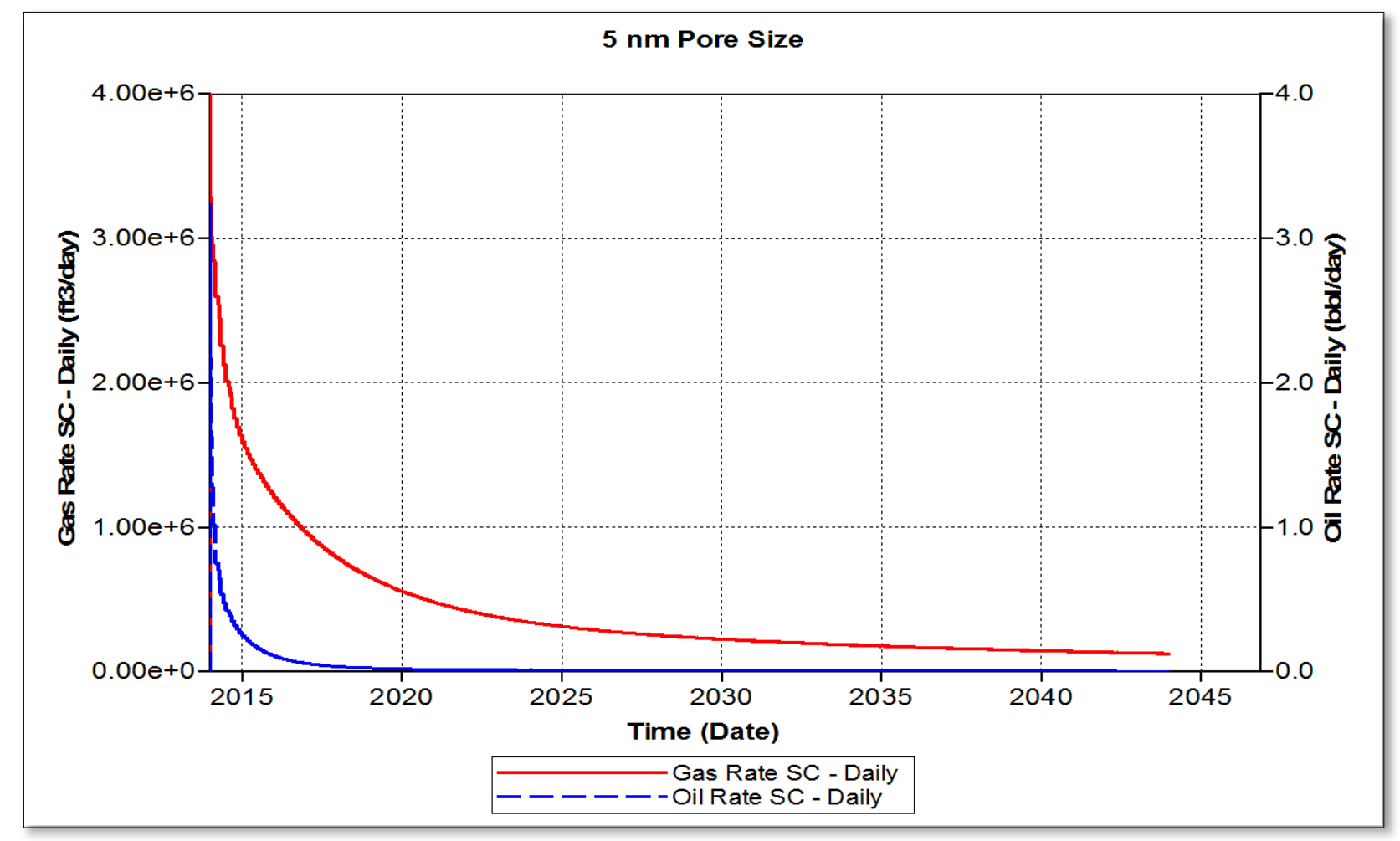

Fig. 33 gas and oil daily production of the confined case with pore size of $\mathbf{5 m}$ for 30 years.

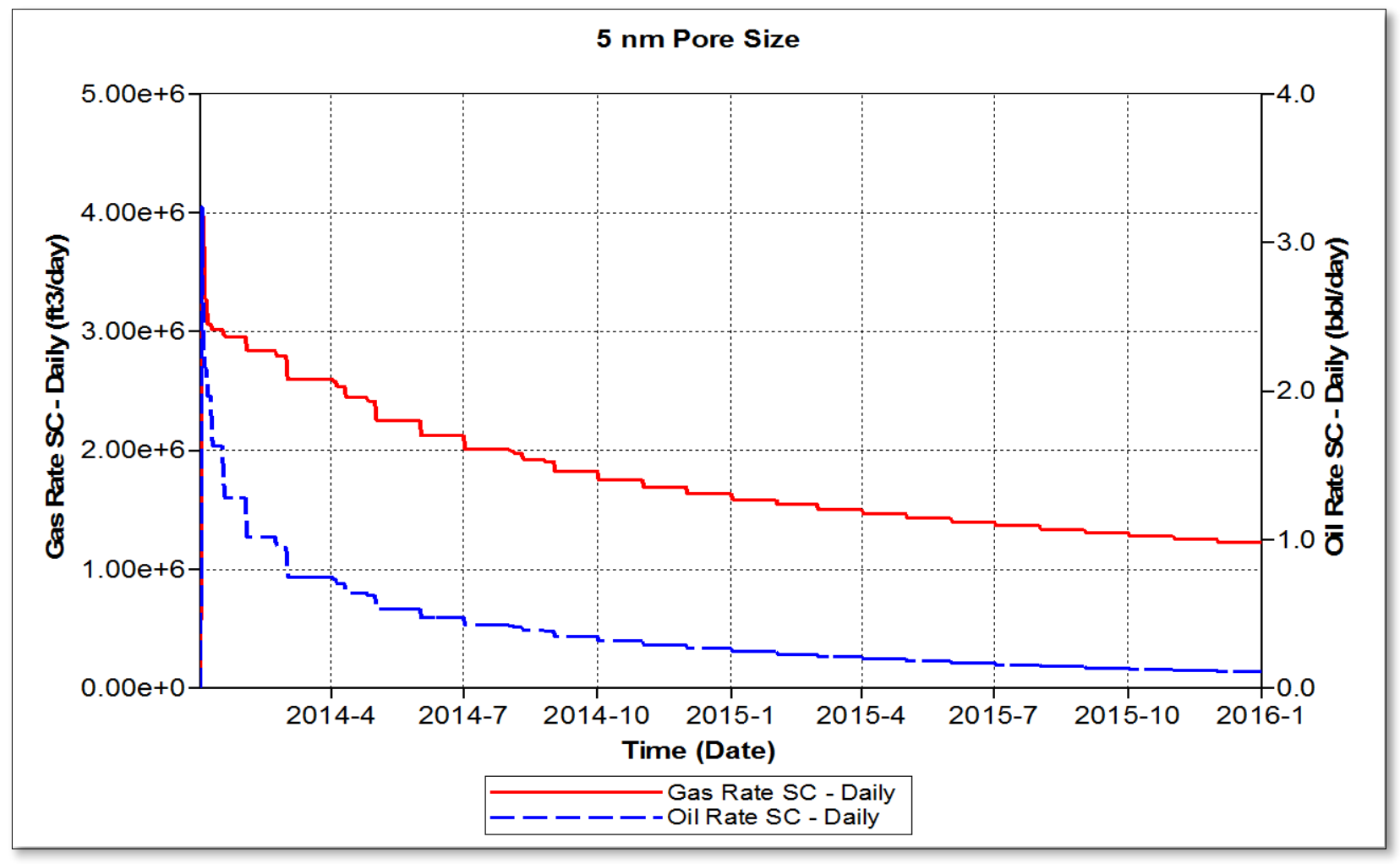

Fig. 34 gas and oil daily production of the confined case with pore size of $5 \mathbf{n m}$ for the first two years. 


\subsection{Gas Recovery Factor of the Unconfined and Confined Cases}

After simulating the four reservoir models for the unconfined and confined cases to estimate gas and condensate production after 30 years, the four reservoir models were run to estimate the value of the initial gas in place for each case in order to calculate the gas recovery factor value (Table 16 shows the gas in place value for each case). It was found that the confinement case of the $2 \mathrm{~nm}$ pore size reduced the initial gas in place value, whereas the $4 \mathrm{~nm}$ and the $5 \mathrm{~nm}$ cases increase the value of the initial gas in place. This deviation in the initial gas in place is attributed to the change in the gas properties with an emphasis on the gas compressibility. It was found that the pore confinement has a significant impact on the gas compressibility and consequently the volume of the gas within shale formation changes for each case of the confinement with different pore sizes.

Table 16 initial gas in place for the unconfined and confined cases.

\begin{tabular}{|c|c|c|c|}
\hline \multicolumn{4}{|c|}{ Initial Gas in Place (IGP) SCF } \\
\hline Unconfined case & 2nm Pore Size Case & 4nm Pore Size Case & 5nm Pore Size Case \\
\hline $8.44 E+09$ & $7.63 E+09$ & $8.83 E+09$ & $9.24 E+09$ \\
\hline
\end{tabular}

Once the values of the initial gas in place were estimated, the gas recovery factor for each case was calculated for different time of the production as shown in Table 17.

Table 17 gas recover factor values for the unconfined and the confined cases.

\begin{tabular}{|c|c|c|c|c|}
\hline \multirow{2}{*}{$\begin{array}{c}\text { Time } \\
\text { (Years) }\end{array}$} & \multicolumn{4}{|c|}{ Gas Recovery Factor } \\
\cline { 2 - 5 } & Unconfined case & 2nm Pore Size Case & 4nm Pore Size Case & 5nm Pore Size Case \\
\hline 2 & $19 \%$ & $21 \%$ & $17 \%$ & $14 \%$ \\
\hline 5 & $29 \%$ & $31 \%$ & $27 \%$ & $25 \%$ \\
\hline 10 & $37 \%$ & $38 \%$ & $36 \%$ & $34 \%$ \\
\hline 30 & $50 \%$ & $49 \%$ & $51 \%$ & $50 \%$ \\
\hline
\end{tabular}

From Table 17, it can be seen that the $2 \mathrm{~nm}$ pore size case provides the highest gas recovery factor values in the early years of the production compared with the other cases. The high gas recovery 
factor in the early time of the production is important for the gas producers because that benefits to achieve the optimum economic advantages after short time of the production.

\subsection{Permeability Adjustment Due to Confinement Effects}

The values of the permeability for the four reservoir models were not adjusted according to the change in the pore sizes for each case of the confinement. The reason of not adjusting the permeability values was because the production of the shale reservoir is mainly controlled by the permeability of the hydraulic fractures, whereas the matrix permeability does not affect the production significantly. To demonstrate the above outlined, the permeability value of the $2 \mathrm{~nm}$ pore size reservoir model was adjusted to be equal to ( $\mathrm{K}=0.000064 \mathrm{md})$ and the reservoir model was simulated to investigate the impact of considering permeability adjustment on the obtained results in this research.

The simulation results of the $2 \mathrm{~nm}$ pore size show that the permeability adjustment does not have a significant effect on the gas and condensate production. Table 18 depicts the gas and condensate cumulative production after adjusting the permeability value for the reservoir model with $2 \mathrm{~nm}$ pore size. Table 18 shows there is a slight change in the gas and condensate cumulative production compared with Table 13, which represents the results of the $2 \mathrm{~nm}$ pore size reservoir model without permeability adjustment. Moreover, Table 18 depicts that $2 \mathrm{~nm}$ pore size still provides the best condensate production compared with the other cases of the confinement.

Table 18 oil and gas production under confinement effects with $2 \mathrm{~nm}$ pore size with the permeability adjustment.

\begin{tabular}{|c|c|c|}
\hline Time (Years) & Cumulative Oil Production (bbl.) & Cumulative Gas Production (SC) \\
\hline 2 & 4846 & $1.42 \mathrm{e}+9$ \\
\hline 5 & 7227 & $2.179 \mathrm{e}+9$ \\
\hline 10 & 8965 & $2.777 \mathrm{e}+9$ \\
\hline 30 & 11420 & $3.664 \mathrm{e}+9$ \\
\hline
\end{tabular}


Table 19 shows the values of the gas recovery factor for the $2 \mathrm{~nm}$ pore size with the permeability adjustment. By comparing the values of the Table 19 with the Table 17 values, it can be seen that the obtained values of the gas recovery factor from the $2 \mathrm{~nm}$ pore size with the permeability adjustment still higher than the other confined cases.

From the above outlined and from Fig 35, it can be concluded that considering permeability changes with different pore sizes of the confinement will not impact the obtained results from this study significantly and the $2 \mathrm{~nm}$ pore size still enhances the gas and condensate production in shale formation.

Table 19 gas recovery factor of the $2 \mathrm{~nm}$ pore size reservoir model with the permeability adjustment.

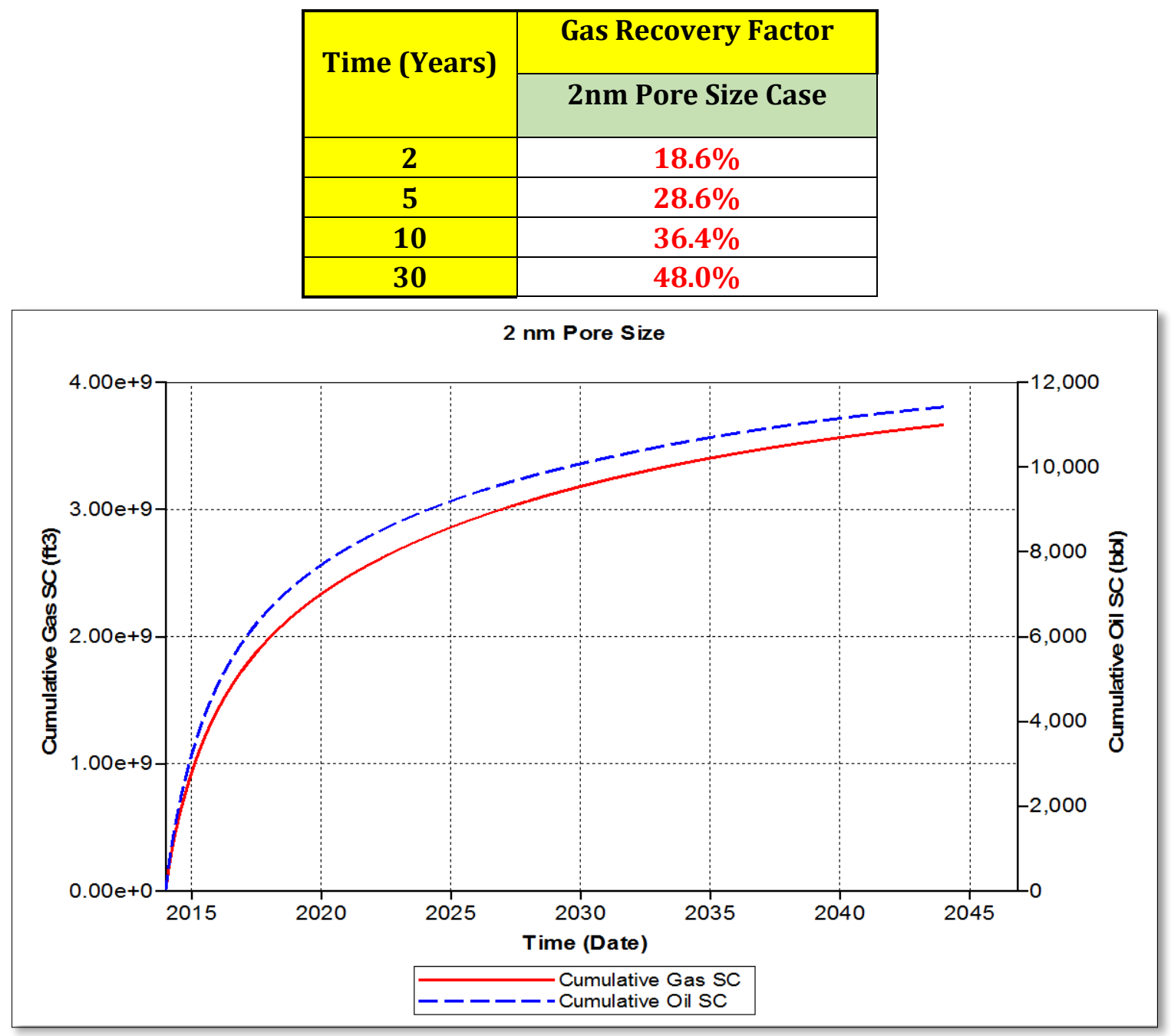

Fig. 35 gas and oil cumulative production of the $2 \mathrm{~nm}$ pore with permeability adjustment. 


\section{Chapter 5 - Conclusions}

The purpose of this research was to investigate the impact of pore size on the confined gas condensate in the Marcellus shale. Three case studies represent the confinement cases with different pore size of $2 \mathrm{~nm}, 4 \mathrm{~nm}, 5 \mathrm{~nm}$, and a fourth unconfined case were investigated in this research. After studying and analyzing the results of the previous chapter, the finding of this research can be proposed as follows:

1. The pore confinement has a significant impact on the critical properties and the phase behavior of the gas condensate with an emphasis of the dew point pressure. It was found that the pore size of $2 \mathrm{~nm}$ significantly reduces the dew point pressure, whereas the $4 \mathrm{~nm}$, and 5 nm increase the dew point pressure.

2. After investigating the phase behavior of the gas condensate, it was found that the case of 2 $\mathrm{nm}$ pore size retards liquid production whereas the $4 \mathrm{~nm}$ and $5 \mathrm{~nm}$ cases hasten liquid generation from the gas within reservoir conditions.

3. The confinement case with pore size of $2 \mathrm{~nm}$ enhances condensate production due to lowering the value of dew point pressure and the change in the phase behavior while the $4 \mathrm{~nm}$ and $5 \mathrm{~nm}$ cases have a negative impact on condensate production.

4. The $2 \mathrm{~nm}$ pore size case enhances gas production in the early time of the production due to the delay in time of the reaching to the dew point pressure and reducing liquid accumulation throughout the reservoir.

5. The $4 \mathrm{~nm}$ and $5 \mathrm{~nm}$ pore size case were found to increase the cumulative gas production after long time of the production due to the more initial gas in place and the higher permeability relative to the other cases.

6. The cumulative gas production after long time from the $2 \mathrm{~nm}$ pore size case is less than the other case due to the reduction in the permeability and initial gas in place. 
7. The $2 \mathrm{~nm}$ pore size case provides the best gas recovery factor in the beginning of the production compared with the other cases.

8. Considering permeability adjustment with different pore size does not affect the obtained results of this study significantly. 


\section{References}

Adewumi, M. (2014). Peng-Robinson EOS (1976). Retrieved from PENNSTATE: https://www.eeducation.psu.edu/png520/m11_p2.html

Ahmed, T., Evans, J., Kwan, R., \& Vivian, T. (1998). Wellbore Liquid Blockage in Gas-Condensate Reservoirs. SPE 51050.

Alavian, S. A., Whitson, C. H., \& Martinsen, S. O. (2014). Global Component Lumping for EOS Calculations. SPE-170912-MS.

Al-Lamki, A., Daungkaew, S., Mott, R., Whittle, T. M., \& Gringarten, A. C. (2000). Well Test Analysis in Gas-Condensate Reservoirs. SPE 62920.

Ashour, I., AL-Rawahi, N., Fatemi, A., \& Nezhaad, G. V. (2011). Applications of Equations of State in the Oil and Gas Industry. Retrieved from InTECH:

http://www.intechopen.com/books/thermodynamics-kinetics-of-dynamic-

systems/applications-of-equations-of-state-in-the-oil-and-gas-industry

Bamum, R. S., Brinkman, F. P., Richardson, T. W., \& Spillette, A. G. (1995). Gas Condensate Reservoir Behavior: Productivity and Recovery Reduction Due to Condensation. SPE30767.

Bruner, K. R., \& Smosna, R. (2011). A Comparative Study of the Mississippian Barnett Shale, Fort Worth Basin, and Devonian Marcellus Shale, Appalachian Basin. U.S. Department of Energy.

Builder User's Guide.Calgary:CMG. (2011). Computer Modeling Group.

Burwen, J., \& Flegal, J. (2013, March). Unconventional Gas Exploration \& Production. American Energy Innovation Council.

Bustos, C. I., \& Toledo, P. G. (2003). CONTACT ANGLE HYSTERESIS EFFECTS ON THE RELATIVE PERMEABILITY OF GAS AND CONDENSATE IN THREE-DIMENSIONAL PORE NETWORKS. Latin American applied research.

Civan, F., \& Michel, G. (2013). Impact of Fluid Behavior Modification under Elevated Pressure and Temperature Conditions on Shale-Gas/Condensate Reservoir Engineering and Production Analysis. SPE 167186.

Coleman, R. (2014). Abbreviated Gas Reservoir Fluid Study. Morgantown, West Virginia: Stone Energy Corporation .

Curtis, R. (2011, January 14). What rock layers are above and below Marcellus shale. Retrieved from THE INSTITUTE FOR ENERGY \&ENVIRONMENTAL RESEARCH: http://energy.wilkes.edu/pages/159.asp

Curtis, R. (2011, January 14). What is Marcellus shale? Retrieved from THE INSTITUTE FOR ENERGY \& ENVIRONMENTAL RESEARCH: http://energy.wilkes.edu/pages/152.asp 
Curtis , R. (2011, January 14). What rock layers are above and below Marcellus shale? Retrieved from THE INSTITUTE FOR ENERGY \& ENVIRONMENTAL RESEARCH: http://energy.wilkes.edu/pages/159.asp

Dehane, A., Tiab, D., \& Osisanya, S. O. (2000). Comparison of the Performance of Vertical and Horizontal Wells in Gas-Condensate. SPE 63164.

Devagowda, D., Sapmanee, K., Civan, F., \& Sigal, R. (2012). Phase Behavior of Gas Condensate in Shales Due to Pore Proximity Effects: Implications for Transport, Reserves and Well Productivity. SPE 160099.

Engelder , T., \& Lash, G. G. (2008 , May). Marcellus Shale Play's Vast Resource Potential Creating Stir In Appalachia. Retrieved from THE AMERICAN OIL\&GAS REPORTER: http://www.aogr.com/magazine/cover-story/marcellus-shale-plays-vast-resourcepotential-creating-stir-in-appalachia

Fan, L., Harris, B. W., Jamaluddin, A., Kamath, J., Mott, R., Pope, G. A., ... Whitson, C. H. (2005/2006). Understanding Gas-Condensate Reservoirs. Oilfield Review.

Fevang, O., \& Whitson, C. H. (1996). Modeling Gas-Condensate Well Deliverability. SPE Reservoir Engineering .

Generalized Equation of State Model Reservior Simulator. (n.d.). Retrieved from University of Waterloo:

http://science.uwaterloo.ca/ mauriced/earth691duss/CO2_General\%20C02\%20Sequestr ation\%20materilas/CMG\%20GEM.pdf

Hart, N. (2008). The Marcellus Shale Formation. Retrieved from The Marcellus Shale Formation Information Site: http://www.marcellusshaleformation.com

Hashemi, A., \& Gringarten, A. C. (2005). Comparison of Well Productivity Between Vertical, Horizontal and Hydraulically Fractured Wells in Gas-Condensate Reserviors. SPE 94178.

Hoffman , E. (2012, August 31). fractured garrett county. Retrieved from ClimateHoward: https://climatehoward.wordpress.com/2012/08/31/fractured-garrett-county

Hooks, J. (2013). Impact of Retrograde Condensation on Production in the Ohio Utica Point Pleasant. Morganown, West Virginia.

Hosein, R., Dawe, R. A., \& Amani, M. (2011). Peng-Robinson Equation of State Predictions for Gas Condensate Before and After Lumping. Advances in Petroleum Exploration and Development.

King, H. (n.d.). Marcellus Shale - Appalachian Basin Natural Gas Play. Retrieved from geology.com: http://geology.com/articles/marcellus-shale.shtml

Lee, D. S., Herman, J. D., Elsworth, D., Kim, H. T., \& Lee, H. S. (2011). A Critical Evaluation of Unconventional Gas Recovery from the. KSCE Journal of Civil Engineering, 681. 
Leimkuhler, J., \& Leveille, G. (2012). Unconventional Resources.

Marir, B., \& Tiab, D. (2006). Performance of Horizontal Wells in Gas Condensate Reserviors : Hassi R'Mel Feild , Alegeria. SPE 100753.

Nagarajan, N. R., Honarpour, M. M., Sampath, K., \& McMichael, D. (2004). COMPARISON OF GASCONDENSATE RELATIVE PERMEABILITY USING LIVE FLUID vs. MODEL FLUIDS. SCA200409.

Natgas. (2013, September 20). Unconventional Natural Gas Resources. Retrieved from NaturalGas.org: http://naturalgas.org/overview/unconventional-ng-resources/

Newell, R. (2011). Annual Energy Outlook 2011. U.S. Energy Information Adminstration. Retrieved from PENNSTATE: http://www.psu.edu

Peng, D., \& Robinson, D. B. (1976). A New Two-Constant Equationof State. Ing. Eng. Chem., Fundam. Vol 15, No.1.

Quantity of Organic Matter. (n.d.). Retrieved from Department of Conservation and Natural Resources: http://www.dcnr.state.pa.us/topogeo/econresource/oilandgas/marcellus/sourcerock_inde x/sourcerock_quantity/index.htm

Singh, S. K., Sinha, A., Deo, G., \& Singh, J. K. (2009). Vapor-Liquid Phase Coexistence, Critical Properties, and Surface Tension of Confined Alkanes. J. Phys. Chem. C 2009, 113, 7170-7180.

Sumi, L. (2008). Shale Gas:Focus on the Marcellus Shale. Washington, D.C.: OIL \& GAS ACCOUNTABILITY PROJECT.

Unconventional Resources. (n.d.). Retrieved from CGG: http://www.cgg.com/default.aspx?cid=3501 


\section{Appendix A}

Reservoir pressure distribution throughout the reservoir (Third layer)

\section{Unconfined case}
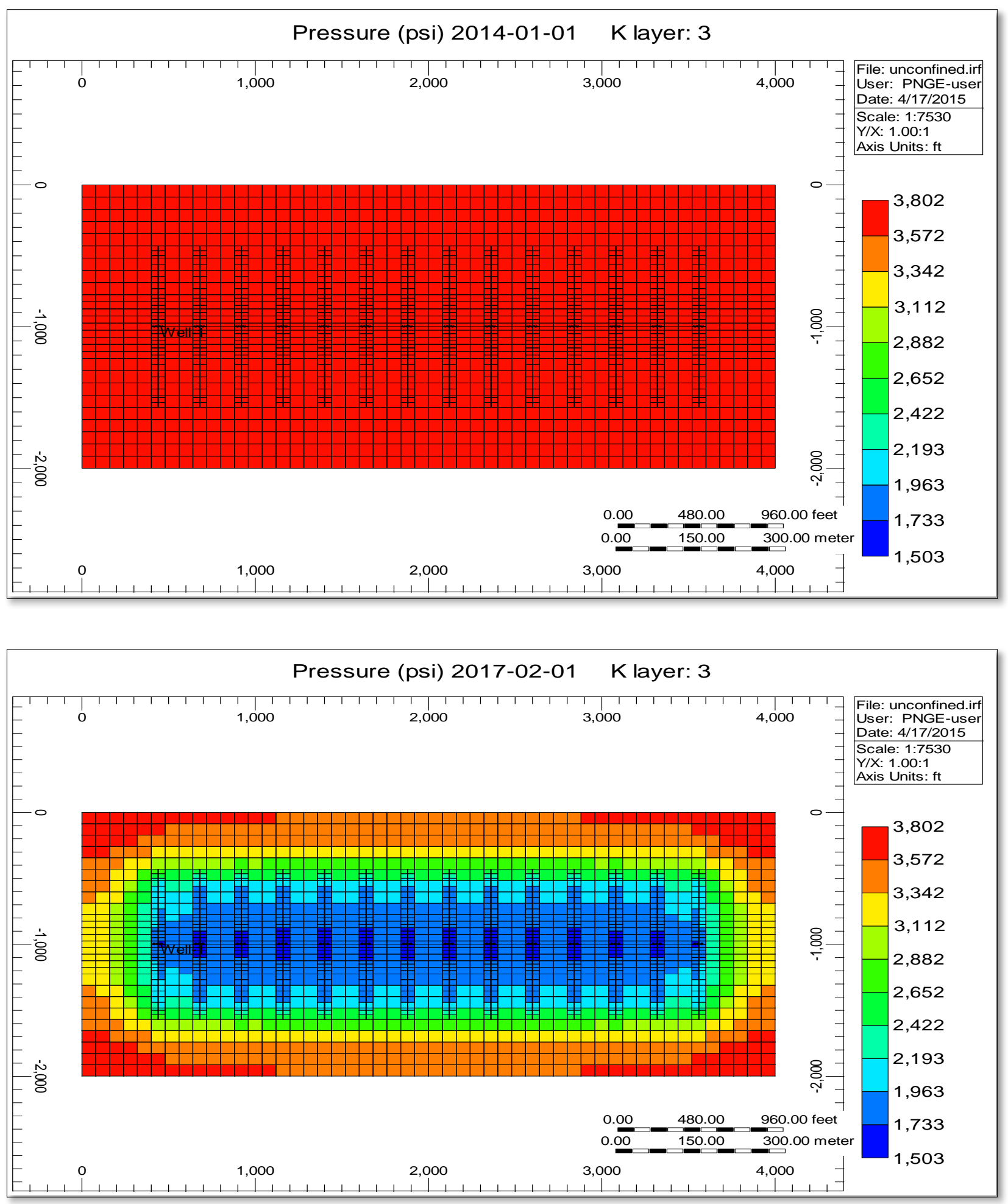

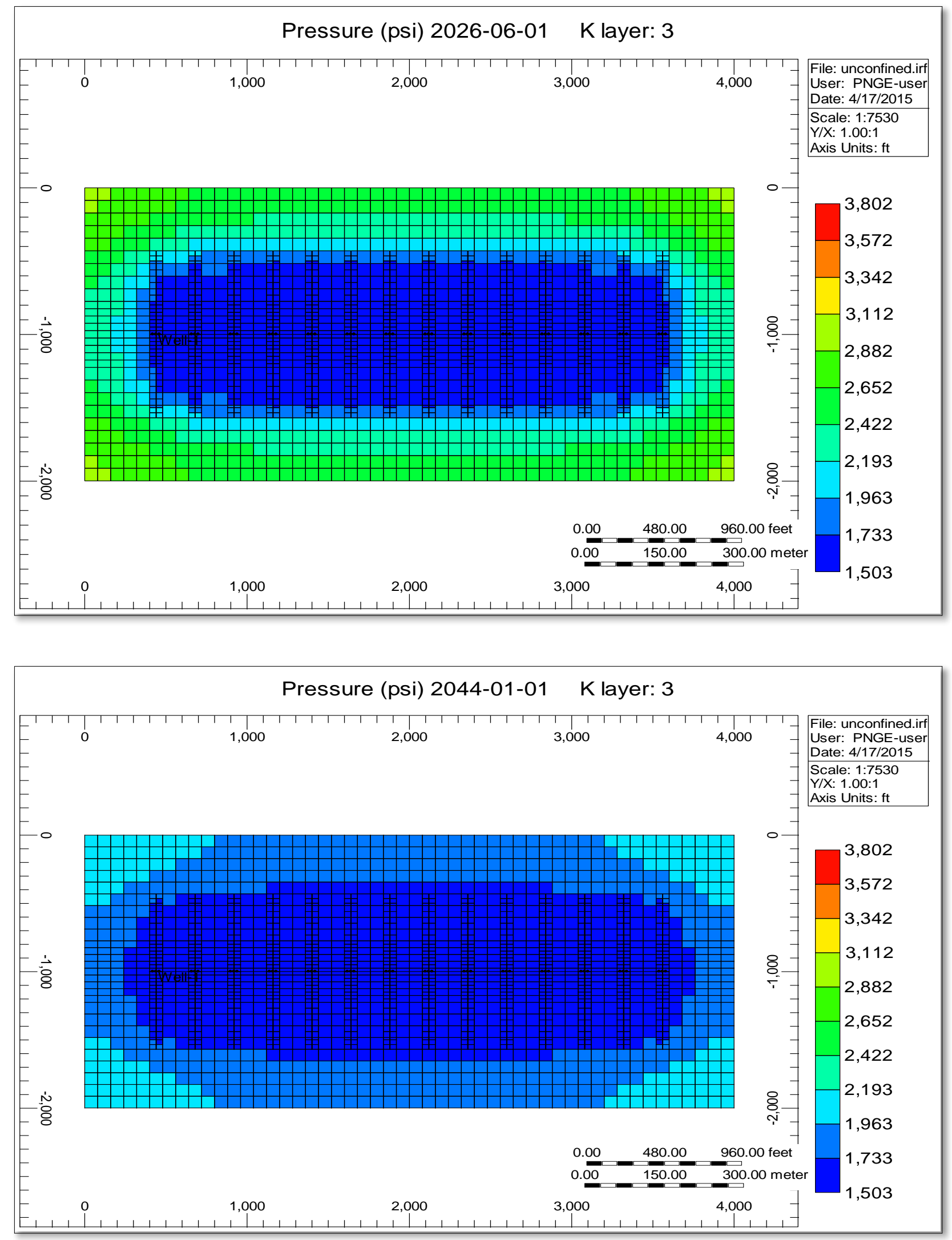


\section{Confined case with $\mathbf{2} \mathrm{nm}$ pore size}
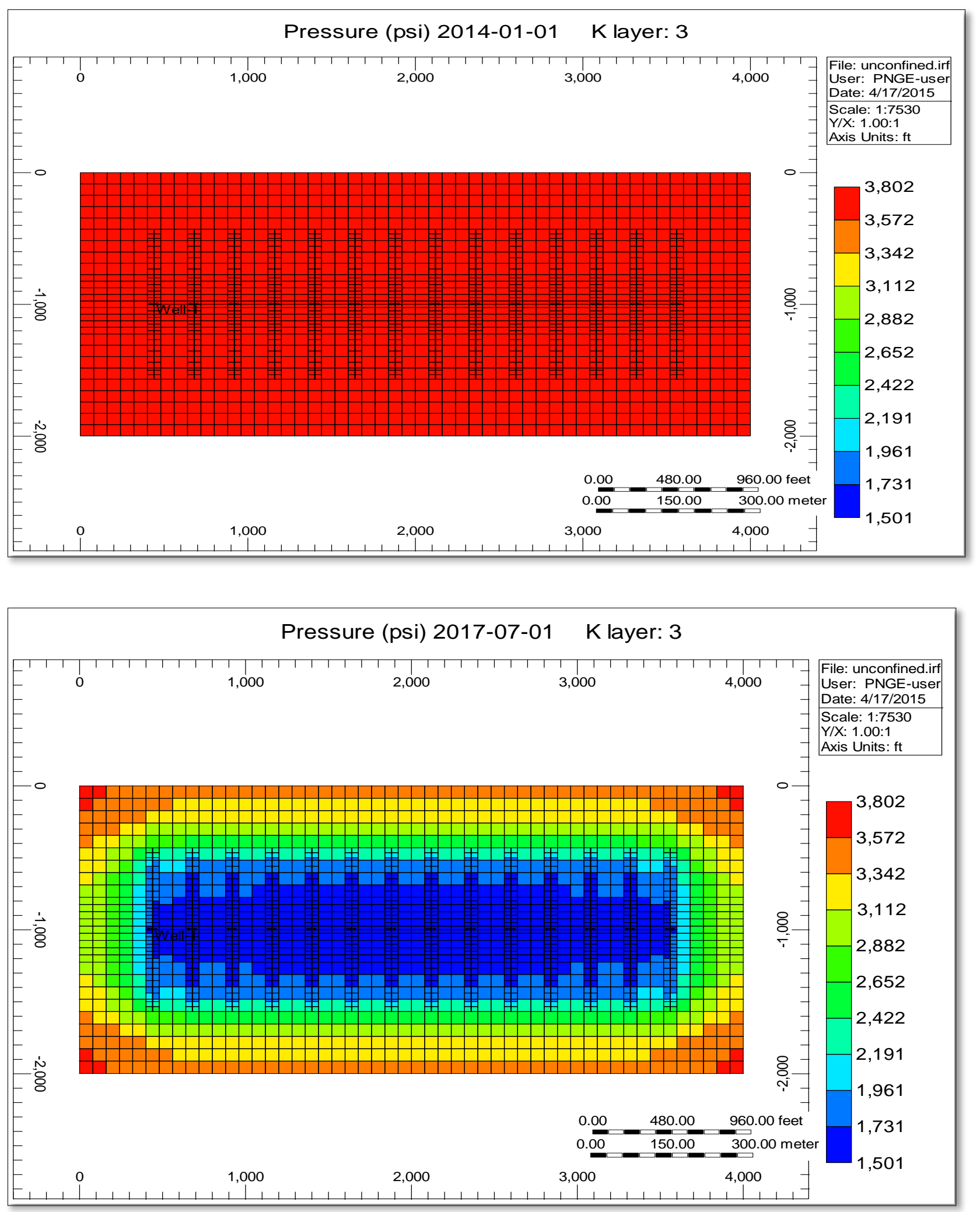

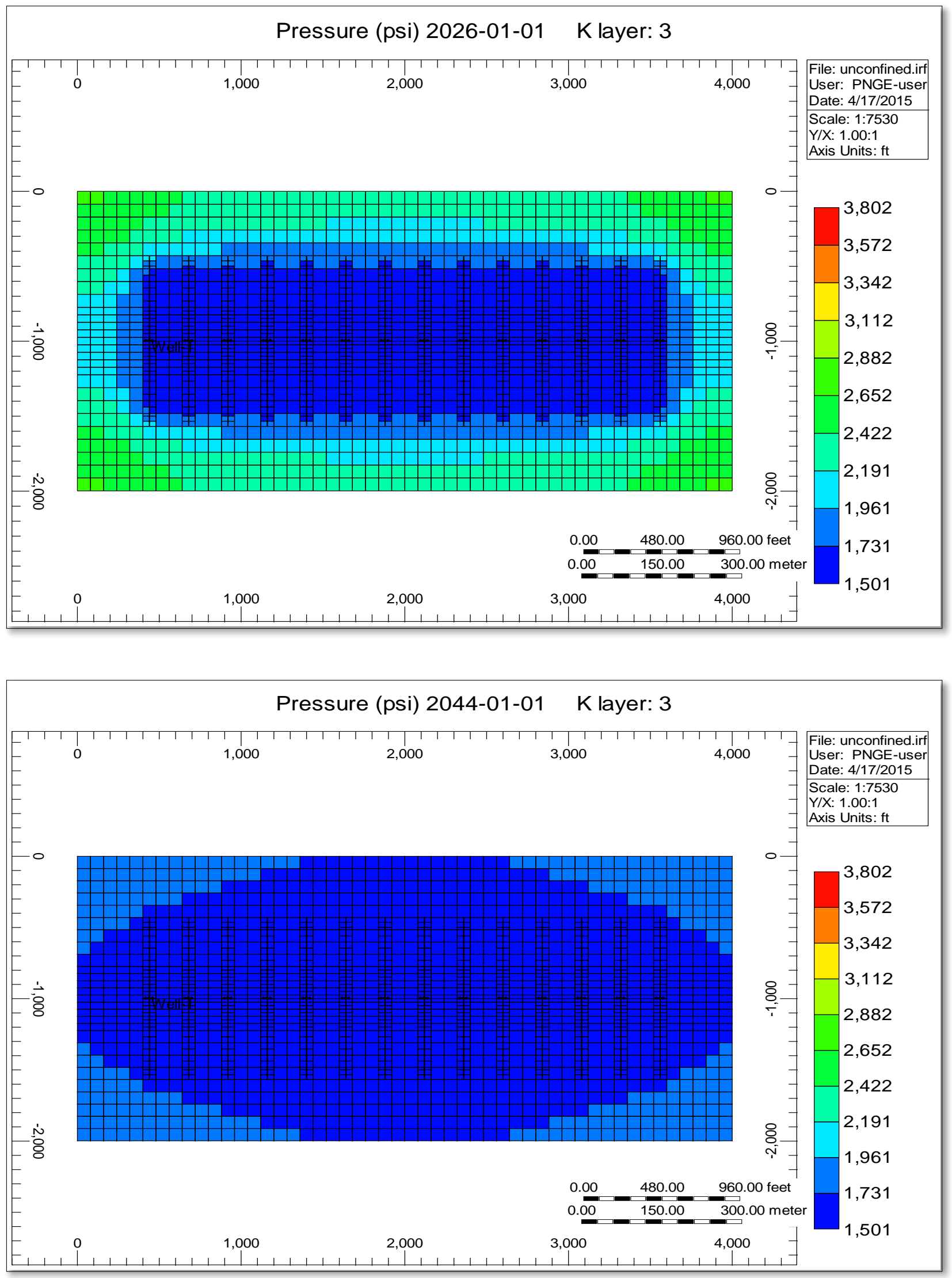


\section{Confined case with $4 \mathrm{~nm}$ pore size}
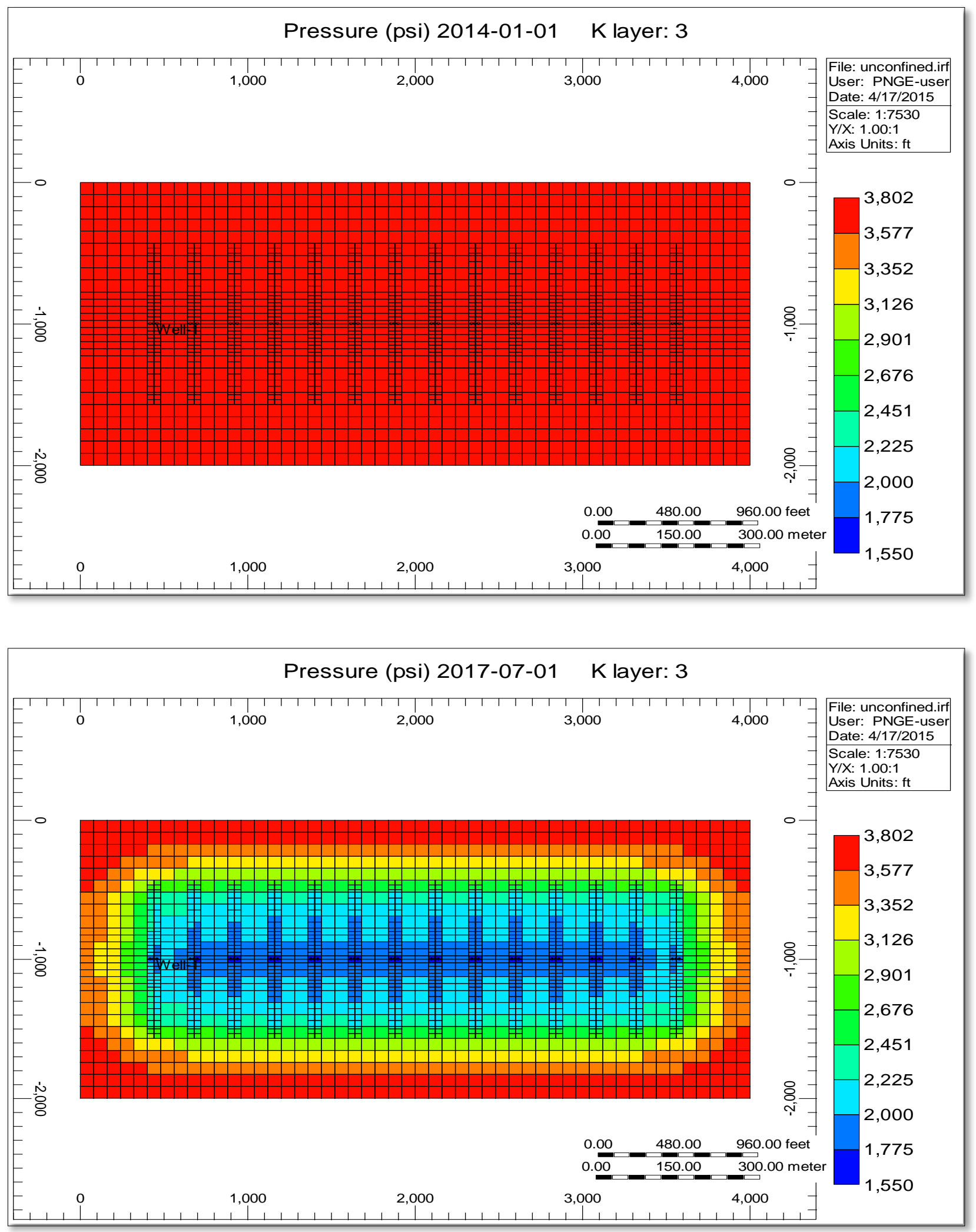

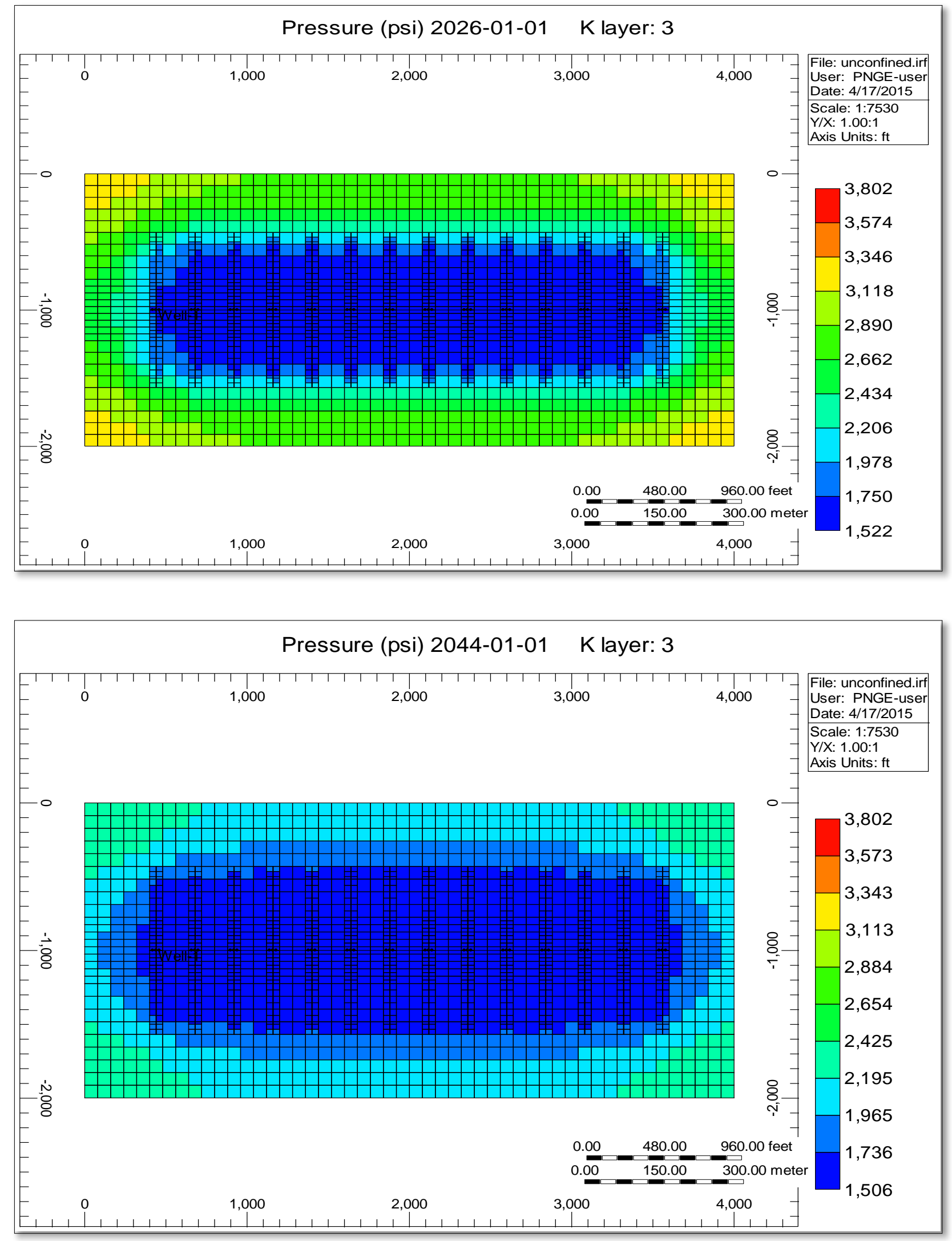


\section{Confined case with $5 \mathrm{~nm}$ pore size}
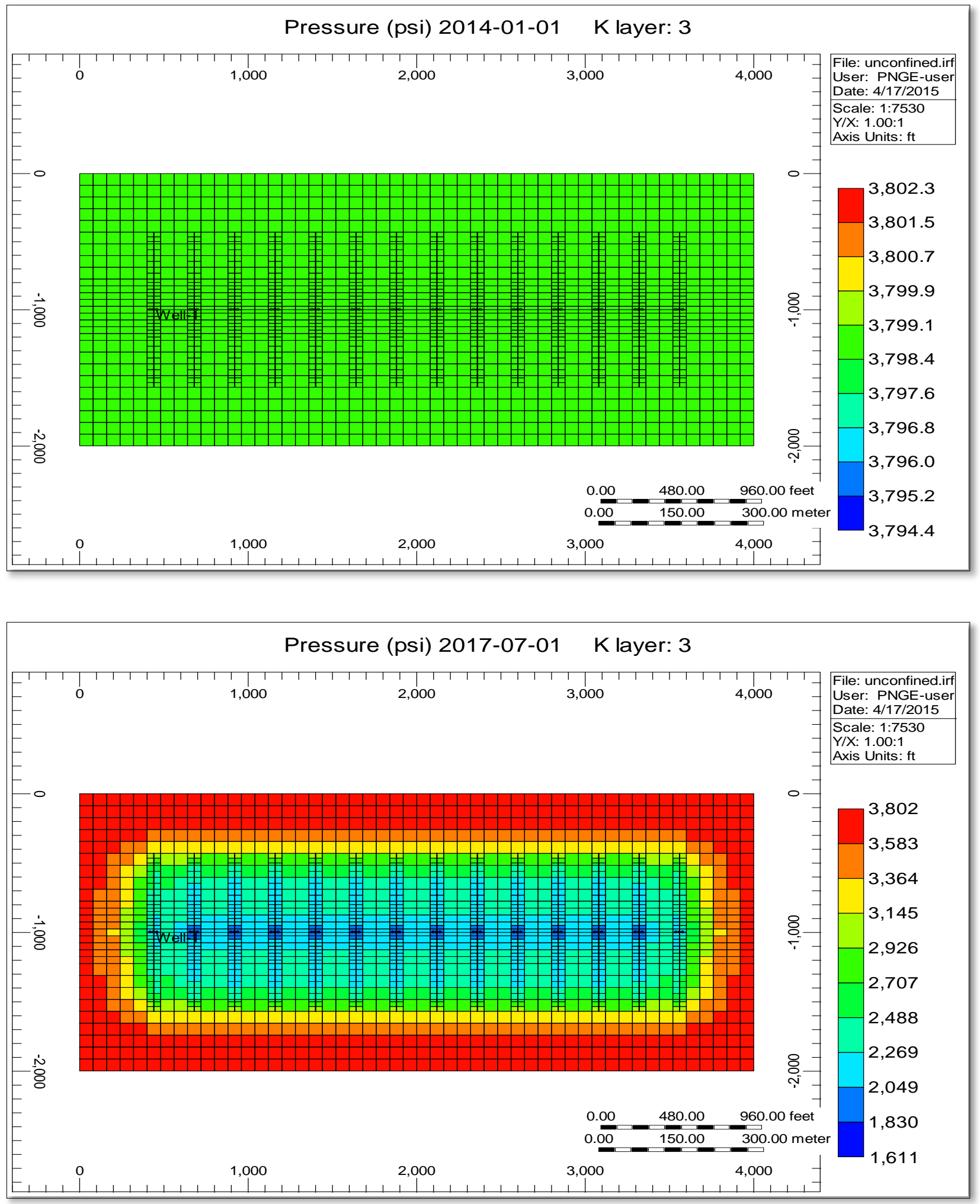

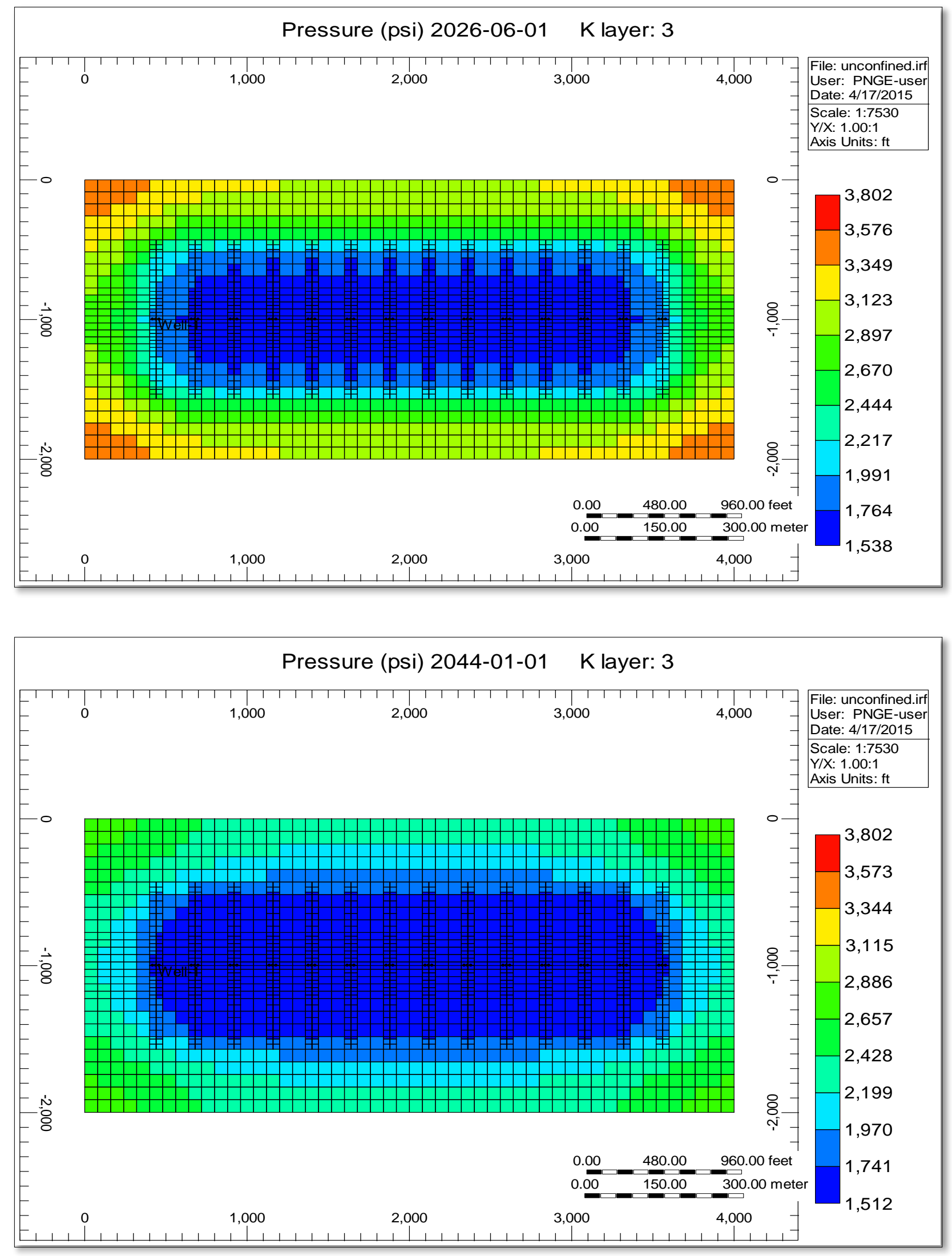


\section{Appendix B}

Oil saturation throughout the reservoir (Third layer)

\section{Unconfined case}
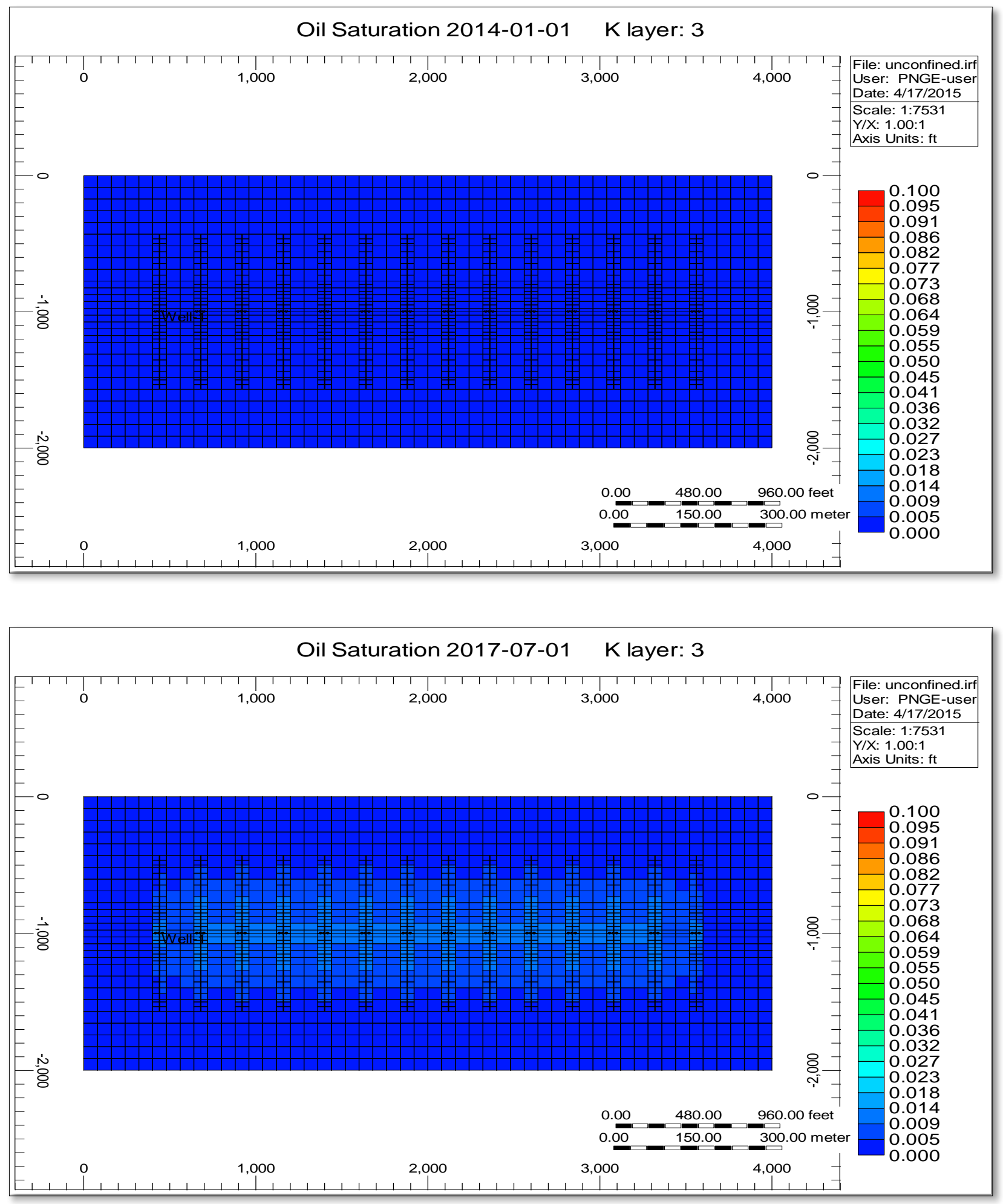

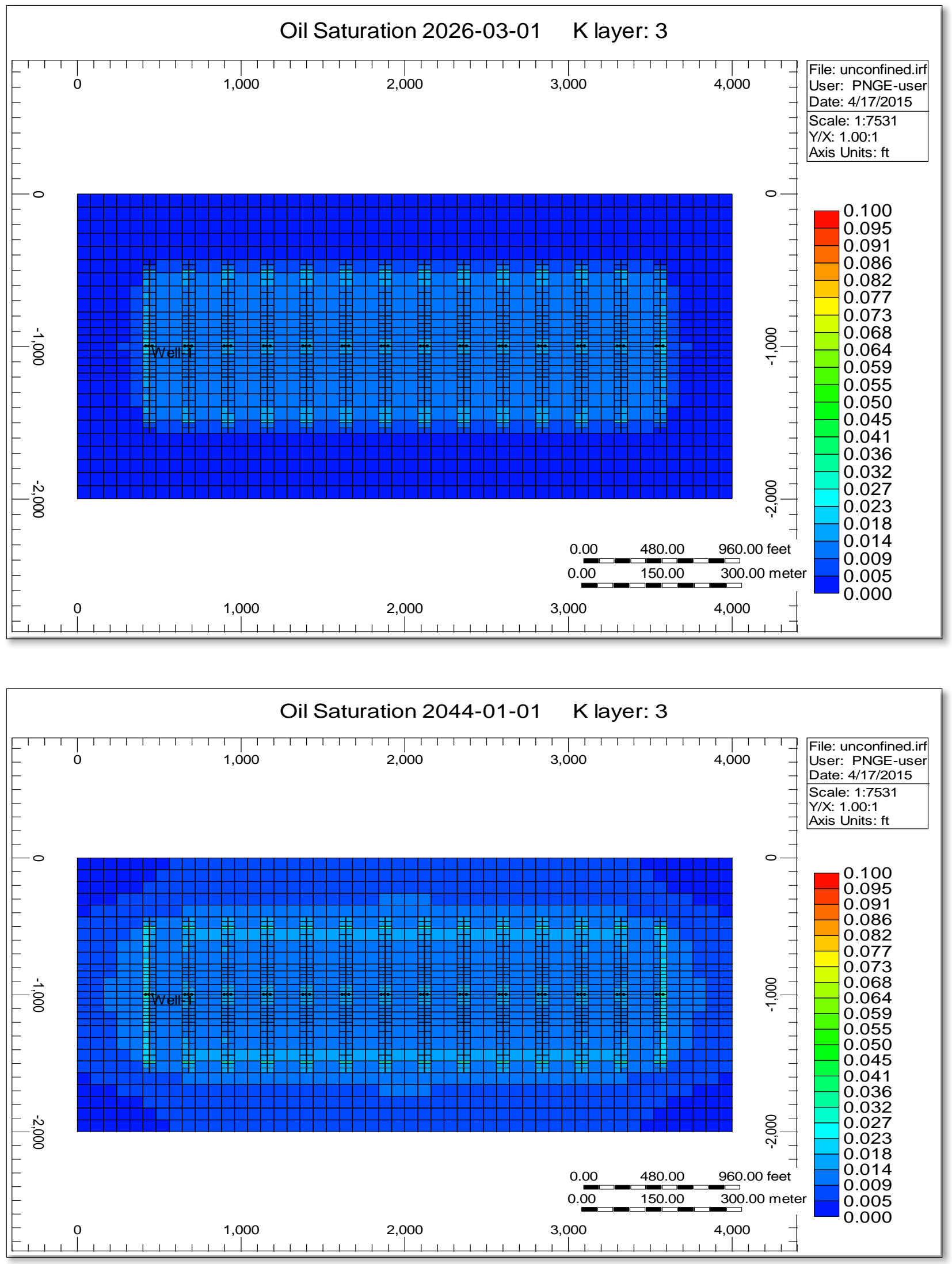


\section{Confined case with $2 \mathrm{~nm}$ Pore size}
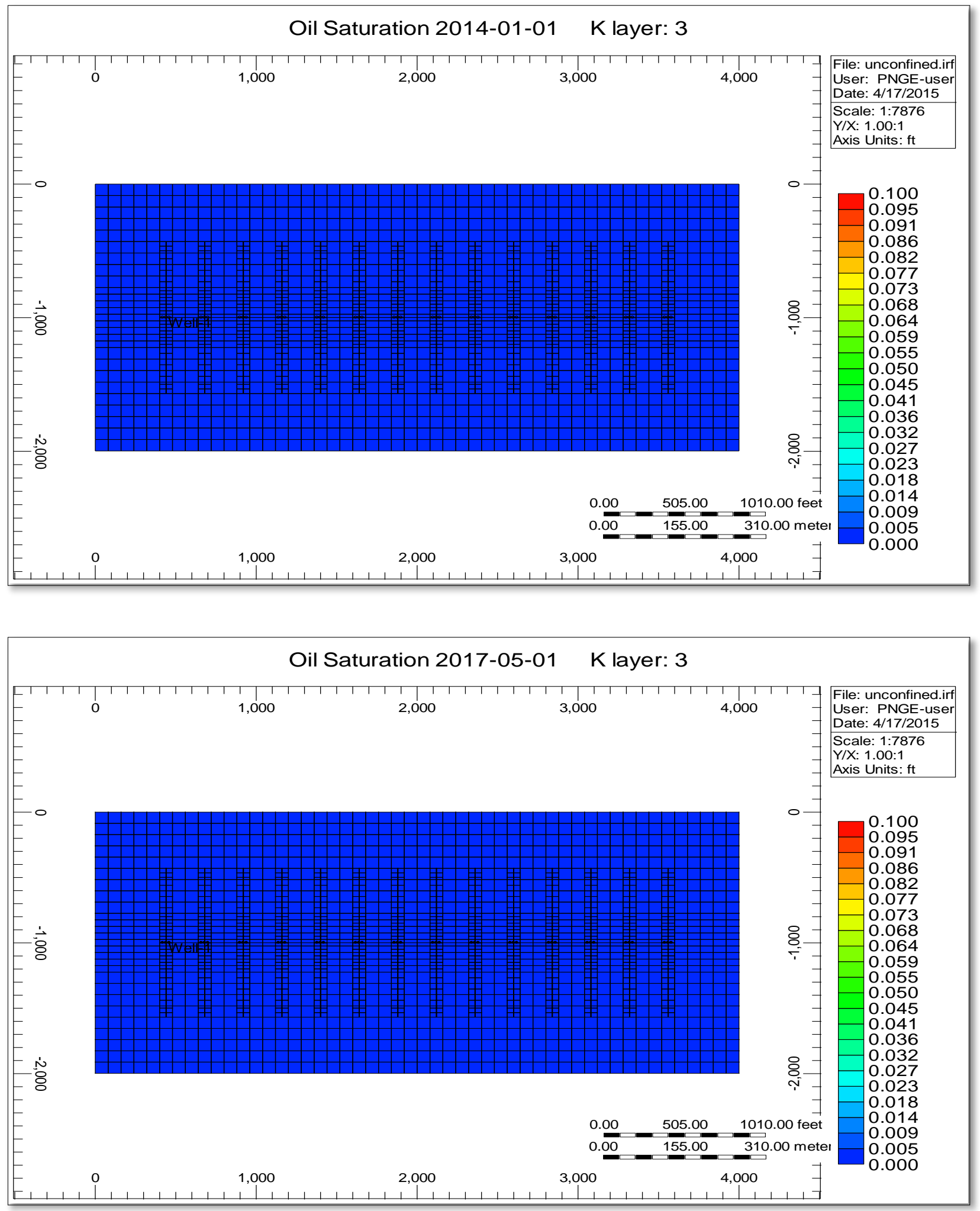

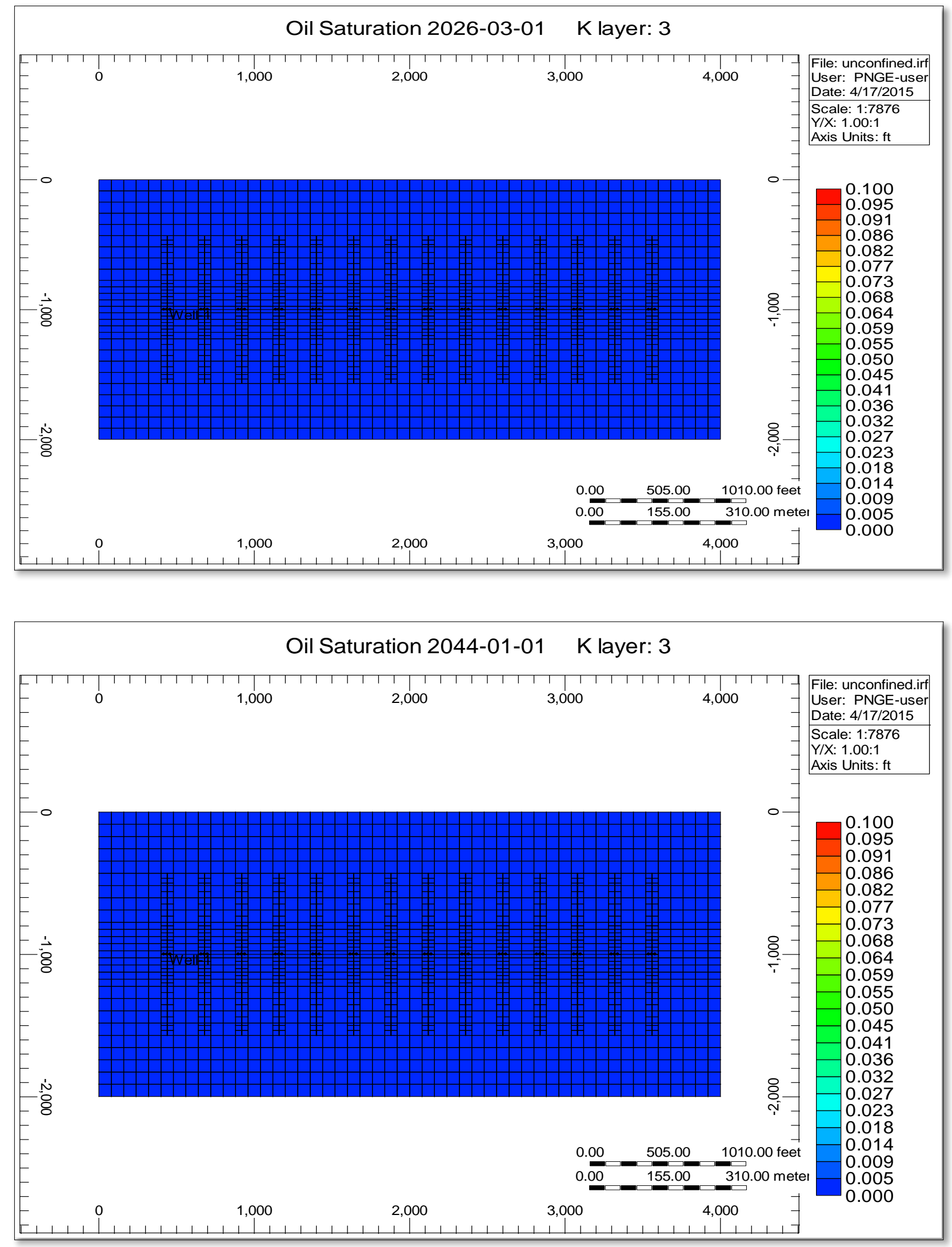


\section{Confined case with $4 \mathrm{~nm}$ Pore size}
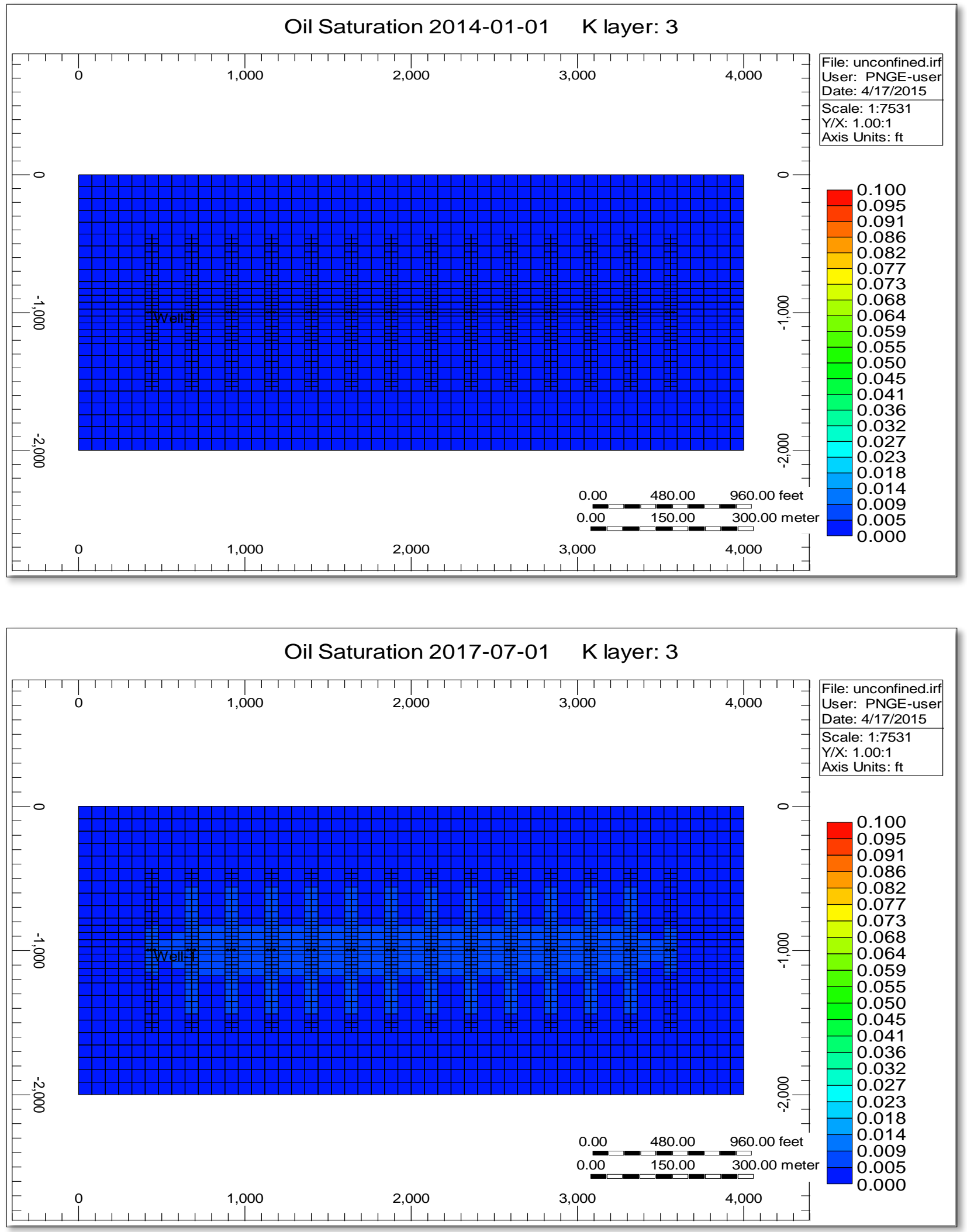

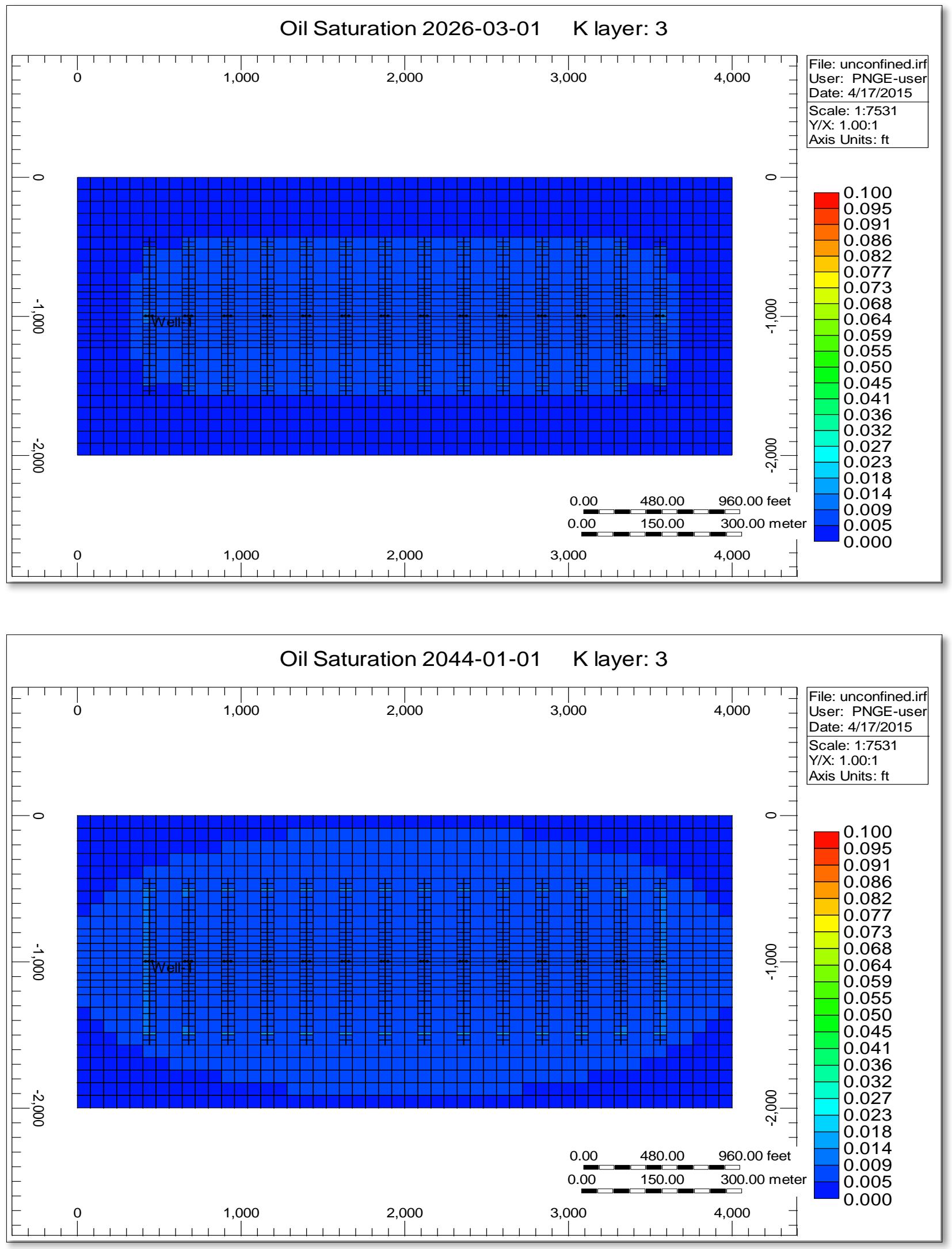


\section{Confined case with $5 \mathrm{~nm}$ Pore size}
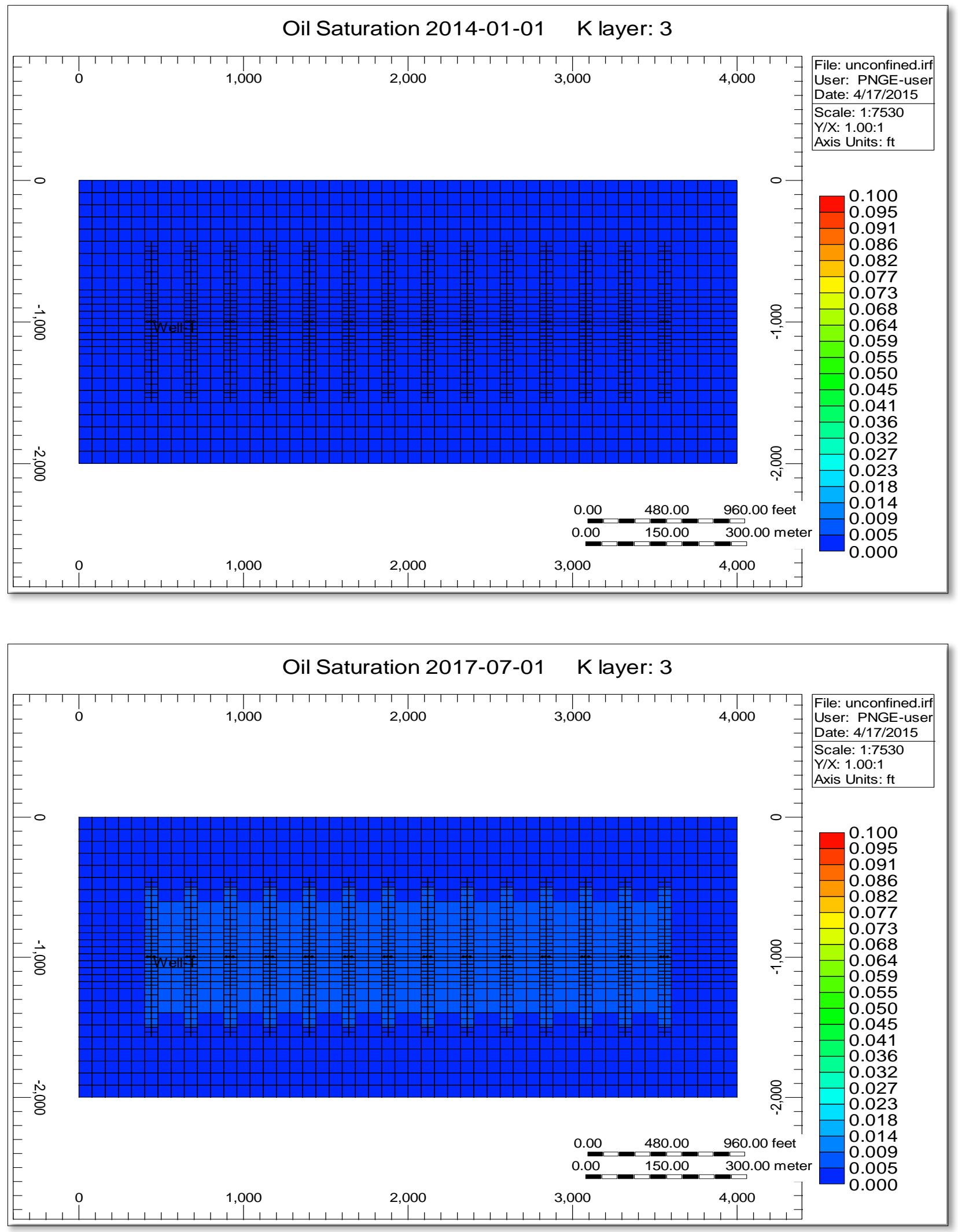

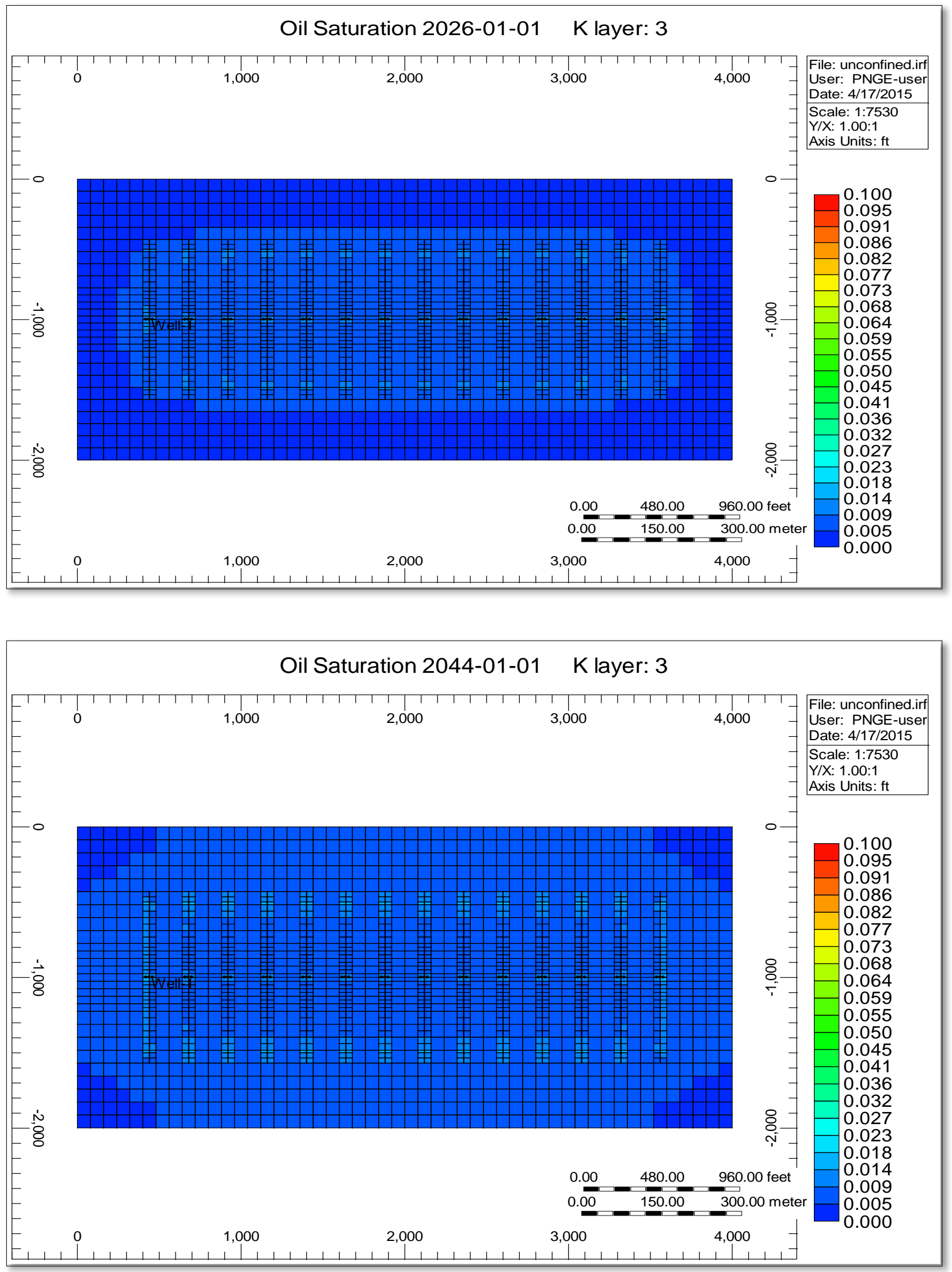